\title{
AVALIAÇÃO DE DESEMPENHO OPERACIONAL DE UM PULVERIZADOR PNEUMÁTICO COSTAL MOTORIZADO UTILIZADO NO CONTROLE DE MOSQUITOS VETORES DE DOENÇAS
}

\author{
MARCO ANTONIO FERREIRA DA COSTA
}

Dissertação apresentada à Escola Superior de Agricultura "Luiz de Queiroz", Universidade de São Paulo, para obtenção do título de Mestre em Agronomia, Área de Concentração: Máquinas Agrícolas.

PIRACICABA

Estado de São Paulo - Brasil

Agosto - 2002 


\title{
AVALIAÇÃO DE DESEMPENHO OPERACIONAL DE UM PULVERIZADOR PNEUMÁTICO COSTAL MOTORIZADO UTILIZADO NO CONTROLE DE MOSQUITOS VETORES DE DOENÇAS
}

\section{MARCO ANTONIO FERREIRA DA COSTA \\ Engenheiro Agrônomo}

Orientador Prof. Dr. MARCOS MILAN

\begin{abstract}
Dissertação apresentada à Escola Superior de Agricultura "Luiz de Queiroz", Universidade de São Paulo, para obtenção do título de Mestre em Agronomia, Área de Concentração: Máquinas Agrícolas.
\end{abstract}

PIRACICABA

Estado de São Paulo - Brasil

Agosto - 2002 
Dados Internacionais de Catalogação na Publicação (CIP) DIVISÃO DE BIBLIOTECA E DOCUMENTAÇÃO - ESALQ/USP

\author{
Costa, Marco Antonio Ferreira da \\ Avaliação de desempenho operacional de um pulverizador \\ pneumátic o costal motoriza do utiliza do no controle de mosquitos vetores \\ de doenças/ Marco Antonio Ferreira da Costa. - - Piracicaba, 2002. \\ 99 p. : il. \\ Dissertação (mestrado) - - Escola Superior de Agricultura Luiz de \\ Queiroz, 2002. \\ Bibliografia. \\ 1. Insetic idas- Aplic ações 2. Inseto-vetor-d e-doença-controle 3. \\ Desempenho 4. Pulveriza dores - Ava liação I. Título
}

CDD 631.3

'Permitida a cópia total ou parcial deste documento, desde que citada a fonte - O autor" 


\section{DEDICO}

À minha esposa, Sônia e meu filho, Daniel e a meus pais Aldemar e Rosa Maria 


\section{AGRADECIMENTOS}

A Deus que me deu forças em todos os momentos.

A Superintendência de Controle de Endemias, por disponibilizar os recursos necessários ao desenvolvimento do trabalho.

Aos Prof $^{\circ}$ s. do Setor de Máquinas Agrícolas, em especial ao Prof ${ }^{\circ}$ Dr. Casimiro que deu toda a orientação e amizade, ao $\operatorname{Prof}^{\circ}$ Dr. Marcos Milan pela paciência e voto de confiança e ao $\operatorname{Prf}^{\circ}$ Dr. Molin pelas sugestões na conclusão deste trabalho.

A diretora da DCV, Sra. Carmen Moreno Glasser pela compreensão nos períodos de ausência no trabalho.

A Escola SENAI "Mário Dedini”, na pessoa do seu Diretor Orlando Cristofoletti; ao professor instrutor Marçon e o Sr. Rosa , responsável pela Oficina de Mecânica.

A Prof ${ }^{\mathrm{a}}$ de Estatística Experimental, Maria Cristina Stolf.

Ao Prof ${ }^{0}$ Villa Nova do Setor de Agrometeorologia.

Em especial aos funcionários Juarez e Áureu do Laboratório de Instrumentação do Setor de Máquinas Agrícolas que foram fundamentais no sucesso do trabalho.

Aos funcionários Francisco, Juquita e Afonso da Oficina do Setor de Máquinas Agrícolas.

Aos funcionários da Regional de SUCEN de Campinas, à sua diretora Renata, ao encarregado de setor Corseti, e o mecânico Euclair.

Aos Prof ${ }^{\circ}$ s. Tarlei , Frizone, Luís Artur. Ao Hélio do Setor de Hidráulica. A Eliana e Silvia ambas da biblioteca, e a todos os colegas do curso de mestrado e àqueles que de alguma forma colaboraram na finalização do trabalho. 


\section{SUMÁRIO}

\section{Página}

LISTA DE FIGURAS........................................................................... viii

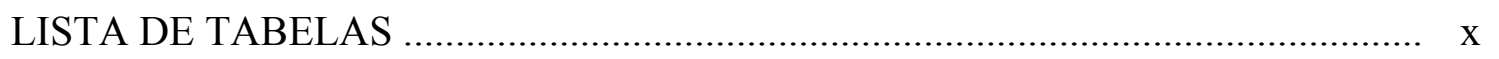

LISTA DE QUADROS..............................................................................

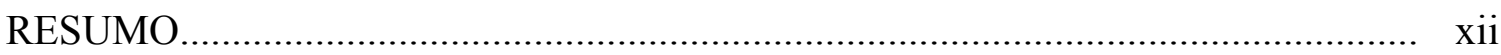

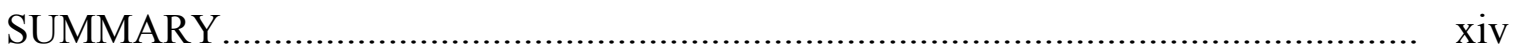

1 INTRODUÇÃO

2 REVISÃO DE LITERATURA.................................................................. 4

2.1 Dengue no Brasil e no estado de São Paulo...................................................... 4

2.2 Princípio da subdivisão de gotas............................................................... 5

2.3 Aplicações em ultra baixo volume................................................................. 11

2.4 Métodos de calibração de pulverizadores........................................................ 12

2.5 Histórico e utilização dos pulverizadores pneumáticos costais motorizados.......... 14

2.6 Classificação e descrição técnica dos pulverizadores pneumáticos costais

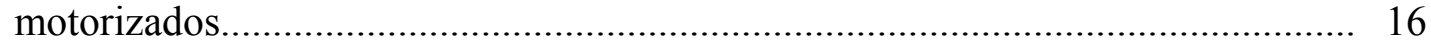

2.7 Ensaio e seleção dos pulverizadores pneumáticos costais motorizados................ 19

2.8 Avaliações de desempenho de pulverizadores pneumáticos costais motorizados... 20

2.9 Avanços tecnológicos nos pulverizadores pneumáticos costais motorizados......... 24

2.10 Instrumentos/sensores para medições em ensaios de máquinas agrícolas............ 26

2.10.1 Intrumentos/sensores para medição de rotação........................................... 28 
2.10.2 Instrumentos/sensores para medição da pressão................................................. 29

2.10.3 Instrumentos/sensores para medição da temperatura......................................... 30

3 MATERIAL E MÉTODOS................................................................................. 32

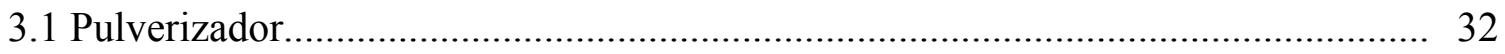

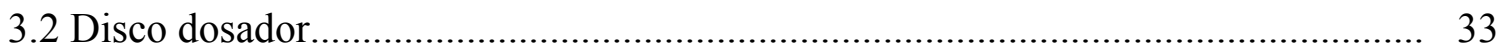

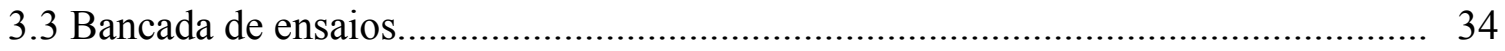

3.3.1 Estrutura para apoio do pulverizador........................................................... 35

3.3.2 Sistema de aquisição de dados...................................................................... 36

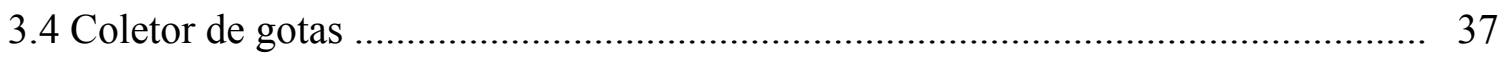

3.5 Instrumentação............................................................................................. 39

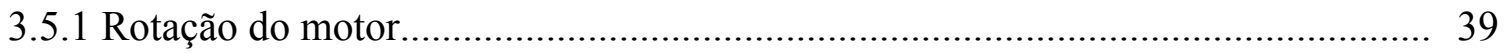

3.5.2 Pressão no interior do reservatório de calda e nos circuitos hidráulico e pneumático do pulverizador......................................................................... 40

3.5.3 Temperatura da água no interior do reservatório da calda e temperatura

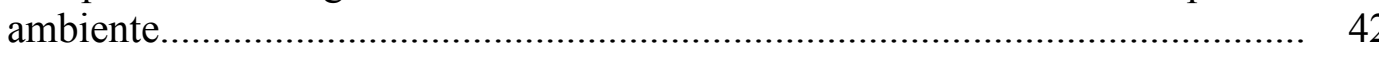

3.5.4 Velocidade do ar na saída do bocal................................................................. 43

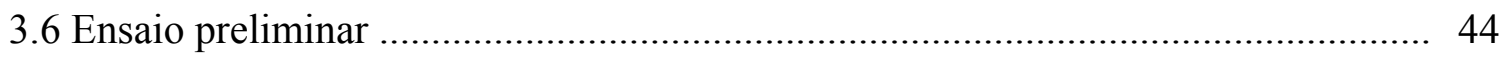

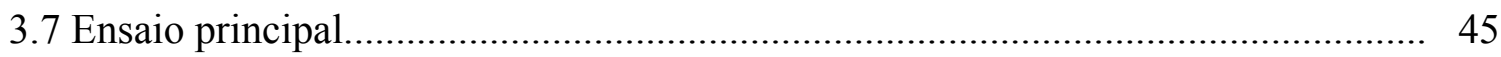

3.7.1 Medição dos diâmetros dos orifícios dos discos dosadores.................................. 45

3.7.2 Avaliação da altura da coluna de líquido no circuito hidráulico........................... 46

3.7.3 Cálculo da vazão teórica............................................................................ 49

3.7.4 Cálculo da vazão média experimental............................................................... 50 
3.7.5 Planejamento estatístico............................................................................... 52

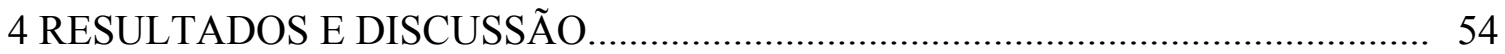

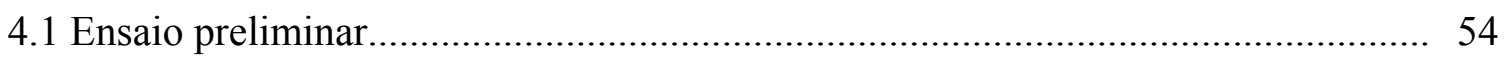

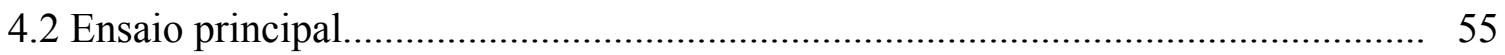

4.2.1 Diâmetro do orifício do disco dosador........................................................... 55

4.2.2 Análise da influência da rotação do motor na vazão média ................................. 57

4.2.3 Análise da influência dos fatores disco dosador e ângulo da lança na vazão média 59

4.2.4 Análise das pressões de serviço nos circuitos hidráulico e pneumático da

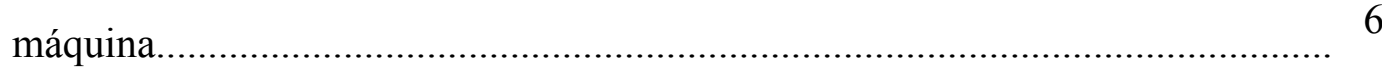

4.2.5 Dados experimentais versus teóricos................................................................ 65

4.2.6 Temperatura do reservatório de calda e do ambiente durante os ensaios.............. 68

4.2.7 Efeito do ângulo da lança e da distância na velocidade do ar na saída do bocal... 70

4.3 Considerações finais...................................................................................... 72

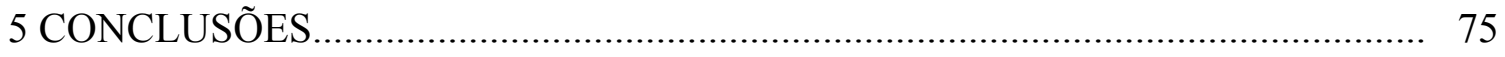

ANEXOS

REFERÊNCIAS BIBLIOGRÁFICAS....................................................................... 86

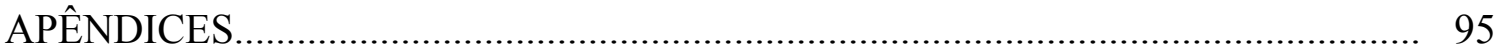




\section{LISTA DE FIGURAS}

1 Número de casos de dengue (x1000). Brasil, 1986-2001(dados provisórios).

2 Esquema dos bicos pneumáticos Air Jet (A), Air Tec (B) e Lo Air (C), adaptado de Womac, et al. (1988).....

3 Esquema do injetor utilizado por Feitosa Filho, et al. (1998), ( 1- câmara de mistura e 2 - solução)....

4 Esquema da condução de ar e calda no pulverizador pneumático costal motorizado, adaptado de Patel (1979).

5 Esquema de um pulverizador pneumático costal motorizado e suas partes constituintes (1- turbina, 2- lança, 3- registro de calda, 4- registro de combustível, 5- curva móvel, 6- motor, 7- reservatório de combustível, 8-reservatório de calda, 9- alça, 10- chassis e 11-bomba centrífuga), adaptado de Maquinaria... (1987).

6 Esquema dos bicos tipo jato comum e cilindro rotativo, adaptado de Patel (1979)... 25

7 Esquema do bico eletrostático ( 1- tubo de alimentação de calda, 2- gerador de alta voltagem, 3- distribuidor de alta voltagem, 4- eletrodos de alta voltagem, 5- corpo do bico (plástico ou metal), 6- nuvem de calda), adaptado de Moser \& Hussain (1985)

8 Diagrama dos elementos funcionais de um sistema de medição (A- meio a ser medido, I- sensor principal, II- conversão da variável, III- manipulação da variável, IV- transmissão de dados, V- apresentação dos dados, B- observador), adaptado de Doebelin (1966) 
9 Circuito simples de um termopar (A e B- fios diferentes, T1 e T2- temperaturas e V- voltímetro), adaptado de Doebelin (1966).

10 Equipamentos utilizados no ensaio principal ( 1- pulverizador , 2- estrutura de apoio do pulverizador e 3- sistema de aquisição de dados).

11 Detalhes da estrutura de apoio do pulverizador.

12 Detalhe do local escolhido para instalação dos circuitos eletrônicos

13 Vista frontal do coletor de gotas e bancada de ferro (1-coletor, 2- estrutura de ferro, 3-lamela de plástico, 4-tubo de inox).

14 Detalhes do posicionamento e colocação do cabo de fibra óptica próxima ao rotor da máquina (1- rotor, 2- cabo de fibra óptica, 3- chave fotoelétrico ou amplificador.

15 Pontos de tomada de pressão e detalhes dos sensores nos pontos 1 (P1), 2 (P2), 3 (P3) e 4 (P4).

16 Termopar instalado no reservatório de calda.

17 Termopar instalado para registro de temperatura ambiente.

18 Esquema utilizado para determinação de velocidade do ar na saída do bocal (1ângulos da lança, 2- distâncias do bocal e 3- bocal do pulverizador.

19 Tubo indicador de nível.

20 Vista superior dos discos dosadores A (diâmetro $=0,76 \mathrm{~mm}$ ) e B (diâmetro $=0,42$ $\mathrm{mm}$ ).

21 Curvas das vazões médias obtidas nos tratamentos para os discos dosadores A e B em função do ângulo da lança.

22 Comportamento das pressões de serviço P1 (pressão 1), P2 (pressão 2), P3 (pressão 3) e P4 (pressão 4) em função das vazões médias, determinadas para os discos dosadores

23 Comportamento da pressão P3 com a variação do ângulo da lança

24 Comparação das vazões dos discos dosadores A e B, dados teóricos versus

experimentais. 68

25 Velocidade do ar $\left(\mathrm{m} . \mathrm{s}^{-1}\right)$ em função das distâncias do bocal e ângulo da lança 


\section{LISTA DE TABELAS}

Página

1 Taxas de separação (\%) e tempo inicial de escoamento (s) obtidos para a distância do coletor e ângulo da lança................................................................ 55

2 Diâmetro dos orifícios dos discos dosadores utilizados na escolha dos discos A e B.

3 Estatística descritiva dos dados de rotação monitorados durante os ensaios

4 Análise de covariância dos valores da vazão média com aplicação do teste F.

5 Análise de variância dos valores da vazão média com aplicação do teste F. 60

6 Vazões médias obtidas para os discos dosadores A e B em função dos ângulos da 60 lança, nos 14 tratamentos.

7 Teste de correlação de Pearson para as pressões médias.

8 Cargas hidráulicas estáticas determinadas no ponto de saída da calda de acordo com os ângulos da lança.

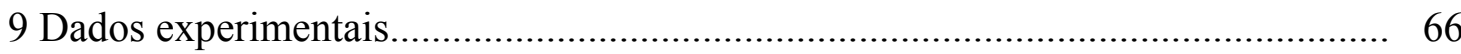

10 Dados experimentais e teóricos das vazões parao os discos dosadores A e B...... 67

11 Temperaturas médias inicial e final dentro do reservatório de calda e do ambiente, durante os ensaios

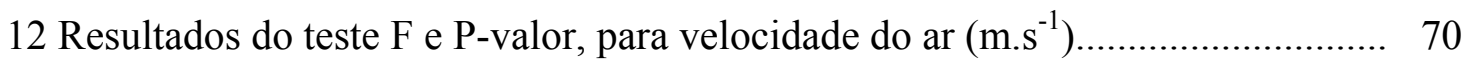

13 Estatística descritiva dos dados de velocidade do ar......................................... 71

14 Volume médio de água remanescente no sistema hidráulico de acordo com os tratamentos 


\section{LISTA DE QUADROS}

1 Classe de pulverizações em função do tamanho das partículas (Fonte: ABNT, 1988).

Página

2 Classe de pulverizações em função do tamanho das partículas (Fonte: Matthews, 1992).

3 Classificação do tipo de aplicação de acordo com o volume de aplicação (L.ha ${ }^{-1}$ ) Fonte: ABNT, 1991)

4 Quadro das vazões média $\left(L \cdot \mathrm{min}^{-1}\right)$, média de três repetições com diferentes posições do bico, de acordo com diferentes máquinas pulverizadoras.

5 Valores de pressão $(\mathrm{kPa})$ no reservatório de calda, na máxima elevação do bico, em diferentes máquinas pulverizadoras 


\title{
AVALIAÇÃO DE DESEMPENHO OPERACIONAL DE UM PULVERIZADOR PNEUMÁTICO COSTAL MOTORIZADO UTILIZADO NO CONTROLE DE MOSQUITOS VETORES DE DOENÇAS
}

\author{
Autor: MARCO ANTONIO FERREIRA DA COSTA \\ Orientador: Prof.Dr. MARCOS MILAN
}

\section{RESUMO}

A caracterização operacional de um pulverizador pode contribuir para a otimização do trabalho em condições de campo e melhorar a eficiência da aplicação para o controle do vetor. O objetivo do trabalho foi avaliar as vazões médias produzidas pelo pulverizador pneumático costal motorizado sob diferentes condições de aplicação. Os estudos foram conduzidos no Laboratório de Tecnologia de Aplicação de Defensivos Agrícolas do Departamento de Engenharia Rural, ESALQ/USP, Piracicaba. O delineamento experimental foi o inteiramente casualizado com esquema fatorial 2x7 (14 tratamentos) com 5 repetições e os seguintes fatores: dois diâmetros de orifício de disco dosador: 0,46 e $0,76 \mathrm{~mm}$; sete ângulos da lança do pulverizador. Sensores foram instalados no pulverizador para monitoramento da rotação do motor, da pressão nos sistemas hidráulico e pneumático, da temperatura interna no reservatório de calda e conectados a um sistema de aquisição de dados. Foi determinada a velocidade do ar na saída do bocal através de um anemômetro. Os resultados permitem concluir que as 
vazões foram afetadas significativamente pela associação entre diâmetro dos orifícios dos discos e ângulo da lança. O disco dosador de maior diâmetro apresentou menor uniformidade de vazão. A variação na rotação não influenciam os resultados de vazão média. A pressão determinada próximo ao bocal mostrou alta correlação com a vazão média. Recomenda-se ao operador utilizar o disco restritor com orifício de menor diâmetro aumentando o tempo de aplicação nos ângulos maiores e diminuir o tempo nos ângulos menores, para uma mesma dosagem de defensivo. 


\title{
EVALUATION OF OPERATIONAL PERFORMANCE OF MOTORIZED COSTAL PNEUMATIC SPRAY USED IN THE CONTROL OF MOSQUITOS VECTORS OF ILLNESSES
}

\author{
Author : MARCO ANTONIO FERREIRA DA COSTA
}

Adviser : Prof. Dr. MARCOS MILAN

\section{SUMMARY}

The operational characterization of motorized knapsack mistblower can contribute for the optimization of the work in field conditions and improve the efficiency of the application for the control of the vector. The objetive of the work was to evaluate the average flow rate produced by the motorized knapsack mistblower under different application conditions. The study was conducted in the Laboratory of Application of Defensive Techonology of Rural Engineering, ESALQ/USP, Piracicaba. The experimental design was entirely randomized with factorial $2 \times 7$ (14 handlings) with 5 repetitions and the following factors: two diameters of restrictor orifices: $0,46 \mathrm{~mm}$ and $0,76 \mathrm{~mm}$; and seven angles of the air delivery tube. A CR10X data logger system was assembled with sensors in the atomizer for monitoring of the engine rotation, pressure in the hydraulic and pneumatic systems, internal temperature in the spray reservoir and of air. Air speed in the exit of the nozzle was determined. The results allowed to conclude that the average flow rate had been significantly affected by the association between the diameter of the restrictor orifices and the angles of the air delivery tube. The restrictor 
with the largest diameter presented less application uniformity in the tested angles. The fall in the rotation did not influence the results of the average flow rate. The pressure close to the restrictor with the largest diameter presented less application uniformity in the tested angles. The fall in the rotation did not influence the results of the average flow rate. The pressure close to the output showed high correlation with the average flow rate. The operator is advised to utilize the restrictor orifice with the lesser diameter increasing time application exposure in the wider angles in order to compensate the lower flow rate and to diminish the application exposure time in the lesser angles, when the same defensive dose is used. 


\section{INTRODUÇÃO}

No mundo, dentre os insetos associados ao meio urbano, o mosquito Aedes aegypti, principal transmissor da dengue, é uma das mais perigosas espécies em áreas tropicais, onde o Brasil se localiza. Para o controle dessa espécie são utilizadas medidas preventivas como o manejo ambiental através do controle mecânico, o saneamento básico e medidas emergenciais ou de caráter temporário como o uso de produtos químicos e o controle biológico. Os programas de controle que envolvem essas medidas vêm sofrendo importantes modificações no Brasil durante as duas últimas décadas e inúmeras estratégias tem sido utilizadas, baseadas principalmente numa combinação de métodos.

O manejo ambiental não é prioridade no âmbito das políticas públicas no Brasil. Dados da Fundação Instituto Brasileiro de Geografia e Estatística - FIBGE (2000) mostram que apenas 451 municípios fazem coleta seletiva de lixo e 352 realizam reciclagem. O controle biológico, como por exemplo o uso de copépodos (microcrustáceos) para o controle das larvas do mosquito, tem evoluído em termos de pesquisas científicas, no entanto, ainda apresentam problemas operacionais, investimentos e portanto, sustentabilidade. O controle químico ainda é o mais importante no controle integrado de mosquitos vetores de doenças.

Em 1995, cerca de 50\% dos inseticidas fabricados no mundo eram utilizados por países em desenvolvimento, onde se inclui o Brasil, (Klassen, 1995). De acordo com os dados do Sindicato Nacional da Indústria de Produtos para Defesa Agrícola - SINDAG (2000) foram comercializados em 1999, 596 milhões de dólares em inseticidas.

A Superintendência de Controle de Endemias - SUCEN, que desde 1986 atua como órgão público responsável pelo controle de vetores no Estado de São Paulo, 
consumiu em 1987 cerca de 35 mil kg de ingrediente ativo de inseticidas para o controle do mosquito Ae. aegypti em sua forma adulta. No biênio 91-92 esse número passou para cerca de 13 mil $\mathrm{kg}$ de ingrediente ativo.ano ${ }^{-1}$. Nos anos seguintes houve uma redução acentuada, em razão dos critérios utilizados para iniciar uma pulverização. No ano de 2001 foram consumidos, até julho, cerca de $1600 \mathrm{~kg}$ de ingrediente ativo de inseticidas $\left(\right.$ Costa $\left.^{1}\right)$.

Os pesquisadores têm procurado alternativas de controle, mais harmoniosas ao ambiente devido a problemas como o surgimento de resistência aos inseticidas, o uso de produtos químicos cada vez mais caros, o envenenamento dos ecosssistemas (solo e água superficial), o fracasso das campanhas de erradicação e o recrudescimento de doenças antes controladas, nos últimos anos do século XX (Natal, 2000).

No âmbito da tecnologia de aplicação é importante a preocupação com relação aos efeitos dos defensivos agrícolas que são grandemente influenciados pelos métodos, a época de aplicação, às recomendações da operação e a acurácia do equipamento usado (Ozkan, 1999).

Os equipamentos mais comumente usados na saúde pública são o pulverizador a pressão com jato lançado manualmente, o pneumático costal motorizado, o pneumático montado em viatura, o termonebulizador manual ou montado em viatura, a polvilhadora manual e o equipamento de aplicação aérea.

A forma de aplicação mais utilizada para o controle da forma alada do mosquito Aedes aegypti é a aplicação espacial, na forma de aerossol, que visa manter as partículas líquidas suspensas o tempo suficiente para atingir os insetos que estão no espaço tratado, Associação Brasileira de Normas Técnicas - ABNT (1988); American Society of Agricultural Engineers - ASAE (1996).

A utilização dos equipamentos de pulverização aérea e dos pneumáticos montados em viaturas, que geram partículas em forma de aerossol, não tem sido recomendados no estado de São Paulo, para o controle do mosquito. Nessas aplicações a interação de diversos fatores (principalmente climáticos) afetam a trajetória das partículas

1 COSTA, M.A.F. da. (Superintendência de Controle de Endemias, São Paulo, SP). Histórico dos consumos anuais de inseticida utilizados pela SUCEN, Secretaria de Estado da Saúde de São Paulo. (Não publicado) 
dificultando a penetração no espaço interno das residência, onde as fêmeas adultas do mosquito habitualmente estão presentes, resultando num baixo impacto no controle da transmissão da doença e gerando um alto custo da aplicação.

Sendo assim os pulverizadores pneumáticos costais motorizados vêm sendo utilizados nas aplicações terrestres de inseticidas, na forma de aerossóis em ultra baixo volume (UBV) e baixo volume (BV), para o controle de epidemias.de dengue. Nos anos de 1999, 2000 e até julho de 2001 a SUCEN, utilizando-se deste tipo de máquina, em atividades de bloqueio de casos, pulverizou 745482, 520512 e 858223 domicílios, respectivamente $\left(\operatorname{Costa}^{2}\right)$.

O pulverizador pneumático costal motorizado apesar de ser muito utilizado em saúde pública, principalmente no estado de São Paulo, apresenta apenas três fabricantes no Brasil, ofertando no máximo oito modelos. A bibliografia de saúde pública no Brasil é carente de dados técnicos de desempenho sobre essas máquinas. A maioria dos trabalhos referem-se principalmente aos resultados de eficiência dos inseticidas utilizados e aos investimentos na busca de novos produtos, com diferentes tipos de formulação, sem associá-los com a avaliação de desempenho das máquinas de aplicação.

Empiricamente constata-se que a aplicação pode se mostrar ineficiente em função da forma de utilização do pulverizador. Sendo assim o trabalho teve como objetivo avaliar o desempenho operacional de um pulverizador pneumático costal motorizado, disponível no mercado nacional e utilizado em aplicações terrestres em UBV. O principal aspecto estudado foi a uniformidade da aplicação representada pela vazão média sob o efeito de diferentes diâmetros de disco dosador, ângulos da lança e pressões.

\footnotetext{
${ }^{2}$ COSTA, M.A.F. da. (Superintendência de Controle de Endemias, São Paulo, SP). Número de domicílios nebulizados pela SUCEN no estado de São Paulo para o controle do mosquito transmissor da dengue. (Não publicado)
} 


\section{REVISÃO DE LITERATURA}

\subsection{Dengue no Brasil e no estado de São Paulo}

No Brasil, o mosquito transmissor da dengue, Ae. aegypti, está disperso em 3600 municípios dos 27 estados. O número de casos de dengue de 1986 até 2001 (dados provisórios) é mostrado na Figura 1.

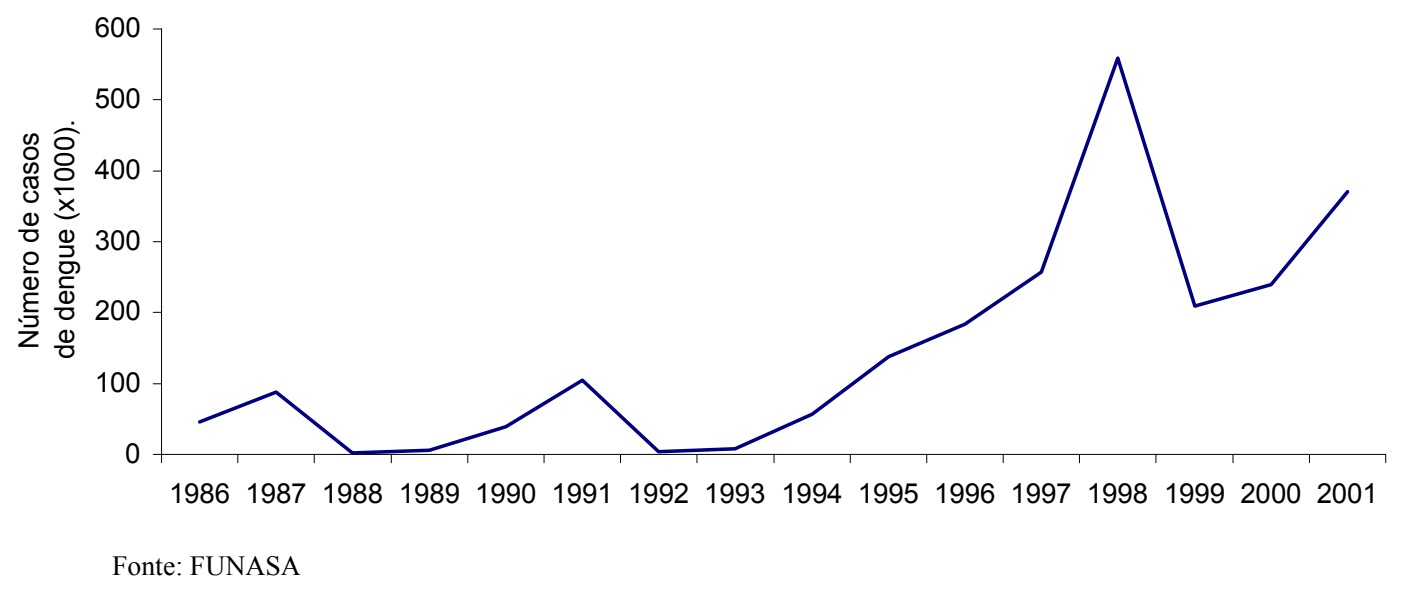

Figura 1- Número de casos de dengue (x1000).Brasil, 1986-2001(dados provisórios).

Em 1998 houve a mais importante onda epidêmica desde 1986, com cerca de 570 mil casos em todo o país. No ano de 2000 ocorreu uma redução no número de casos sendo confirmados cerca de 238 mil e 3 óbitos, no ano de 2001 voltou a crescer o número de casos com cerca de 370 mil e 28 óbitos, segundo dados provisórios da Fundação Nacional de Saúde - FUNASA (2001). 
No estado de São Paulo, até setembro de 2001 o número de casos confirmados de dengue foi de 51115, contra os 3529 casos no ano anterior, representando um aumento de $1448,4 \%$.

O número de municípios, no estado de São Paulo, infestados pelo Aedes aegypti, passou de 126 em 1987 para 482 no ano de 2001, representando um aumento de 382,5 \%, segundo o Centro de Vigilância Epidemiológica - CVE (2001).

Dentre os vários fatores que determinam a distribuição geográfica do mosquito vetor, destacam-se o clima, a altitude e a disponibilidade de uma grande diversidade de criadouros para essa espécie, notadamente no ambiente urbano. Esse último fator contribui decisivamente para a dispersão do vetor, haja vista a grande concentração da população nas áreas urbanas. No Brasil, dos 169,5 milhões de habitantes, 81,2\% vivem nas cidades; no Estado de São Paulo essa proporção corresponde a 93,4\%, segundo o FIBGE (2000).

\subsection{Princípio da subdivisão de gotas}

Diversos autores concordam que para se obter sucesso na técnica de pulverização é necessário produzir gotas de tamanho adequado e colocá-las numa área alvo durante o período de maior atividade do inseto que se deseja controlar (Cambrigde Animal and Public Health Limited, 1987; El Awady, 1978; Patel, 1981).

Existem diversas classificações para o tamanho de gotas, todas elas são baseadas no diâmetro mediano de volume. Uma dessas classificações é apresentada no Quadro 1, segundo a Norma da ABNT (1988).

\begin{tabular}{|l|c|}
\hline Classes & Diâmetro mediano de volume $-\operatorname{dmv}(\mu \mathrm{m})$ \\
\hline Aerossol & $<50$ \\
Pulverização muito fina (neblina) & 51 a 100 \\
Pulverização fina & 101 a 200 \\
Pulverização média & 201 a 400 \\
Pulverização grossa & $>400$ \\
\hline
\end{tabular}

Quadro 1- Classe de pulverizações em função do tamanho das partículas (Fonte: ABNT, 1988). 
A classificação utilizada pela ASAE (1996) apresenta diferenças com relação às classes de pulverização fina, média e grossa sendo representadas respectivamente pelas faixas de 101 a $400 \mu \mathrm{m}, 401$ a $1200 \mu \mathrm{m}$ e acima de $1200 \mu \mathrm{m}$. Matthews (1992) utiliza outra classificação como é mostrada no Quadro 2.

\begin{tabular}{|l|c|}
\hline Classes & Diâmetro mediano de volume $-\operatorname{dmv}(\mu \mathrm{m})$ \\
\hline Aerossol fino & $<25$ \\
Aerossol grosso & $25-50$ \\
Pulverização muito fina (neblina) & 51 a 100 \\
Pulverização fina & 101 a 300 \\
Pulverização média & 201 a 300 \\
Pulverização grossa & $>300$ \\
\hline
\end{tabular}

Quadro 2- Classe de pulverizações em função do tamanho das partículas (Fonte: Matthews, 1992).

A classificação do tamanho de gotas visa selecionar a máquina a ser utilizada, bem como controlar o volume de líquido gasto numa determinada aplicação (Balastreire, 1987). Gotas acima de $100 \mu \mathrm{m}$, por exemplo, quando utilizadas para o controle da forma alada do mosquito, podem se depositar rapidamente. Por outro lado, gotas muito pequenas, menores que $15 \mu \mathrm{m}$ podem sofrer o arrastamento pelo vento ou evaporação, principalmente em países tropicais (Matthews, 1992).

$\mathrm{Na}$ subdivisão em gotas no processo pneumático dos pulverizadores costais motorizados ocorre o impacto do líquido, sob baixa pressão, com uma corrente de ar de alta velocidade, produzida geralmente por uma bomba centrífuga (Gadanha Júnior et al., 1991).

Segundo Bernacki et al. (1976) quando a gota do líquido move-se numa corrente de ar, está sujeita a forças externas resultantes da resistência do meio bem como das forças internas que originam da tensão superficial com tendência a impedir a ruptura da corrente e formar a menor superfície possível.

Em geral, o processo de quebra das gotas pode ser apresentado da seguinte forma: 
$\mathrm{P}_{\mathrm{i}}=\mathrm{P}_{\mathrm{a}}+\mathrm{Ps}$

em que,

$\mathrm{Pi}=$ pressão interna $(\mathrm{Pa})$,

$\mathrm{Pa}=$ pressão externa $(\mathrm{Pa})$,

Ps $=$ pressão produzida pela tensão superficial para uma esfera, representada pela eq. (2)

$\mathrm{P}_{\mathrm{s}}=2 \sigma / \mathrm{r}$

em que,

$\sigma$ é a tensão superficial do líquido $\left(\mathrm{N} \cdot \mathrm{m}^{-1}\right) \mathrm{e}$

r é o raio da esfera (m).

O estado de equilíbrio da gota é dado pela eq. (1) que continua até que o valor de $\mathrm{P}_{\mathrm{a}}$ mude, causado pelo excessivo aumento da velocidade da gota. Inicialmente a gota torna-se achatada, como resultado da diminuição do raio de curvatura. Entretanto, com um valor apropriadamente alto de $\mathrm{P}_{\mathrm{a}}, \mathrm{P}_{\mathrm{s}}$ não muda suficientemente para anular $\mathrm{a}$ variação de $\mathrm{P}_{\mathrm{a}}$, com $\mathrm{P}_{\mathrm{i}}$ constante. Se isto ocorre, a gota se rompe para formar uma série de pequenas gotas nas quais as forças da tensão superficial são maiores, devido ao menor raio de curvatura. Tais sub-divisões ocorrem até o momento em que o diâmetro das gotas tornam-se suficientemente pequenas para manter o equilíbrio. De acordo com esta teoria o aumento na velocidade das gotas em relação ao ar causa (até um certo limite) uma diminuição no diâmetro das gotas como também uma influência significativa sobre a tensão superficial e as propriedades do meio no qual as gotas percorrem.

Womac et al. (1988), trabalhando com projetos de bicos pneumáticos (ABNT, 1993), constataram que dobrando a vazão de 0,06 L. min $^{-1}$ obtiveram um aumento no diâmetro mediano volumétrico das gotas de 48, 54 e 24\% para os bicos mostrados na Figura 2, Air Jet (Figura 2A), Air Tec (Figura 2B) e Lo Air (Figura 2C), respectivamente. Nesse experimento foi utilizada uma solução de água destilada, óleo de soja com $2 \%$ de espalhante e duas marcas de óleo mineral. A faixa de pressão para cada projeto de bico, variou de 12 a $66 \mathrm{kPa}$. Houve também uma diminuição nas vazões de ar 
de 8,18 e $8 \%$, respectivamente, com os orifícios dos bicos 0,$51 ; 0,89$ e $1,5 \mathrm{~mm}$, para os bicos Air Jet, Air Tec e Lo Air. Segundo Womac et al. (1988) com os dados dos projetos dos bicos, pressão de ar, tipo de calda e da vazão, pode-se produzir uma faixa ampla de espectro de gotas, resultando inclusive no tamanho de gota desejado

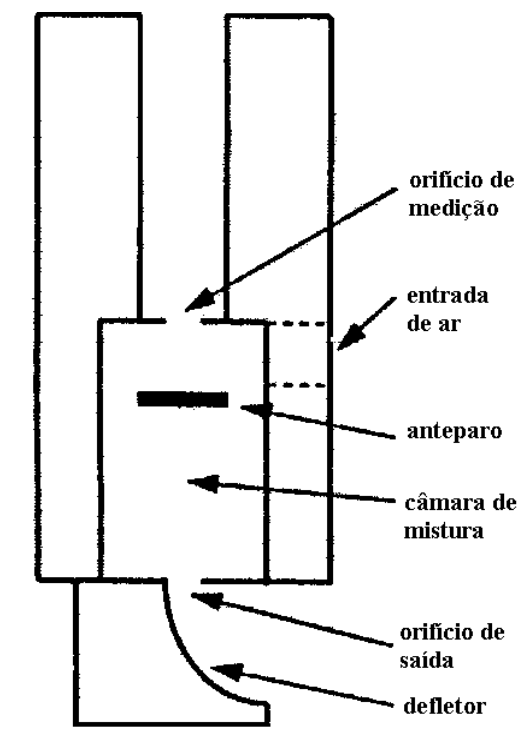

A) Air jet

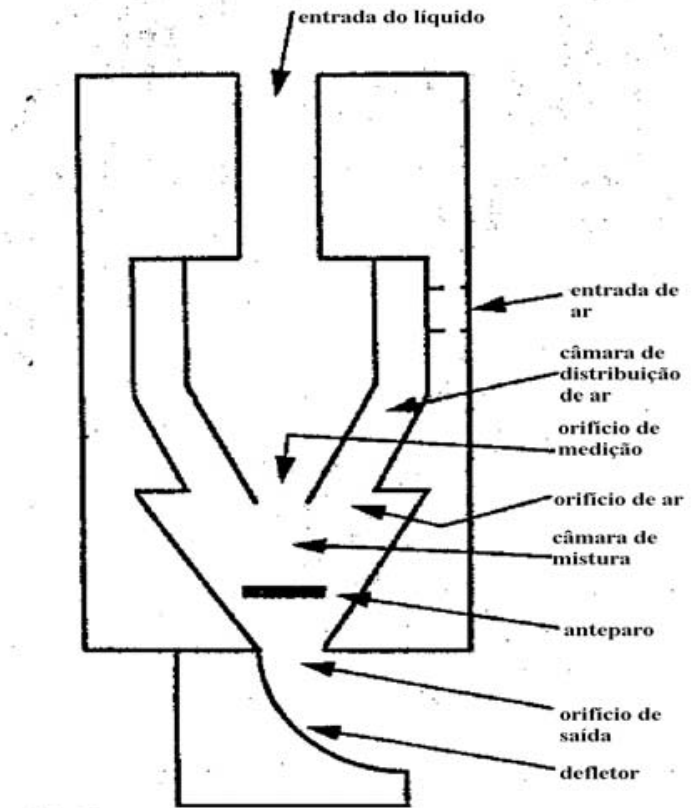

B) Air tec

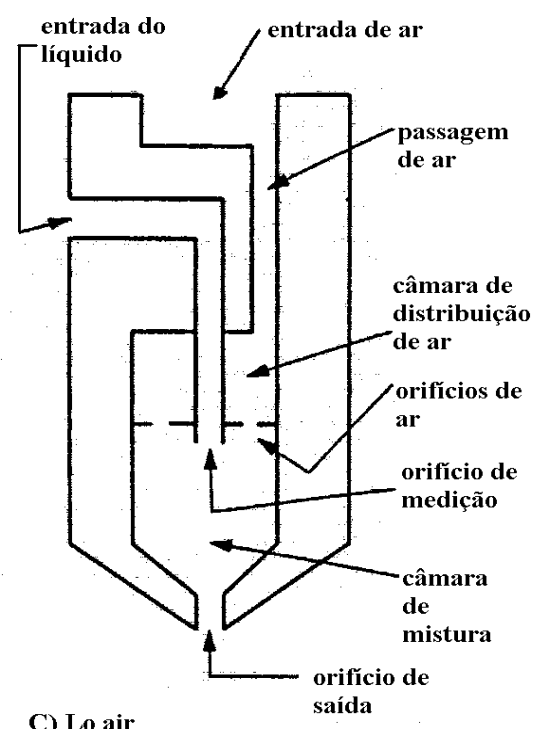

Figura 2- Esquema dos bicos pneumáticos Air Jet (A), Air Tec (B) e Lo Air (C), adaptado de Womac, et al. (1988). 
Segundo a ASAE (1996) os bicos pneumáticos podem misturar o ar e o líquido dentro do bico, como é o caso dos utilizados por Womac et al. (1988) e fora do bico, nesse caso o líquido é succionado do sistema de alimentação de calda com pressões negativas, através do princípio de Venturi e lançado numa corrente de ar. Segundo a ABNT (1993), existem diferentes tipos de bicos e são classificados de acordo com a principal fonte de energia utilizada para a pulverização do líquido, podendo ser hidráulicos, quando o líquido é pulverizado sob pressão; pneumáticos, quando o líquido é pulverizado por ação de um gás ou vapor; centrífugos, quando é utilizada a energia de um mecanismo giratório; eletrostático, quando o líquido é pulverizado por ação de energia elétrica, térmicos, quando é o líquido é pulverizado por ação da energia térmica e cinéticos, quando o líquido é pulverizado por ação de energia cinética.

Segundo Balastreire (1987), deve-se aumentar a eficácia do processo de obtenção de gotas com o mínimo gasto de energia possível. Segundo Feitosa Filho et al. (1998), os injetores que utilizam o princípio de venturi necessitam de maiores estudos para avaliar formas mais adequadas de instalação, manejo e modelos que condicionem menor perda de carga e menor custo. Feitosa Filho et al. (1998), mostraram que o injetor, mostrado na Figura 3, quando submetido a diferentes condições de pressão e vazão, apresentou redução na perda de carga de $32,4 \%$ da pressão de serviço e quando comparado a descarga pressurizada e com a descarga livre, ocorre um aumento de $27 \%$ na relação entre energia útil de sucção e energia total do sistema, considerado aqui como rendimento.

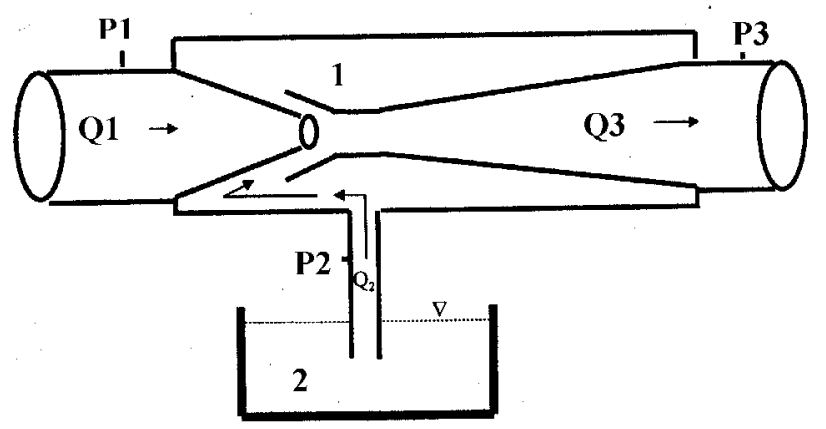

Figura 3- Esquema do injetor utilizado por Feitosa Filho, et al. (1998), (1- câmara de mistura e 2- solução). 
Os parâmetros avaliados no trabalho foram: pressões de serviço $\left(P_{1}\right.$ e $\left.P_{3}\right)$ variando de 98,6 até 343,2 $\mathrm{kPa}$, com incrementos de 49,0 kPa; diferenciais de pressão no interior do injetor (entre a pressão positiva na tubulação de saída do injetor e uma pressão negativa na tubulação de sucção $\left(P_{2}\right)$ e; entre o ponto imediatamente a montante do injetor e ponto na saída do injetor), vazões $\left(Q_{1}\right.$ e $\left.Q_{3}\right)$, pressões motrizes, perdas de carga acidentais e rendimentos. Segundo os autores, a vazão succionada $\left(Q_{2}\right)$ e o desempenho do injetor dependem do tipo de funcionamento ou do diferencial de pressão. Aumentando o diferencial de pressão entre um ponto imediatamente a montante do injetor e outro ponto instalado na tubulação imediatamente a jusante, a vazão succionada aumenta. Nas pressões de serviço menores obtiveram-se os maiores rendimentos. Apesar disso, no caso de quimigação, os autores sugerem trabalhar com rendimentos menores, pois esse parâmetro nem sempre é o aspecto mais importante, e pode ser compensado com possíveis mudanças na concentração dos produtos a serem aplicados.

Segundo El Awayd (1978), o projeto de um equipamento requer cuidadosa variação na geometria do bico, bem como na pressão de pulverização e na propriedade dos líquidos. O processo de formação das gotas de tamanho uniforme não é simples, e exige das máquinas de aplicação de inseticidas esta qualidade, devendo haver um modo de controle na formação das mesmas (Laureano, 1983).

De acordo com Ward (1985), que investigou um sistema com disco rotativo modelo Herbi-Ulva, marca Micro Sprayer, foram detectadas variações na rotação do disco rotativo, devido a mudanças na vazão e na viscosidade, para diferentes misturas de glicerol, água e um surfactante não iônico, apesar de não existir nenhum mecanismo controlador da rotação do disco, no sistema utilizado. Com pequenas vazões obtidas no seu trabalho, 0,06 a 0,30 L.min ${ }^{-1}$ e rotação do rotor variando de $1423 \mathrm{rpm}$ a $1528 \mathrm{rpm}$, obteve dois tipos de formação de gotas: o primeiro, formação direta e o segundo com a formação de ligamentos e eventual formação de gotas. A vazão, propriedade reológica 
do líquido (densidade, viscosidade e tensão superficial), velocidade do disco e modo de formação de gotas determinam o tamanho de gota produzida.

No processo centrífugo de geração de gotas o líquido é introduzido a baixa pressão no interior de um mecanismo giratório, que pode ser um cilindro de tela, escova circular, ou mesmo um rotor ranhurado (Gadanha Júnior et al.,1991).

\subsection{Aplicações em ultra baixo volume}

O termo ultra baixo volume foi citado pela primeira vez num trabalho realizado na África para o controle de locusto (gafanhoto do deserto), Schistocerca gregaria com o uso de calda concentrada do princípio ativo dieldrin (Lofgren, 1970). No Brasil, o tipo de aplicação de defensivos denominado ultra-baixo-volume é classificado segundo a Norma da Associação Brasileira de Normas Técnicas - ABNT (1991) e utiliza como critério o volume de água aplicado pelo pulverizador, como pode ser visto no Quadro 3.

\begin{tabular}{|c|c|c|c|}
\hline Sigla & denominação & \multicolumn{2}{|c|}{ aplicação terrestre (L.ha ${ }^{-1}$ ) } \\
\hline & & $\begin{array}{c}\text { culturas de porte baixo } \\
\text { (anuais) }\end{array}$ & $\begin{array}{c}\text { cultura de porte alto } \\
\text { (árvores e arbustos) }\end{array}$ \\
\cline { 3 - 4 } AV & volume alto & Mais de 600 & Mais de 1000 \\
MV & volume médio & entre 200 e 600 & entre 500 e 1000 \\
BV & volume baixo & entre 50 e 200 & entre 200 e 500 \\
MBV & volume muito baixo & Entre 5 e 50 & Entre 50 e 200 \\
UBV & volume ultra baixo & menos de 5 & Menos de 50 \\
\hline
\end{tabular}

Quadro 3- Classificação do tipo de aplicação de acordo com o volume de aplicação $\left(\right.$ L.ha $\left.^{-1}\right)$ (Fonte: ABNT, 1991).

A aplicação em ultra baixo volume, dispensando o uso de água como veículo, proporcionou a vantagem de economia no custo do trabalho (Takenaga, 1973). No caso dos pulverizadores pneumáticos costais motorizados, a técnica de aplicação em ultra baixo volume só foi possível com a utilização de discos perfurados ou pequenos registros medidores montados na linha de fluxo do inseticida, reduzindo desta forma a vazão dos inseticidas, World Health Organization - WHO (1997). 
Alguns pulverizadores pneumáticos costais motorizados utilizam acessórios para trabalhar com aplicações em ultra baixo volume e deste modo podem utilizar formulações diluídas. Foi o que ocorreu, por exemplo, em um trabalho realizado em Bangkok, Tailândia, usando a máquina Fontan $\mathrm{R} 12^{3}$ com o inseticida de nome comercial

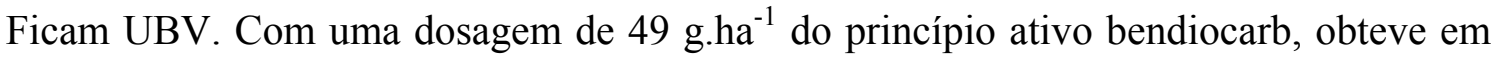
24 h após o tratamento, $100 \%$ de mortalidade de mosquitos Ae. aegypti quando presos em gaiolas (Cambridge Animal and Public Health Limited, 1987).

Em saúde pública a técnica de aplicação em ultra baixo volume é predominante no controle de forma adulta do Ae. aegypti (Aragão et al., 1988). Segundo Thompson (1973), as operações de pulverização em ultra baixo volume apresentam erros que são acentuados quando as taxas de aplicação são menores. As falhas ocorrem na determinação da vazão influenciada pela temperatura, que altera a viscosidade do líquido; no número de gotas por unidade de área e no tipo de solução formada com a adição de solventes, tornando-as mais ou menos voláteis.

Segundo Dukes et al. (1990), nas aplicações de inseticidas em ultra baixo volume, utilizando os nebulizadores montados em veículos é produzida uma grande porcentagem de gotas menores que $48 \mu \mathrm{m}$ de diâmetro, eficientes no controle de mosquitos adultos. Ocorre neste tipo de aplicação uma interação positiva entre vazão e pressão, devendo aumentar a vazão com o aumento da pressão com o uso de um compressor, utilizado para manter o espectro de gotas constante.

\subsection{Métodos de calibração de pulverizadores}

Segundo Marer (1988) a principal razão para a calibração dos pulverizadores é a determinação da quantidade de defensivo que se deve colocar no reservatório de calda para assegurar que a quantidade correta de princípio ativo seja aplicada, para o efetivo controle da praga, da proteção humana e do ambiente, prevenindo desperdícios e cumprindo com a legislação.

\footnotetext{
${ }^{3}$ A citação de fabricantes, marcas e modelos no presente trabalho, não representa recomendação de seus produtos, por parte do autor e tem por finalidade apenas facilitar a designação do material.
} 
De acordo com Salyani \& Serdynski (1993), os erros que ocorrem nas aplicações de defensivos agrícolas são causados por misturas incorretas no reservatório de calda ou calibração inadequada, e se tornam críticos com a utilização de formulações mais concentradas e caras. Os erros na calibração originam-se de bicos impróprios, defeituosos ou desgastados; da velocidade de deslocamento utilizada e na determinação das vazões.

Segundo Thompson (1973) nas operações de pulverização em ultra baixo volume o erro na determinação das vazões de líquidos viscosos é ampliado quando a temperatura é alterada. Segundo Thompson (1973) a curva que representa a vazão em função da temperatura é basicamente uma hipérbole e o platô da curva, se ocorrer dentro dos limites operacionais, pode ser útil trabalhando-se com um pulverizador dentro dessa faixa de temperatura.

Taylor \& Richardson (1972) apresentaram um método simples e rápido na determinação do volume de calda a ser aplicado (L.ha ${ }^{-1}$ ), baseado na deposição de calda numa placa de Petri com área conhecida e uma cujos resultados podiam ser comparáveis àqueles obtidos através de métodos mais complexos, como o espectrofotométrico.

Patel (1981); Salyani \& Serdynski (1993) citam formas de calibração através de fórmulas, tabela-gráfico e o método volume-área, o mais prático e fácil a ser adotado pelo operador, no qual enche-se o reservatório de calda do pulverizador com água limpa até um nível conhecido, aplica-se o líquido normalmente na velocidade utilizada pelo operador num ritmo constante, numa área previamente demarcada e determina-se a quantidade aplicada completando o reservatório até a marcação inicial. A taxa de aplicação é então determinada por cálculos, se a taxa não é aceitável, então o pulverizador e/ou os parâmetros de aplicação necessitam ser ajustados.

Segundo Marer (1988) e Matthews (1994), nos pulverizadores pneumáticos costais motorizados não é possível coletar o líquido pulverizado em um recipiente devido à forte corrente de ar, por isso o método volume-área sendo mais fácil de ser utilizado. Segundo a Jacto (s.d.), nesse caso se o volume encontrado não for o desejado deve-se substituir o disco dosador da vazão por um de menor ou maior diâmetro, lembrando que o acelerador deve estar sempre no máxima rotação para a regulagem. 
Kümmel et al. (1991) desenvolveram um separador de calda lamelado, para determinar o modelo de distribuição da calda no plano vertical, haja vista, no caso do grupo dos pulverizadores assistidos a ar, existir uma falta de medidas verticais de fluxo. Ainda, segundo os autores, o modo de distribuição dos fluidos pode ser influenciado pelo sistema de fluidos (arranjo e orientação dos bicos, volume de fluxo do bico e volume mediano de diâmetro - v.m.d, área efetiva de um simples bico) e sistema de fluxo de ar (tipo de ventilador e seu tamanho, volume de ar, velocidade do fluxo, orientação do fluxo, turbulência) e deve ser manejado de modo a corresponder à demanda da área a ser tratada.

\subsection{Histórico e utilização dos pulverizadores pneumáticos costais motorizados}

O primeiro pulverizador costal motorizado acionado por motor de combustão interna de dois tempos, foi desenvolvido na Alemanha em 1950; adaptado para polvilhadora, foi utilizado para aplicar formulações em pó em pomares e no cultivo de videiras (Solo, 2001). Na África durante a década de 60 o pulverizador costal já se destacava dentre os tipos de pulverizadores mais utilizados para o controle de pragas na cultura cacaueira (Higgins, 1966).

$\mathrm{Na}$ saúde pública, o primeiro registro de utilização destes pulverizadores, foi durante a Guerra do Vietnã para o controle do mosquito transmissor da malária. A área pulverizada era considerável e podia ser efetuada em locais acessíveis somente a pé. Essas atividades visavam a proteção das patrulhas, unidades isoladas ou individuais, operando fora da base operacional e cercadas militarmente (Holway, 1967).

Desde 1970 nas zonas urbanas da Tailândia eram feitas aplicações de malathion em ultra-baixo-volume com pulverizadores pneumáticos costais motorizados para o controle do mosquito Ae. Aegypti (OMS,1977). Em 1978 um censo realizado em Gana mostrou que existiam mais de 200 mil pulverizadores costais motorizados utilizados no controle de capsídeos (percevejos sugadores), dos quais 50\% tinham motores com cilindrada de $35 \mathrm{~cm}^{3}$ ou menos (Clayphon, 1979). 
Mais recentemente na África Oriental, os pulverizadores pneumáticos costais motorizados não são mais populares e apresentam-se em mau estado de conservação. Dentro de um grupo de 25 questionários enviados a 15 países daquela região, houve apenas 12 citações a cerca do uso desta máquina, utilizada principalmente nas culturas de cacau e citrus, e em algumas culturas alimentícias (Van Der Meijden, 2000). Na Índia, em pequenas propriedades, o pulverizador costal motorizado é popular porque com um baixo custo operacional em relação a outras máquinas melhora a eficácia das pulverizações (Bansal, 1998).

Com o êxito no emprego de pulverizadores pneumáticos costais motorizados nas favelas do Rio de Janeiro em 1984 e nas epidemias ocorridas nas cidades do estado de São Paulo, a partir de 1985, contra Ae. aegypti, (Aragão et al., 1988), alguns órgãos de saúde pública como SUCEN e FUNASA passaram a utilizá-las com maior freqüência. A FUNASA por exemplo possuía em 1999, 739 pulverizadores deste tipo, o que representava $6,5 \%$ de toda a frota de pulverizadores em uso no país, exceto o estado de São Paulo (Teixeira Neto ${ }^{4}$ ). No estado de São Paulo o número de pulverizadores utilizados pela SUCEN para o controle do mosquito da dengue era de 897 unidades em 1996, sendo 297 (33,2\%) pulverizadores do tipo pneumático costal motorizado. No ano de 2001 a SUCEN passou a utilizá-los em praticamente 100\% das aplicações de inseticidas para o controle do mosquito transmissor da dengue $\left(\right.$ Costa $\left.^{5}\right)$. Além de serem usadas no controle de mosquitos, também controlam moscas e larvas (Pratt \& Littig, 1976).

$\mathrm{Na}$ agricultura o pulverizador pneumático costal motorizado é uma máquina adequada para aplicação de inseticidas ou fungicidas em culturas de cereais, citrus, frutas, hortaliças e legumes, de elevado índice de área foliar, não sendo indicado para aplicação de herbicidas (Gadanha Júnior et al. 1991, Takenaga, 1973). A qualidade da pulverização é satisfatória porque permite que o produto aplicado atinja inclusive a superfície inferior das folhas (Gadanha Júnior et al., 1991). Apesar da diversidade de culturas agrícolas onde o pulverizador pneumático costal motorizado pode ser utilizado,

${ }^{4}$ TEIXEIRA NETO, I. (FUNASA, Brasília, DF). Comunicação pessoal. 1999

${ }^{5}$ COSTA, M.A.F. da. Pulverizadores utilizados pela SUCEN no controle das endemias no estado de São Paulo. (Não publicado) 
o número deles no estado de São Paulo é pequeno em relação a outros tipos de pulverizadores.

Ramos et. al (1998) pesquisando em 3000 propriedades rurais do estado de São Paulo, selecionadas de 100 municípios através de critérios técnicos e sócio-econômicos verificaram que $81,64 \%$ dos proprietários utilizavam a pulverização como um dos métodos de proteção de plantas. Dos pulverizadores utilizados 1,61\% eram pneumáticos costais motorizados, 38,17\% eram a pressão com jato lançado manual, 25,21\% a pressão com jato lançado tratorizado, 23,81\% a pressão com jato lançado motorizado, 9,0\% a pressão com jato transportado tratorizado de ventilador axial e 2,21\%, outros tipos.

\subsection{Classificação e descrição técnica dos pulverizadores pneumáticos costais motorizados}

Segundo Matthews (1992), as máquinas que utilizam fluxo de ar para o transporte das partículas até o alvo fazem parte do grupo de pulverizadores com assistência de ar.

Segundo a ABNT (1991b) as máquinas aplicadoras de defensivos são classificadas quanto à classe, energia para formação de gotas, transporte de gotas, deslocamento da máquina e forma de acionamento. A máquina conhecida como atomizador costal, atomizador costal motorizado ou ainda pulverizador costal motorizado é classificada como pulverizador pneumático costal motorizado (Gadanha Júnior et al., 1991). Na saúde pública este tipo de pulverizador também é chamado de nebulizador.

O pulverizador pneumático costal motorizado é constituído de um motor de combustão interna monocilíndrico de ciclo dois tempos, a gasolina, de baixa potência, que trabalhando na máxima rotação aciona uma bomba centrífuga. O líquido contido no reservatório de calda (formulação do inseticida + veículo) pode ser conduzido por gravidade, através de um sistema de mangueiras, passando por um registro de saída de calda até o mecanismo dosador instalado na lança, que é um ducto alongado responsável pela condução da corrente de ar e melhor posicionamento da pulverização com relação ao alvo, possui ainda o registro e o bico (ABNT, 1993). 
No caso de alguns pulverizadores pneumáticos costais motorizados pode ocorrer ainda uma derivação da bomba centrífuga até o reservatório de calda, fornecendo pressão para a condução do líquido pela mangueira, como pode ser visto no esquema da Figura 4.

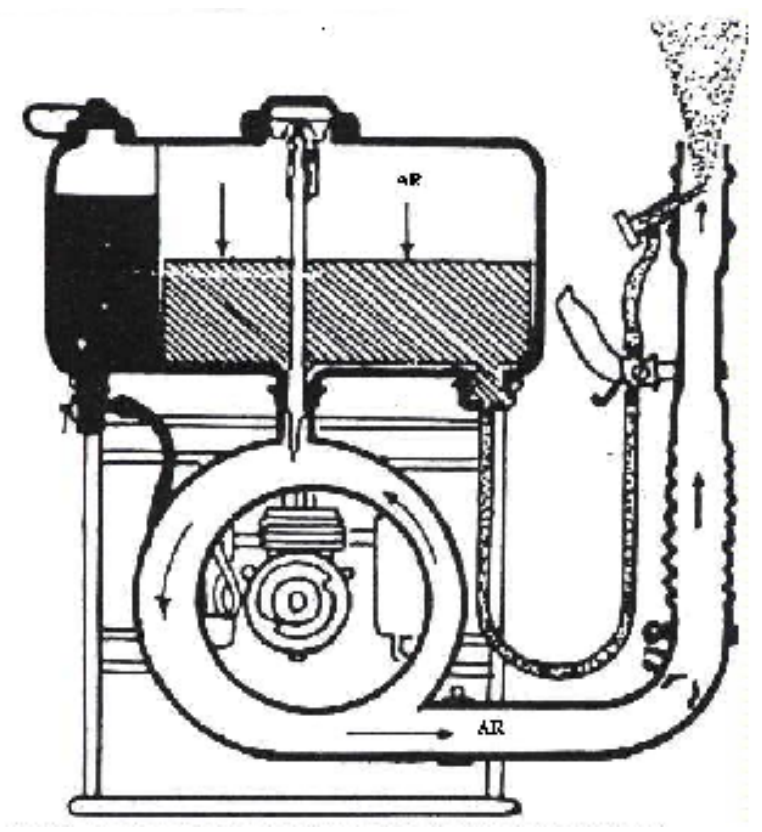

Figura 4- Esquema da condução de ar e calda no pulverizador pneumático costal motorizado, adaptado de Patel (1979).

Constitui-se ainda, de um reservatório de combustível e um chassi com alças para atrelamento da máquina às costas do operador. Reservatório, mangueiras e registro devem ser constituídos de material anti-corrosivo (Takenaga,1973; Balastreire, 1987; Gadanha Júnior et al.,1991 e WHO, 1997). As partes constituintes do pulverizador são apresentadas na Figura 5. As mangueiras que conduzem o líquido e o registro de calda fazem parte do circuito hidráulico da máquina, a mangueira que conduz o ar até o reservatório de calda faz parte do circuito pneumático. Componentes como o reservatório de calda, motor e bomba centrífuga fazem parte de ambos os circuitos. 


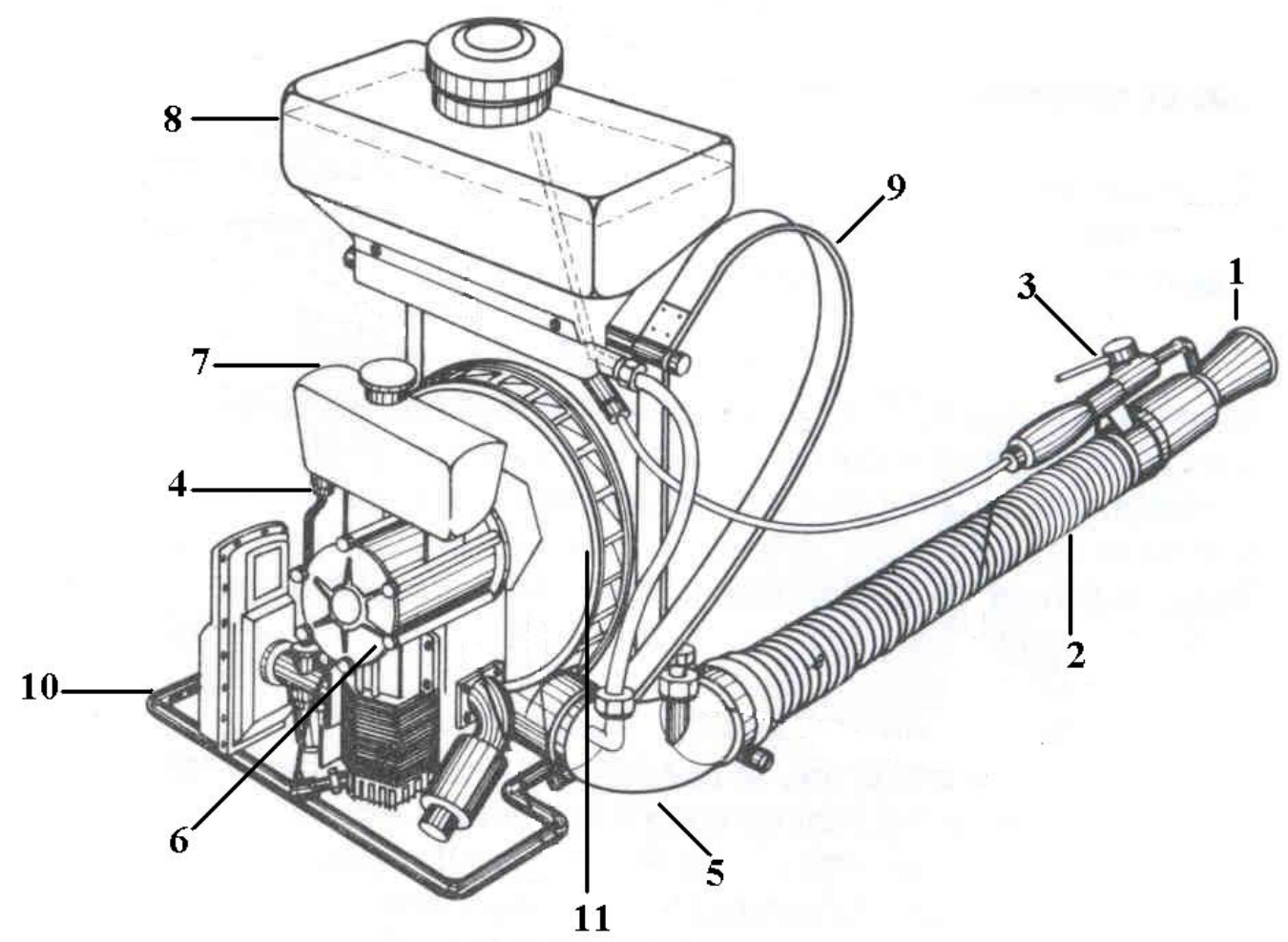

Figura 5- Esquema de um pulverizador pneumático costal motorizado e suas partes constituintes (1- turbina, 2- lança, 3- registro da calda, 4- registro de combustível, 5- curva móvel, 6- motor, 7- reservatório de combustível, 8reservatório de calda, 9- alça, 10- chassis e 11- bomba centrífuga), adaptado de Maquinaria...(1987).

Segundo Matthews, (1994) estes pulverizadores possuem motores com cilindrada na faixa de 35 a $70 \mathrm{~cm}^{3}$, reservatório de calda normalmente com capacidade para 10 litros e a pressão dentro do reservatório de calda de $25 \mathrm{kPa}(0,25$ bar $)$. Essa máquina pode ser equipada com acessórios que permitem a aplicação de defensivos sólidos na formulação em pó e grânulos (Gadanha Júnior et al., 1991 e OMS, 1977). É ao mesmo tempo simples e versátil, podendo cobrir uma grande área e proporciona fácil acesso em áreas com ruas estreitas, através das quais o equipamento montado em veículo não passa 
(Patel, 1979 e WHO, 1997). Também apresenta ao operador risco de queimadura próximo ao motor, além de desconforto experimentado por calor, vibração e ruído (WHO, 1997).

\subsection{Ensaio e seleção dos pulverizadores costais pneumáticos motorizados}

Um programa de controle de vetores que considere a seleção de uma boa máquina para a aplicação de inseticida é de grande importância na resolução eficiente de problemas (Pratt \& Littig, 1976; WHO, 1997).

Apesar de bem estabelecido e aplicado o uso de pulverizadores pneumáticos costais motorizados, diferentes projetos de máquinas podem afetar o desempenho e a acurácia da aplicação (Jollands, 1991), até mesmo com a utilização do mesmo projeto básico (Matthews, 1992). Nesse aspecto a avaliação de desempenho de máquinas é uma questão ampla e pode ser fonte supridora de dados para a tomada de decisões, para a seleção racional e garantia da qualidade na sua aquisição (Mialhe, 1996).

Uma vez decidido o equipamento necessário para uma operação, deve-se examinar as diferentes marcas e modelos disponíveis e se possível, comparar a sua eficácia, mediante os ensaios pertinentes e as especificações correspondentes (OMS, 1977). Segundo a FAO (1998), existem 12 procedimentos de ensaio para a avaliação dos pulverizadores costais motorizados: retenção de superfície, absorção das alças e almofada, vazamento, desempenho da peneira do reservatório, confiabilidade do gatilho do registro liga/desliga, durabilidade do motor, inclinação do pulverizador, resistência química, retenção de líquido no pulverizador, distribuição do tamanho de gotas, durabilidade do motor e alcance horizontal do jato de gotas. Além disso existem as especificações quanto aos requisitos gerais: reservatório de calda e tampa; montagem da lança e mangueira; alças e almofada costal; fonte de potência e bomba centrífuga. A experiência tem mostrado que grande parte dos equipamentos não alcançam uma qualidade técnica satisfatória. 


\subsection{Avaliações de desempenho de pulverizadores pneumáticos costais motorizados}

O Departamento de Engenharia e Mecânica da Agricultura - DEMA (1957-58) avaliando um pulverizador Kiekens, acionado por motor com ciclo dois tempos, marca $\mathrm{BMB}$, de $1,1 \mathrm{~kW}(1,5 \mathrm{cv})$, monocilíndrico e refrigerado a ar, realizou diversas provas de funcionamento utilizando diversas aberturas e diferentes rotações, na faixa de 63,3 rps a 47,5 rps (3800 rpm a $2850 \mathrm{rpm}$ ), e obteve diferentes tempos de esvaziamento para pó e para líquido, desde $270 \mathrm{~s}$ até $1200 \mathrm{~s}$. O alcance do jato a pleno regime foi de 8 a $9 \mathrm{~m}$ de distância horizontal. A pressão exercida na saída do bocal injetor foi de 8,3 $\mathrm{kPa}$. O volume consumido foi de $0,02 \mathrm{~L} \cdot \mathrm{s}^{-1}\left(1,3 \mathrm{~L} \cdot \mathrm{h}^{-1}\right)$, na rotação máxima. Argumentou-se que é possível equilibrar o volume de aplicação através da vazão ou com a velocidade de caminhamento do operário.

Com relação ao tempo de esvaziamento do reservatório de calda e de pó, admite-se que se torna fácil, para cada condição, estabelecer a regulagem de vazão e a velocidade de caminhamento do operário, a par de concentração do produto a ser aplicado (DEMA1957-58).

Clayphon (1971), avaliando o desempenho de lançamento vertical e horizontal e a eficiência no controle de capsídios na cultura do cacau, cultivado em Gana, África, utilizou oito pulverizadores pneumáticos costais motorizados. Em Gana, as plantas de cacau são muito altas e há necessidade de que a calda seja distribuída em toda a sua parte superior e com adequada penetração, obtendo desta forma o controle da praga. Os resultados obtidos foram insatisfatórios para todas as máquinas. $\mathrm{O}$ autor concluiu que era necessário a utilização de pulverizadores em conjunto, para que se obtivesse o volume de calda necessário para o controle. A descarga de ar deveria ser bastante alta para dar melhor penetração.

Arnold \& Thornhill (1979) avaliaram alguns detalhes do projeto de um pulverizador pneumático costal motorizado, marca Fontan, especificamente projetado para gerar gotas do tamanho de aerossol. O chassi, o acelerador, os reservatórios de calda e de combustível, a bomba centrífuga, o filtro de ar sobre o motor e peças da mangueira que conduzem o inseticida, foram alguns dos itens descritos. Os autores 
chamaram a atenção para a necessidade de melhorar o filtro de ar sobre o motor com uma construção robusta, a colocação de uma proteção no gatilho contra temperaturas altas, melhorando o conforto do operador e a resistência das peças da mangueira ao ataque químico de solventes durante 48 horas.

Clayphon (1979) avaliou um pulverizador pneumático costal motorizado para aplicações a ultra baixo volume. A máquina com motor de $79 \mathrm{~cm}^{3}$ de cilindrada, apresentou, nos testes biológicos com capsídios, mortalidade sempre superior a 85\%, após 24 e 48 h. A máquina trabalhou com uma restrição no tubo de descarga de $0,86 \mathrm{~mm}$ e obteve uma taxa média de fluxo de $33.10^{-3} \mathrm{~L}_{\mathrm{min}} \mathrm{m}^{-1}$, a uma rotação de $5100 \mathrm{rpm}$. O alcance vertical obtido pela máquina foi acima dos $12 \mathrm{~m}$ de altura. A máquina apresentou resultados satisfatórios baseado na proposta para a qual ela foi projetada, mostrando-se apropriada para outras aplicações em culturas como café, banana, chá e seringueira jovens para alturas entre 11 e $12 \mathrm{~m}$.

De acordo com Aragão et al. (1988) a Superintendência de Campanhas de SaúdeSUCAM em 1984, no Rio de Janeiro, comparou aplicações feitas por três diferentes tipos de pulverizadores sendo dois deles portáteis e mostrou que as aplicações com portáteis baixavam mais rapidamente os índices de infestação do mosquito Ae. Aegypti. Os índices desejados sempre eram alcançados no prazo programado ou menor. Um dos modelos utilizados foi uma máquina da marca Hatsuta, fabricada no país e cuja vazão mínima era de $34,8.10^{-3} \mathrm{~L} \cdot \mathrm{min}^{-1}$ e diâmetro médio de gotas de $29 \mu \mathrm{m}$. No ano seguinte, com a mesma máquina, reduziu-se a concentração do produto e os gastos de inseticida em áreas íngremes, variando de 12,0 a $21,0.10^{-3}$ L.casa $^{-1}$, enquanto que na favela, num terreno plano, esse gasto foi de $4,5 \cdot 10^{-3} \mathrm{~L}_{\text {.casa }}{ }^{-1}$. Isso sugere que a dosagem vai depender do relevo e do espaço entre as moradias.

Jollands (1991) avaliou os pulverizadores costais motorizados disponíveis no mercado para o controle da ferrugem do café, Hemileia vastatrix. Os resultados mostraram que nenhuma das máquinas (Solo 423, Solo 410, Maruyama MD300, Echo DM9, Silvan M14 e Stihl SC17) satisfez completamente os critérios utilizados pelo autor (peso vazio menor que $98 \mathrm{~N}$, largura da alça maior que $0,04 \mathrm{~m}$, material da alça não absorvente, ignição eletrônica do motor, capacidade do reservatório de calda maior que 
10 litros, pressurização adequada no reservatório de calda na ausência de bomba centrífuga.

As mudanças na posição do bico com diferentes níveis de calda no reservatório resultaram, durante as aplicações de campo, numa grande variação na vazão para todas as máquinas. Os resultados podem ser vistos no Quadro 4.

\begin{tabular}{|c|c|c|c|c|}
\hline \multirow{2}{*}{ Máquina } & \multirow{2}{*}{ Restritor } & Inclinação +45 & horizontal & Inclinação -20 $^{\mathbf{0}}$ \\
\cline { 3 - 5 } & & \multicolumn{3}{|c|}{ L.min $^{-1}$} \\
\hline Solo 423 & Preto 2 & 0,25 & 0,36 & 0,50 \\
\hline Solo 410 & Preto 2 & 0,26 & 0,44 & 0,67 \\
\hline $\begin{array}{c}\text { Maruyama } \\
\text { MD 300 }\end{array}$ & 2 & 0,47 & 1,40 & 1,60 \\
\hline Echo DM9 & 1 & 0,26 & 0,82 & 0,93 \\
\hline Silvan M14 & 3 & 1,35 & 1,65 & 1,78 \\
\hline Stihl SG 17 & 1 & 0,37 & 0,87 & 1,70 \\
\hline
\end{tabular}

Quadro 4- Quadro das vazões médias (L. $\left.\mathrm{min}^{-1}\right)$, média de três repetições com diferentes posições do bico, de acordo com diferentes máquinas pulverizadoras.

A pressão no reservatório de calda foi determinada acoplando um tubo transparente na válvula de fluxo, mantendo-o verticalmente e medindo a altura da água no seu interior, com o motor na rotação máxima. Nenhuma das máquinas testadas obteve pressurização adequada no reservatório de calda, suficiente para manter a vazão constante em diferentes posições do bico e níveis de solução. Os resultados podem ser vistos no Quadro 5. 


\begin{tabular}{|c|c|c|c|c|}
\hline \multirow[t]{2}{*}{$\begin{array}{c}\text { Reservatório de } \\
\text { calda }\end{array}$} & Solo 423 & Solo 410 & $\begin{array}{c}\text { Maruyama } \\
\text { MD300 }\end{array}$ & Sthil SG17 \\
\hline & \multicolumn{4}{|c|}{$\mathrm{kPa}$} \\
\hline CHEIO & 1,2 & 0,35 & 0,1 & 0,09 \\
\hline $1 / 2$ & 0,13 & $-0,75$ & $-0,45$ & $-0,84$ \\
\hline $1 / 6$ & $-0,25$ & $-0,50$ & $-1,15$ & $-1,0$ \\
\hline
\end{tabular}

Quadro 5- Valores de pressão $(\mathrm{kPa})$ no reservatório de calda, na máxima elevação do bico, em diferentes máquinas pulverizadoras.

Bansal (1998), avaliou o desempenho dinâmico de um pulverizador pneumático costal motorizado modelo APSEE BOLO, acionado por um motor de ciclo dois tempos, ciclo Otto, marca Yilliers L34, controlando as vibrações nas fontes e analisando o nível de ruído. Realizou o balanceamento interno das peças do motor e em seguida o pulverizador foi montado nas costas do operador. Foram medidos os níveis de vibração antes e depois do balanceamento em diferentes rotações e partes da máquina, no motor, na bomba centrífuga, no ombro e no chassi do pulverizador. O nível de ruído foi medido junto ao ouvido do operador e registrou um valor na ordem de $93 \mathrm{db}(\mathrm{A})$. Os resultados mostraram uma considerável redução nos níveis de vibração, 43\% para o motor e 33\% para a bomba centrífuga, ambas na direção vertical e após o balanceamento. Os níveis de vibração nos ombros são altamente dependentes da rotação e conseqüentemente da freqüência de excitação. $O$ operador sente um grande alívio quando utiliza o pulverizador em condições de completo balanceamento.

Tosin et al. (2000) apresentaram uma comparação de desempenho de dois modelos de costais motorizados, PL 45 e PL 50 da marca Jacto, com relação aos níveis de ruído e tempo máximo de exposição diária permissível ao operador. Utilizaram formulações em pó e líquido, três rotações $(2300,3500$ e $7000 \mathrm{rpm})$ e três locais para a leitura do ruído. Os autores observaram que o nível de ruído variava com o aumento da rotação e com o local de medição em relação ao operador. Além disso as pulverizações com formulação 
pó reduziram o nível de ruído, sendo que no modelo PL45 os valores medidos foram sempre maiores.

\subsection{Avanços tecnológicos nos pulverizadores pneumáticos costais motorizados}

Preest (1979) modificou um pulverizador pneumático costal motorizado (marca TAS, modelo JKS-37) com o objetivo de tratar plantas invasoras em experimentos com grande número de tratamentos, numa área de regeneração de Pinus. Uma garrafa plástica de um litro, intercambiável, foi colocada próxima a saída da lança, eliminando o reservatório de calda e portanto, diminuindo o tempo de esvaziamento, limpeza e reabastecimento. Com esta modificação não foram percebidas variações no volume de calda aplicada entre as posições de lançamento mais alta e baixa. O tempo necessário para a troca das garrafas, localização das árvores de acordo com a aleatoriedade do projeto e a aplicação foi em média de 2 min.árvore ${ }^{-1}$.

Patel (1979) comparando o bico do tipo jato e um do tipo cilindro rotativo adaptado ao bocal, também conhecido como "micronair", obteve melhorias em todos os parâmetros testados, largura efetiva, volume de aplicação, volume mediano de diâmetro - vmd, tamanho e densidade de gotas. Segundo Laureano (1983) e Mount et al. (1971), o bico do tipo "micronair", consiste de um rotor sobre o qual vai montado co-axialmente um pequeno cilindro rotativo girando a alta rotação, cerca de $12000 \mathrm{rpm}$. O inseticida é lançado dentro do cilindro e forçado através de poros com diâmetro de $20 \mu \mathrm{m}$ para ser subdividido, arremessado na periferia do bico e as partículas transportadas pela corrente de ar gerada mecanicamente ou em alguns casos pelo vento. $\mathrm{O}$ esquema dos dois tipos de bicos é mostrado na Figura 6. 


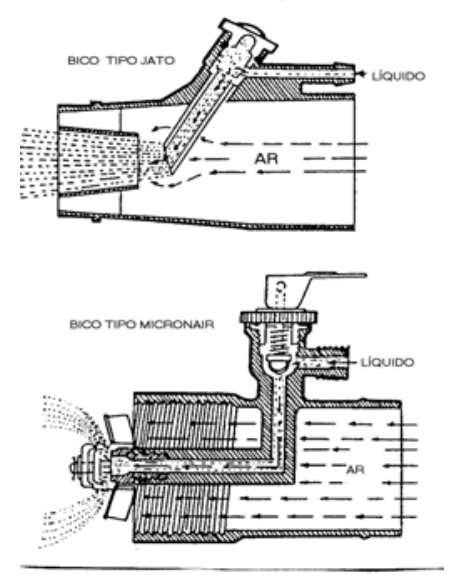

Figura 6- Esquema dos bicos tipo jato comum e cilindro rotativo, adaptado de Patel (1979).

Laureano (1983) agregou um sistema rotativo do tipo "micronair" a um pulverizador pneumático costal motorizado e avaliou o funcionamento da turbina. A partir da corrente de ar na saída do bocal, obteve os níveis de rotação do gerador de gotas. Iniciou o trabalho com $5000 \mathrm{rpm}$, chegando até $7000 \mathrm{rpm}$ com intervalos de 500 rpm entre duas leituras consecutivas. Os valores encontrados para velocidade da corrente de ar na saída do bocal variaram na faixa de $50 \mathrm{~m} \cdot \mathrm{s}^{-1}$ a $75 \mathrm{~m} \cdot \mathrm{s}^{-1}$. Em função dessas velocidades pode-se determinar, pela eq. (3), a rotação do gerador de gotas, cujo maior valor foi de $11775 \mathrm{rpm}$.

$\mathrm{Vg}=-192,8+157,4 \mathrm{~V}$

Em que:

$\mathrm{Vg}=$ rotação do gerador $(\mathrm{rpm}) \mathrm{e}$

$\mathrm{V}=$ velocidade da corrente de $\operatorname{ar}\left(\mathrm{m} \cdot \mathrm{s}^{-1}\right)$.

O autor encontrou excelente correlação linear da rotação com a velocidade da corrente de ar, sendo o coeficiente de determinação de 0,98 e excelente correlação linear da corrente de ar e rotação do gerador com a rotação do motor, com o coeficiente de determinação de 0,99 quando ela varia entre 5000 a 7000 rpm. 
Moser \& Hussain (1985) compararam bicos tradicionais dos pulverizadores pneumáticos costais motorizados com os bicos eletrostáticos, os quais utilizam a força eletrostática que é maior do que a gravitacional e a do vento que movimenta as gotas. A deposição obtida pelo uso de carga eletrostática foi pelo menos 3 a 4 vezes maior se comparado com a deposição obtida pelo método convencional de pulverização e um aumento de $60 \%$ no alcance do alvo. A deposição na frente do alvo foi 2 a 3 vezes maior do que nos lados. Um tipo de bico eletrostático é apresentado na Figura 7.

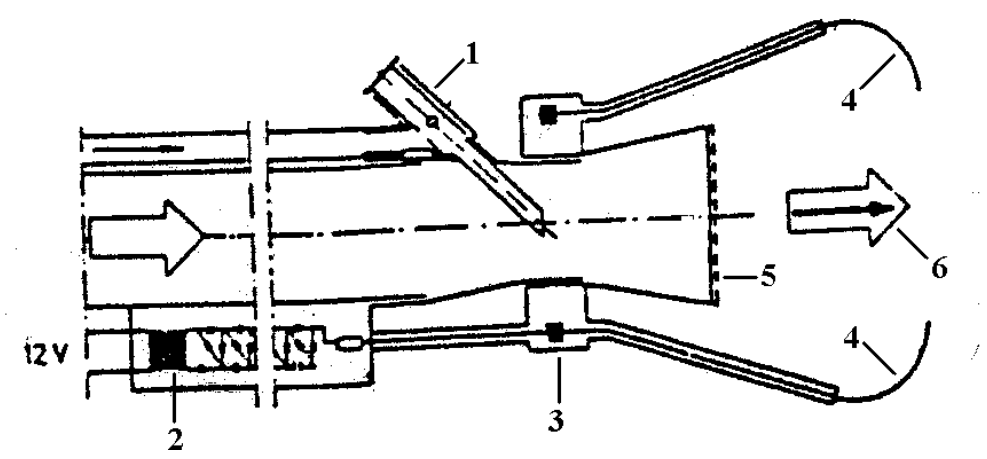

Figura 7- Esquema de um bico eletrostático (1- tubo de alimentação de calda, 2gerador de alta voltagem, 3- distribuidor de alta voltagem, 4- eletrodos de alta voltagem, 5- corpo do bico (plástico ou metal), 6- nuvem de calda), adaptado de Moser \& Hussain (1985).

\subsection{Instrumentos/sensores para medições em ensaios de máquinas agrícolas}

Segundo Doebelin (1966) um instrumento apresenta diversos elementos funcionais, o sensor é a parte sensitiva, ou seja, é aquele que primeiro recebe a energia do meio a ser medido e produz uma saída dependendo de como a quantidade é medida. Os demais elementos são: o transdutor, o elemento de conversão da variável que se quer medir em outra mais disponível, enquanto preserva o conteúdo da informação; o elemento de manipulação que altera o valor numérico de acordo com a função definida mas preserva a natureza física da variável, como por exemplo um amplificador; o 
elemento para transmissão de dados, quando os elementos funcionais estão atuando fisicamente separados e o elemento responsável pela chegada da informação de forma que seja reconhecida por algum dos sentidos do ser humano.

Segundo Doebelin (1966) um instrumento pode envolver os elementos em qualquer número de combinações, não é necessário aparecer na ordem da Figura 8. Um componente físico pode realizar várias funções ao mesmo tempo.

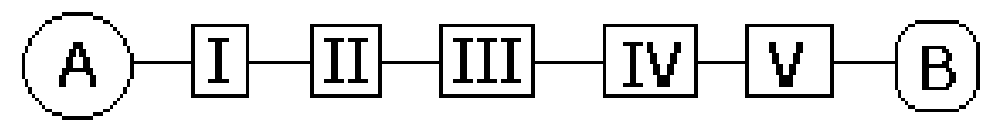

Figura 8- Diagrama dos elementos funcionais de um sistema de medição (A-meio a ser medido, I- sensor principal, II- conversão da variável, III- manipulação da variável, IV- transmissão de dados, V-apresentação de dados, B- observador), adaptado de Doebelin (1966).

Segundo Werneck (1996) o instrumento é um equipamento eletrônico que manipula sinais elétricos e que representam grandezas físicas. Os instrumentos medem, controlam, atuam, monitoram, transferem ou registram informações úteis relativas a eventos naturais ou processos tecnológicos. Nesses instrumentos o transdutor é uma peça que transforma duas formas de energia para fins de medida, produz um sinal elétrico de saída proporcional à grandeza que está sendo medida. O sensor é apenas a parte sensitiva do transdutor.

Segundo Grandke \& Hesse (1989) uma definição precisa do que é sensor não é tarefa tão simples. Existe uma tendência para designar como sensores todos os instrumentos utilizados para a medição técnica de quantidades físicas, químicas ou biológicas.

Segundo a Instrument Society of América - ISA (1975) um transdutor é definido como um dispositivo que fornece uma saída em resposta a uma medida específica. Entretanto, uma saída é definida como uma quantidade elétrica, e a medida é uma quantidade, uma propriedade, ou uma condição física. 
Segundo Grandke \& Hesse (1989) de acordo com a forma de energia que são recebidos e gerados os sinais, os sensores podem ser classificados como mecânicos, térmicos, magnéticos, ópticos, químicos e biológicos.

Segundo Thompson (1973) nas operações de ultra baixo volume, pequenas mudanças nos parâmetros de operação podem reduzir grandemente a eficiência do pulverizador. Para o autor não é aconselhável calibrar o pulverizador na falta de instrumentos de medição, antes de submetê-los às operações de campo.

Segundo Salyani \& Serdynski (1993) referindo-se a métodos de calibração com o uso de sistemas eletrônicos para determinar vazões e velocidade de deslocamento apresentaram limitações referentes à confiabilidade nos circuitos eletrônicos e às medições que são afetadas pela acurácia e confiabilidade dos sensores.

\subsubsection{Instrumentos/sensores para medição de rotação}

Segundo Doebelin (1966) em medidas de movimento os parâmetros fundamentais são comprimento e tempo, entretanto a rotação é basicamente uma função do comprimento. Segundo Doebelin (1966), os instrumentos utilizados para medir a rotação baseiam-se no movimento do eixo de uma linha relativa a outra.

Segundo Werneck (1996) o método mais simples de se obter a rotação é a partir de um sinal de posição fornecido por qualquer transdutor de posição. Como a velocidade é a primeira derivada da posição, o procedimento é monitorar a posição de um objeto e injetar o sinal em um diferenciador para obter o sinal da rotação. O método mais comum de se medir a rotação de um eixo é o uso de tacômetros. Segundo Mialhe (1996) tacômetros são instrumentos que medem diretamente a rotação, fornecendo leituras diretamente em rotações por minuto e de acordo com o princípio de funcionamento podem ser mecânicos, elétricos e eletrônicos. Existem ainda o conta-giros, o instrumento mais simples para medição da rotação e os cronotacômetros que reúnem numa só unidade o conta-giros, cronômetro e tacômetro. 
Para Werneck (1996) tacômetros são dínamos de corrente contínua que ao serem conectados a um eixo em rotação, geram uma tensão contínua proporcional à rotação do eixo.

Segundo Mialhe (1996) os tacômetros eletrônicos mais modernos, apresentam circuitos com memória e interfaces para computadores. Para o uso manual são bastante práticos os denominados tacômetros estroboscópicos que medem a rotação à distância. A combinação do princípio óptico clássico com a moderna eletrônica desenvolve uma variedade de instrumentos de medição eletrônica (Doebelin, 1966). Os acessórios tipo cabo em fibra óptica podem fazer com que objetos sejam detectados sob condições extremas e pouco usuais. Sendo o cabo flexível, as vibrações não são conduzidas para o sensor. O cabo de fibra óptica é a opção ideal quando há problemas de espaço.

Segundo Werneck (1996) o transdutor a fibra óptica conduz um feixe de luz para a região a ser medida e a luz sofre uma modificação de algum de seus parâmetros por efeito do mensurado (a variável que se quer medir). Essa modificação pode ser em comprimento de onda (cor). A luz ao retornar ao ponto de partida carrega consigo a informação do mensurado que é extraída do sinal de retorno através de técnicas optoeletrônicas.

\subsubsection{Instrumentos/sensores para medição da pressão}

Segundo Doebelin (1966), o método básico de medir força e pressão é o mesmo. A maioria das medidas são baseadas na comparação com pesos mortos agindo sobre áreas conhecidas ou com a deflexão de elementos elásticos sujeitos à pressões. Existem muitas formas diferentes de instrumentos que utilizam a deflexão elástica. Segundo Werneck (1996), na prática os sensores de pressão convencionais são em sua grande maioria formados por extensômetros, elementos cuja resistência elétrica varia com a tração ou a compressão, colados em diafragmas (transdutores de pressão) que se distendem de acordo com a pressão do líquido ou do gás fechado em um compartimento. O sensor de pressão diferencial, instrumento de deflexão elástica, mede a diferença entre as pressões aplicadas simultaneamente em lados opostos do diafragma, onde uma pressão positiva 
aplicada num dos lados gera a mesma saída com igual pressão, negativa, aplicada no lado do vácuo (Motorola, 1998).

Existem ainda, os sensores de pressão absoluta que medem uma pressão externa em relação a uma pressão zero de referência (vácuo), fechada dentro de uma câmara de referência durante a fabricação do instrumento (Motorola, 1998).

\subsubsection{Instrumentos/sensores para medição da temperatura}

Segundo Schooley (1986), um sensor de temperatura ou transdutor experimenta mudanças nos parâmetros mensuráveis tais como viscosidade, dimensão, resistência elétrica, resultado da exposição a uma mudança de temperatura. Existem vários instrumentos para medir temperatura: termômetros de expansão térmica, termômetros de resistência, termômetros de radiação e termopares.

Segundo Ismail et al. (1998) um grande número de sensores de temperatura utiliza o fenômeno da expansão térmica de sólidos que é empregada principalmente em elementos bimetálicos.

Segundo Schooley (1986); Göpel, et al. (1990) os termômetros termopares podem ser utilizados em uma grande variedade de sistemas físicos e químicos, no campo científico ou industrial tanto para medições, como para controle de sistemas. Segundo Göpel, et al. (1990) os termopares consistem de dois condutores ou fios de metal (A e B) de diferentes composições, formando um circuito elétrico. Na Figura 9 é apresentado um esquema básico de um sistema termopar. Segundo Göpel, et al. (1990); Doebelin (1966) uma pequena corrente elétrica criada pela diferença das temperaturas em T1 e T2 percorre o circuito e gera um potencial termoelétrico ou também conhecido como força electromotriz (emf). O valor do potencial termoelétrico depende da composição dos condutores escolhidos (A e B) e da diferença de temperatura, $\Delta \mathrm{T}$. Para realizar a determinação da temperatura, uma das duas junções é mantida em uma temperatura constante e conhecida (por exemplo, $0^{\circ} \mathrm{C}$ ). Segundo Göpel, et al. (1990) o termopar pode ser considerado como um dispositivo para a conversão da energia térmica em energia elétrica. 


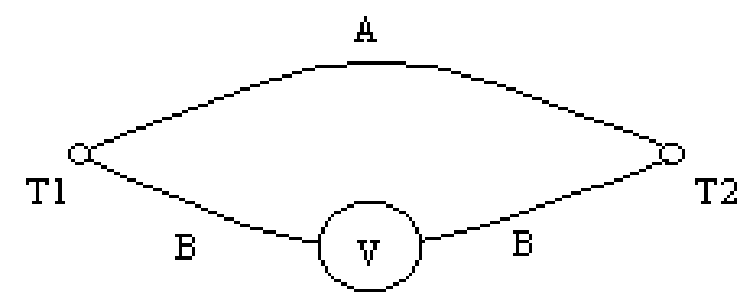

Figura 9- Circuito simples de termopar (A e B- fios diferentes, T1 e T2- temperaturas e V-voltímetro), adaptado de Doebelin (1966)

Segundo Göpel, et al. (1990) tem-se desenvolvido novos sensores como os termômetros infravermelhos, superando problemas de gradientes térmicos ao longo da medição, entretanto uma forte limitação desses sensores é a dependência de suas leituras sobre a emissividade dos materiais alvo. Assim, a filosofia predominante tem sido projetar termômetros para cada material ou categoria de materiais. 


\section{MATERIAL E MÉTODOS}

O trabalho se desenvolveu em etapas com a construção de um coletor de gotas e da estrutura de apoio do pulverizador, ensaio preliminar, modelagem do fenômeno e desenvolvimento do ensaio principal.

Todos os ensaios foram realizadas no Laboratório de Tecnologia de Aplicação de Defensivos Agrícolas do Departamento de Engenharia Rural da Escola Superior de Agricultura "Luiz de Queiroz", Universidade de São Paulo, localizada no município de Piracicaba, estado de São Paulo.

\subsection{Pulverizador}

O pulverizador pneumático costal motorizado foi retirado de um lote de 25 máquinas, adquirido pela SUCEN, com nota fiscal n 003937, emitida pela Deterbom Comercial e Distribuidora Ltda. A máquina foi cedida por empréstimo para o período de realização do trabalho e recebida em caixa lacrada. As especificações do pulverizador pneumático costal motorizado são as seguintes: marca Máquinas Agrícolas Jacto S.A., modelo Multispray 2000 LD, série 9700, peso de 114,7 N. Possui um reservatório de combustível com capacidade para 1,3 L e reservatório de calda em polietileno rígido, cor preta, com capacidade para 2,0 L. O motor e a bomba centrífuga da máquina apresentam as seguintes especificações de acordo com o manual do fabricante (Jacto, s.d.): motor de combustão interna, monocilíndrico, com ciclo dois tempos, refrigerado a ar, modelo JET 400, com potência de $1,9 \mathrm{~kW}(2,6 \mathrm{cv})$, diâmetro do pistão de $40 \mathrm{~mm}$ e curso de 30

$\mathrm{mm}, 37,7 \mathrm{~cm}^{3}$ de cilindrada; rotação máxima de $8000 \mathrm{rpm}$, ignição eletrônica, e partida 
retrátil; bomba centrífuga com vazão do ar gerado de $0,21 \mathrm{~m}^{3} \cdot \mathrm{s}^{-1}$ e velocidade do ar de $85 \mathrm{~m} \cdot \mathrm{s}^{-1}$.

Para abastecimento do reservatório de combustível da máquina utiliza-se uma mistura de óleo lubrificante semi-sintético para motores 2 tempos, nível de desempenho American Petroleum Institute (API) TC e gasolina comum. Para a proporção da mistura de combustível e o funcionamento da máquina foram seguidas as orientações fornecidas no manual de instruções do fabricante (Jacto, s.d.). Todas as conexões do circuito hidráulico e pneumático da máquina foram unidas com abraçadeiras, vedadas com resina epóxi, endurecedor poliamida e cargas minerais, marca Durepoxi e fita veda rosca em teflon, largura de $18 \mathrm{~mm}$, para que não houvesse vazamentos. A averiguação da presença de vazamentos no circuito pneumático foi feita periodicamente com água e detergente. A água utilizada no abastecimento do reservatório de calda não foi armazenada e nem recebeu qualquer tipo de tratamento.

Para facilitar a visualização do fluxo de água no circuito hidráulico da máquina, as mangueiras originais (do reservatório até o registro de calda e do registro até o corpo dosador na turbina), de cor preta, foram substituídas por mangueiras de vinil transparente, diâmetro nominal de 7,94 mm (5/16").

\subsection{Disco dosador}

É a peça responsável pela restrição do fluxo de calda no bico. O corpo é constituído de polietileno rígido e o centro em latão. O fabricante oferece como opção de compra doze cores diferentes: amarela, verde, bege, azul, cinza, rosa, lilás, marron, preta, correspondentes às vazões de 0,$03 ; 0,07 ; 0,10 ; 0,14 ; 0,25 ; 0,38 ; 0,55 ; 0,80$ e 1,12 L.min ${ }^{-1}$, respectivamente e ainda as cores branca, laranja e vermelho, cujas vazões não são apresentadas no manual do fabricante. Nas compras feitas pela SUCEN, os discos verde, amarelo e bege acompanham a máquina na caixa, mas a SUCEN utiliza apenas o disco dosador bege que aparece ocasionalmente com dois diâmetros diferentes, e que são distinguidos apenas visualmente, pois não possuem nenhum informação sobre seus diâmetros de orifício. Foram adquiridas oito unidades do disco dosador bege e 
numeradas. Foram designadas respectivamente de A e B aquelas com diâmetro de orifício maior e menor. Em seguida foram determinados os valores dos seus diâmetros, coeficiente de variação e sorteados um exemplar de A e de B para os ensaios.

\subsection{Bancada de ensaios}

A bancada de ensaios é constituída do pulverizador, descrito no item 3.1, da estrutura de apoio do pulverizador e o equipamento para aquisição de dados, como podem ser vistos na Figura 10.

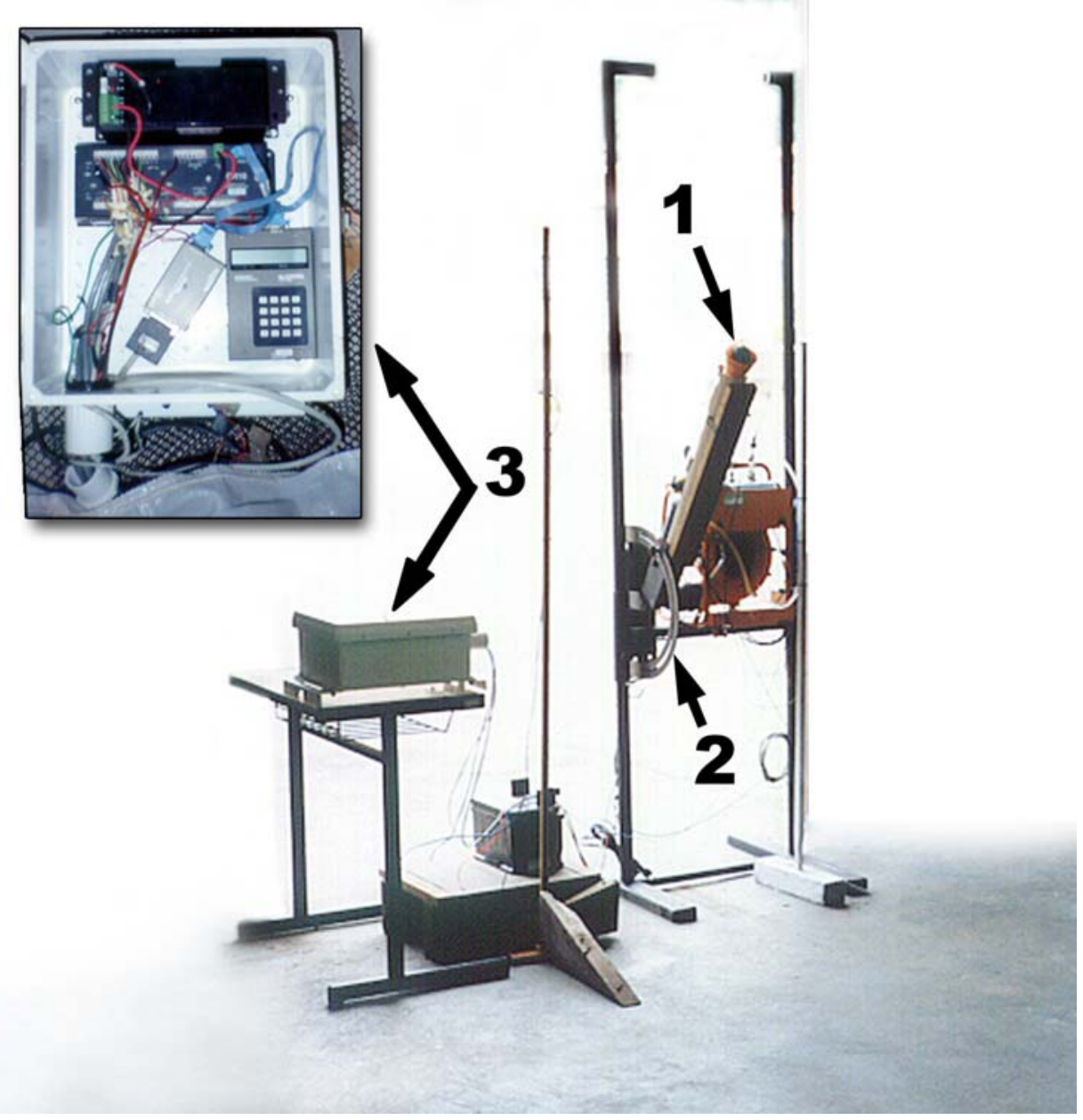

Figura 10- Equipamentos utilizados no ensaio principal (1- pulverizador, 2- estrutura de apoio do pulverizador e 3- sistema de aquisição de dados). 


\subsubsection{Estrutura de apoio do pulverizador}

A estrutura de apoio do pulverizador é constituída de um suporte de ferro, um transferidor e um suporte de madeira para sustentação da lança e direcionamento do jato de gotas. Esse conjunto pode ser visto na Figura 11.

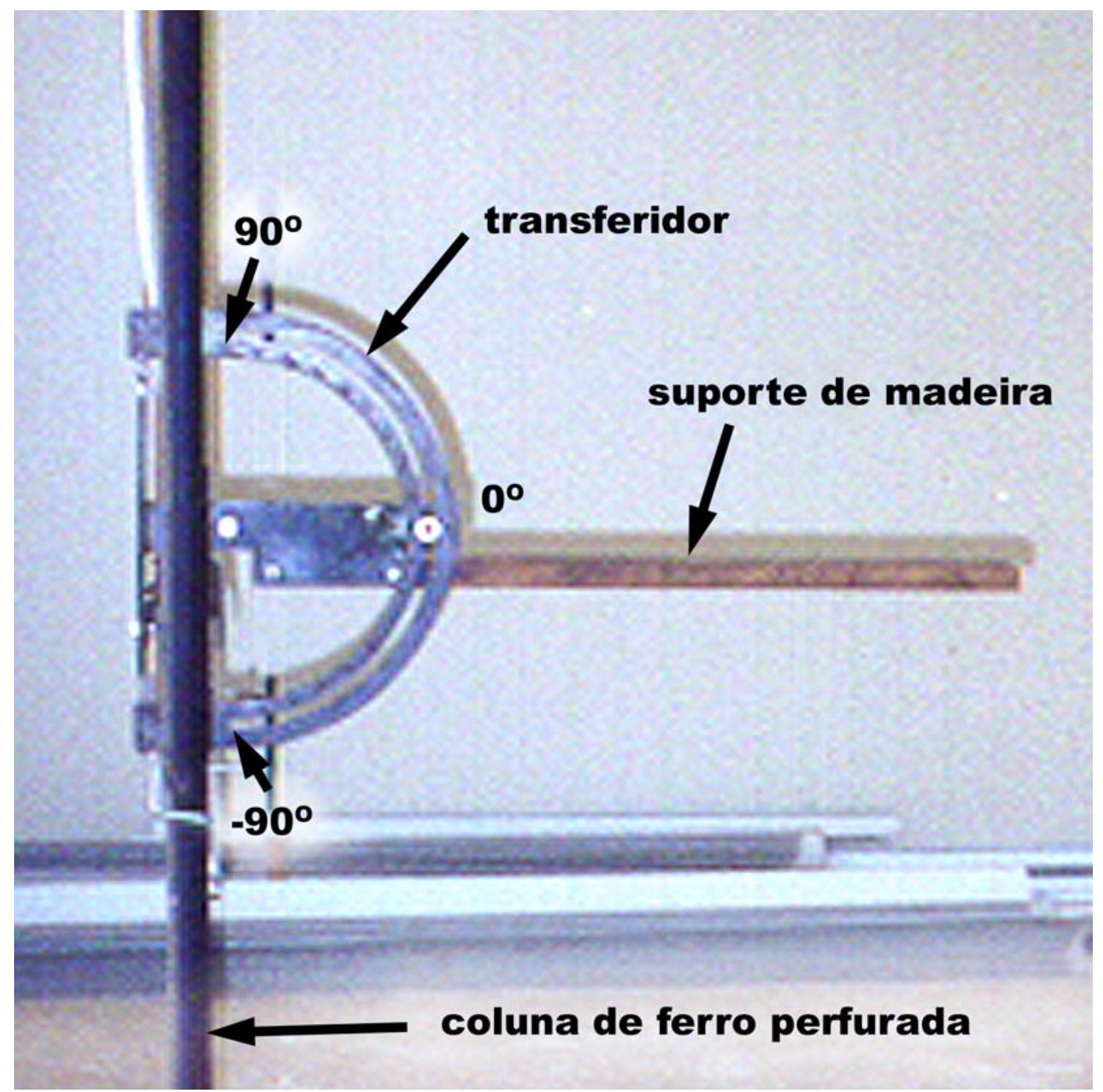

Figura 11- Detalhes da estrutura de apoio do pulverizador

O suporte de ferro é construído com duas colunas redondas laterais perfuradas a cada $0,20 \mathrm{~m}$ para colocação de pinos trava que permitem o posicionamento do 
pulverizador na altura desejada, sustentado por uma barra de ferro transversal. $\mathrm{O}$ desenho técnico do suporte pode ser visto no anexo A.

O transferidor foi construído a partir de uma chapa de aço em forma de arco com $180^{\circ}$. Esse arco foi cortado ao longo de sua extensão permitindo o deslizamento do suporte de madeira e possibilitando a variação do ângulo de lançamento. $O$ suporte de madeira é fixado firmemente através de um parafuso impedindo a ocorrência de erro no posicionamento. Os ângulos no transferidor foram indicados em intervalos de $20^{\circ}$.

\subsubsection{Sistema de aquisição de dados}

Um sistema de aquisição de dados, modelo CR10X, marca Campbell Scientific, Inc., com entrada analógica para 6 canais diferenciais, freqüência de execução de $64 \mathrm{~Hz}$, resolução $0,33 \mu \mathrm{V}$, fundo de escala de $2,5 \mathrm{~V}$ e erro $\pm 0,1 \%$, foi programado com o auxílio do programa PC208 W, versão 2.0, para monitorar e armazenar os dados em tempo real a cada segundo. Os dados foram armazenados e posteriormente transferidos para um computador Pentium $200 \mathrm{MHz}, 32 \mathrm{MB}$ de memória de acesso aleatório - RAM e convertidos em planilha de dados do Microsoft Excel 2000. Os diagramas dos circuitos eletrônicos para os sensores de pressão, para o tacômetro (fibra óptica mais chave fotoelétrica) e a rotina da programação elaborada para a leitura e armazenamento dos dados podem ser vistos nos anexos C, D e E, respectivamente.

Os circuitos eletrônicos dos sensores de pressão e do sistema de leitura óptica ligados ao sistema de aquisição de dados foram protegidos contra danos provocados por solventes ou choques acondicionado-os numa caixa fixada na parte de trás do transferidor como pode ser visto na Figura 12. 


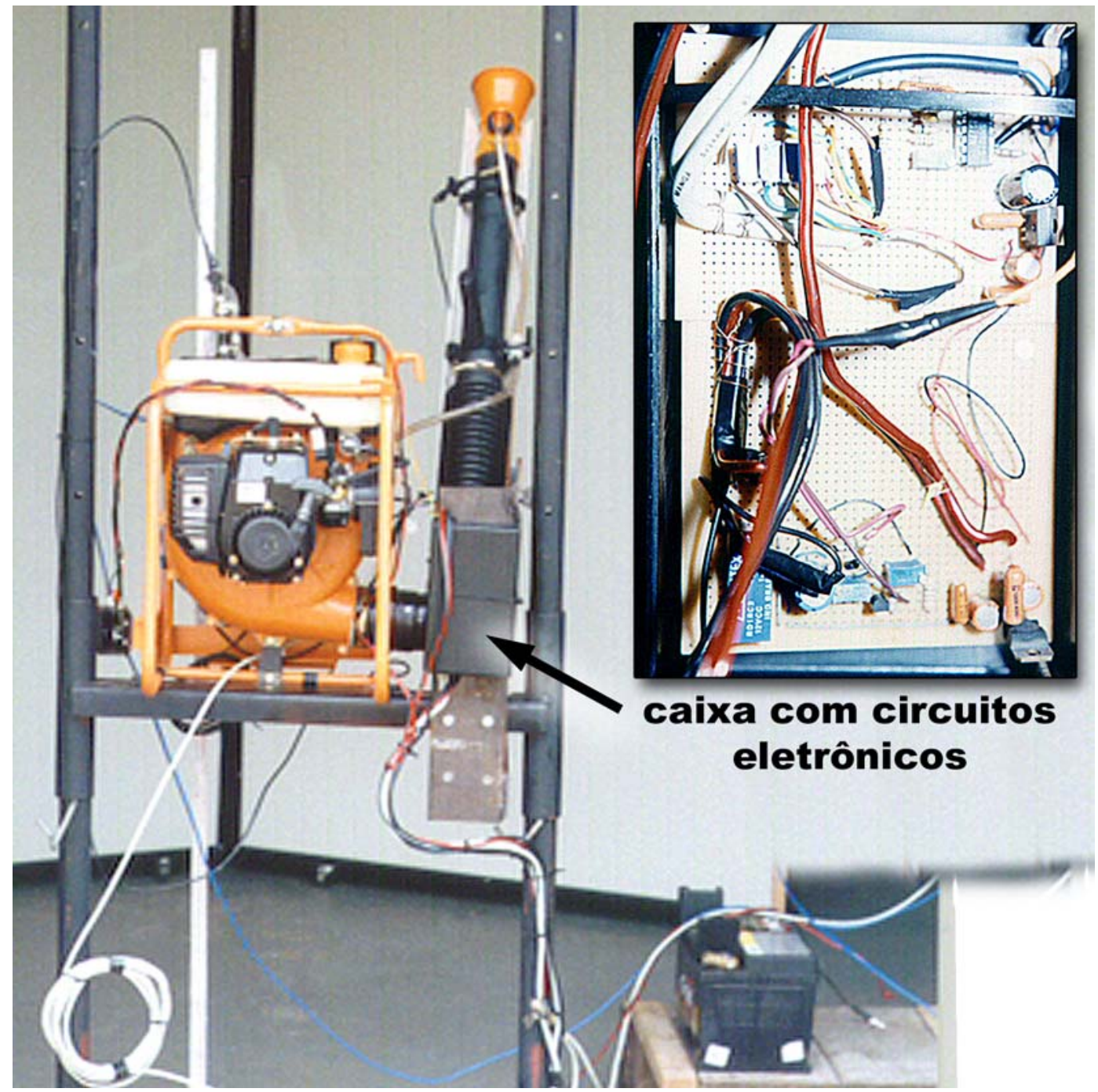

Figura 12- Detalhe do local escolhido para instalação dos circuitos eletrônicos

\subsection{Coletor de gotas}

A estrutura do coletor de gotas, constitui-se de um quadro de secção retangular, com entalhes laterais a cada 0,025 m onde são montadas as lamelas de plástico. As lamelas são canais horizontais de secção ondulada e ressalto interno longitudinal. As laterais do quadro são fechadas por quatro chapas de aço inox. O coletor de gotas foi disposto sobre uma estrutura de ferro, como pode ser visto na Figura 13. 


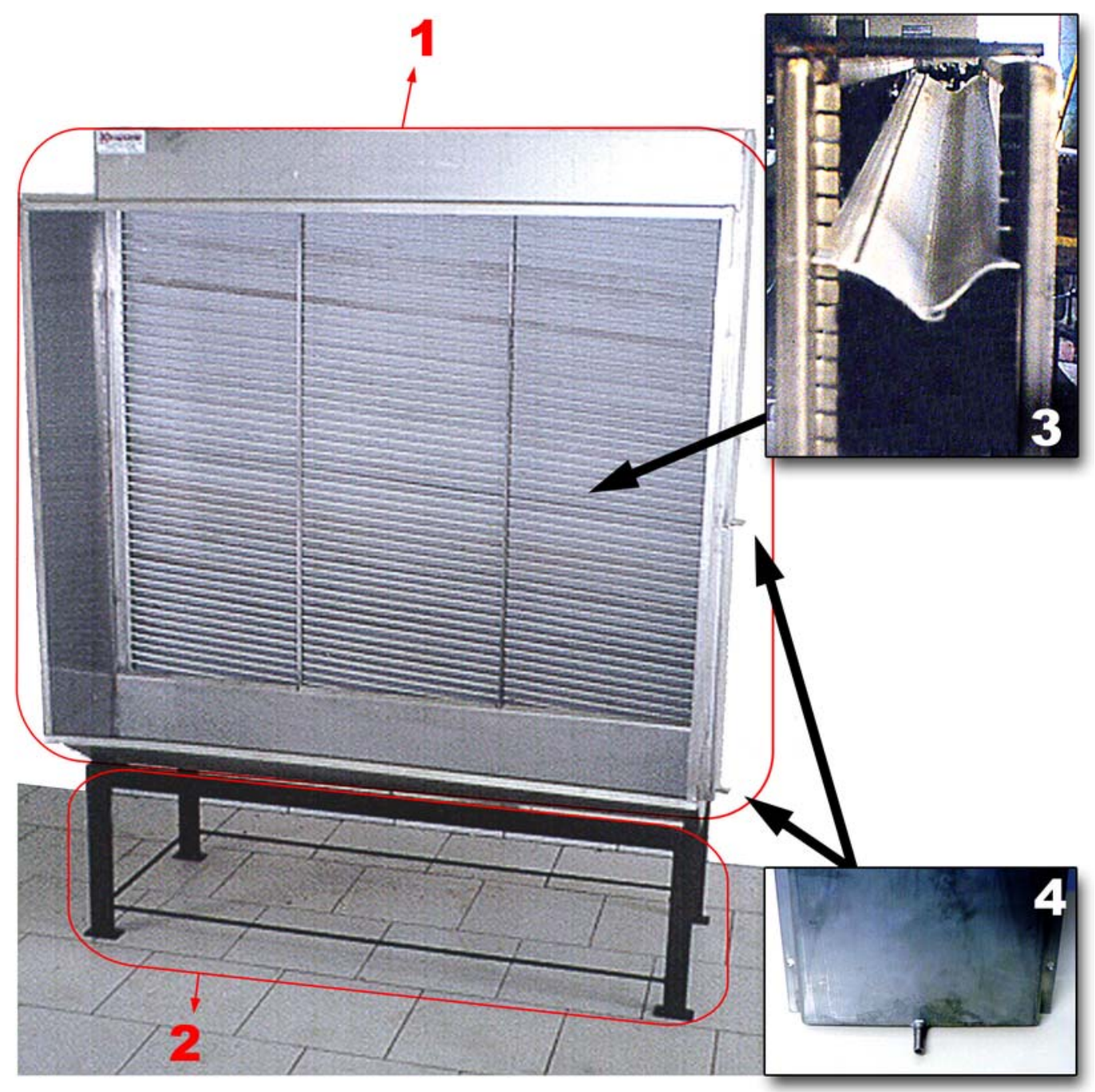

Figura 13- Vista frontal do coletor de gotas (1- coletor, 2 -estrutura de ferro, 3- lamela de plástico, 4- tubo de aço inox)

$\mathrm{Na}$ estrutura principal foram parafusadas duas chapas laterais em aço inox, projetadas para a frente da área de captura do líquido pulverizado, funcionando como anteparos e uma bandeja em aço inox fixada na parte inferior através de parafusos. A água captada nas lamelas é conduzida até provetas, por meio de mangueiras de polietileno conectadas a tubos de aço inox com diâmetro nominal interno de $6,3 \mathrm{~mm}$ $\left(1 / 4^{\prime \prime}\right)$ soldados nas chapas laterais e na bandeja. 
As lamelas foram posicionadas no interior da estrutura com uma declividade de $8 \%$, sendo que a primeira saída lateral para a coleta do líquido situou-se após a $28^{\mathrm{a}}$ lamela e a segunda após a $54^{\mathrm{a}}$. No anexo B apresenta-se o projeto do coletor de gotas e o tipo de perfil das lamelas.

\subsection{Instrumentação}

\subsubsection{Rotação do motor}

A rotação do motor foi medida através de um sensor de fibra óptica cujo cabo modelo E32-DC200, com $2 \mathrm{~m}$ de comprimento, fabricado pela OMRON Corp. foi fixado em um pequeno suporte de ferro em forma de "S", com cerca de 0,05 m de altura. Para que a ponta da fibra óptica permanecesse próxima ao rotor, o suporte foi fixado na tela de proteção da bomba centrífuga. O posicionamento do cabo de fibra óptica pode ser visto na Figura 14.

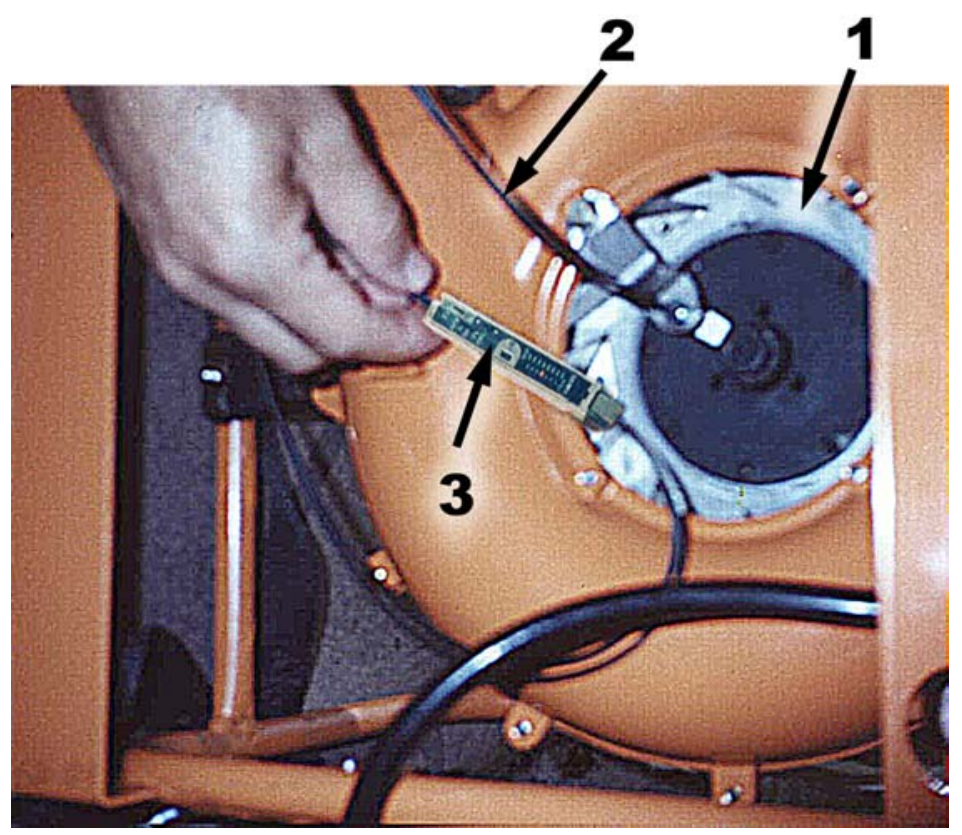

Figura 14- Detalhes do posicionamento e colocação do cabo de fibra óptica próxima ao rotor da máquina (1- rotor, 2- cabo de fibra óptica, 3- chave fotoelétrica ou amplificador). 
Para a aquisição dos sinais luminosos pela fibra óptica foi aplicada tinta preta, na parte exposta do rotor e uma faixa branca transversal aplicada sobre o fundo preto. A seleção e o ajuste de sensibilidade do sistema foram feitos de acordo com programação realizada na chave fotoelétrica ou amplificador, modelo E3X-NH11, fabricado pela OMRON Corp., onde o cabo de fibra óptica foi inserido. Para fornecimento de energia ao sistema foi utilizada uma bateria com tensão nominal de $12 \mathrm{~V}$, marca Craw.

\subsubsection{Pressão no interior do reservatório de calda e nos circuitos hidráulico e pneumático do pulverizador}

Nos ensaios foram utilizados para medição quatro sensores de pressão diferencial, marca Motorola, revestimento 867C-05, série MPX, número de ordem MPX5010DP, com fundo de escala de $10 \mathrm{kPa}$, erro $\pm 5 \%$ na faixa de $0^{\circ}$ a $85^{\circ} \mathrm{C}$, instalados nos circuitos hidráulico e pneumático do pulverizador. O local onde as pressões foram tomadas são mostradas na Figura 15.

As posições e distâncias de localização dos sensores é a seguinte: posição no ponto 1 (P1), na mangueira responsável pela condução do fluxo de ar gerado pela bomba centrífuga, distante $0,06 \mathrm{~m}$ do reservatório de calda; posição no ponto 2 (P2), na mangueira conectada ao reservatório de calda distante $0,8 \mathrm{~m}$ do registro de saída de calda; posição no ponto 3 (P3), após o registro de saída da calda, distante $0,085 \mathrm{~m}$ do corpo do dosador e posição no ponto 4 (P4), instalado na parte de cima do reservatório de calda, registrando a pressurização no interior do mesmo. 


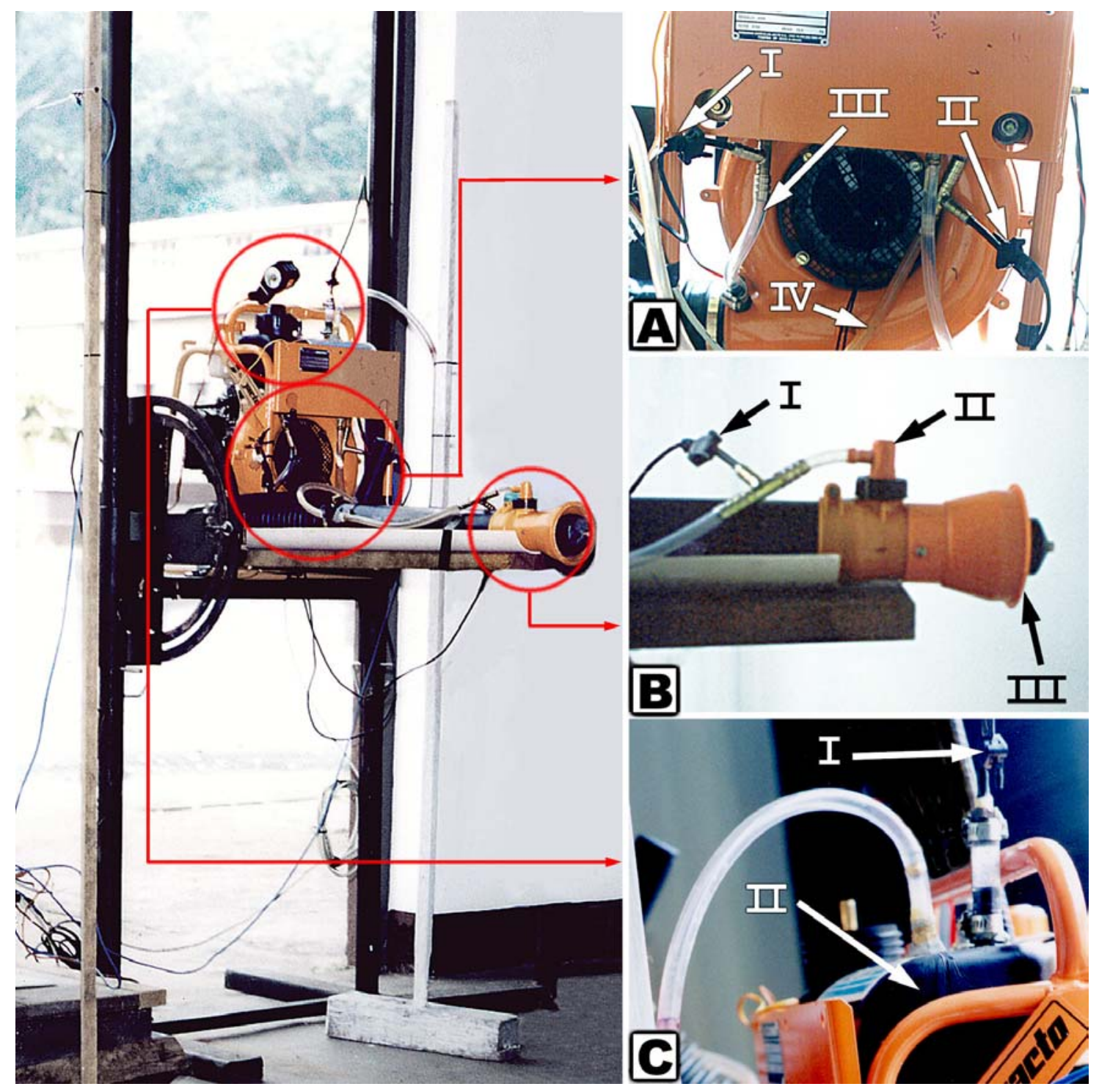

A- I- sensor da pressão no ponto 1 , II- sensor da pressão no ponto 1 , II- mangueira de ar e IV-mangueira da calda.

B- I- sensor da pressão no ponto 3 , $\amalg$ - corpo do dosador e III- bocal

C- I- sensor da pressão no ponto 4 e $\Pi$ - reservatório de calda

Figura 15- Pontos de tomada de pressão e detalhes dos sensores nos pontos 1 (P1), 2 (P2), 3(P3) e $4(\mathrm{P} 4)$.

Os sensores foram posicionados nos pontos P1, P2 e P3 com a colocação de uma conexão hidráulica de ferro galvanizado em forma de "T", com diâmetro nominal 
interno de $6 \mathrm{~mm}$. Os valores resultantes foram registrados em mbar e posteriormente convertidos a $\mathrm{kPa}$.

\subsubsection{Temperatura da água no interior do reservatório da calda e ambiente}

Para verificar a ocorrência de suposta variação na viscosidade da água, visto que esta varia em função da temperatura (Lencastre, 1972), procurou-se determinar a variação de temperatura da água dentro do reservatório de calda e a temperatura média do ambiente durante cada tratamento. Para tanto foram utilizados dois termopares do tipo T, com erro de $\pm 0,75 \%$ na faixa de utilização de -200 a $370{ }^{\circ} \mathrm{C}$.

A ponta completa do sensor, com $0,075 \mathrm{~m}$ de comprimento, foi inserida no interior do reservatório de calda a $0,015 \mathrm{~m}$ do fundo e posicionada a $0,010 \mathrm{~m}$ da conexão de saída da calda, como pode ser visto na Figura 16. Para impedir vazamentos nas paredes do orifício, onde a ponta do termopar foi inserida, a vedação foi completada externamente com pasta de silicone.

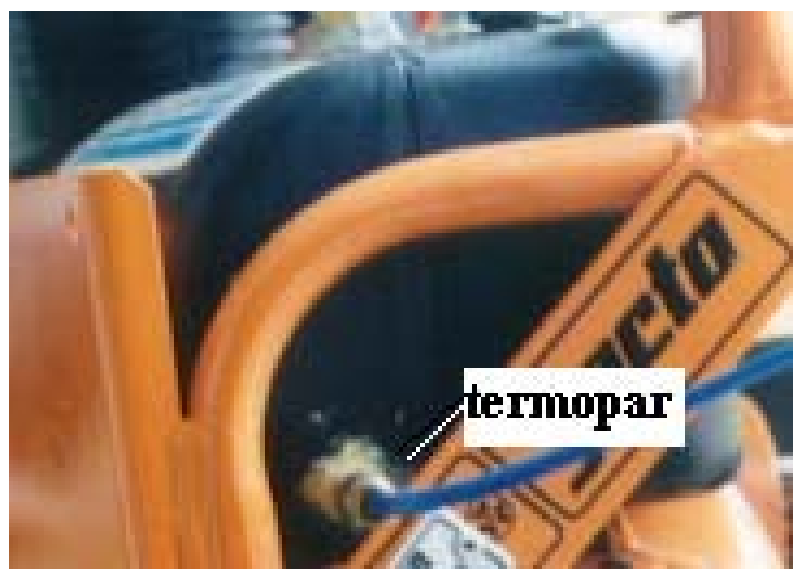

Figura 16- Termopar instalado no reservatório de calda.

O sensor para medição da temperatura ambiente foi fixado numa haste de madeira, como pode ser visto na Figura 19, e posicionado a 1,5 $\mathrm{m}$ de altura do solo e afastado pelo menos $0,5 \mathrm{~m}$ das paredes do local.

Ambos os cabos dos termopares foram posicionados a mais de $0,5 \mathrm{~m}$ do motor, para que não houvesse problema de queima dos mesmos. 


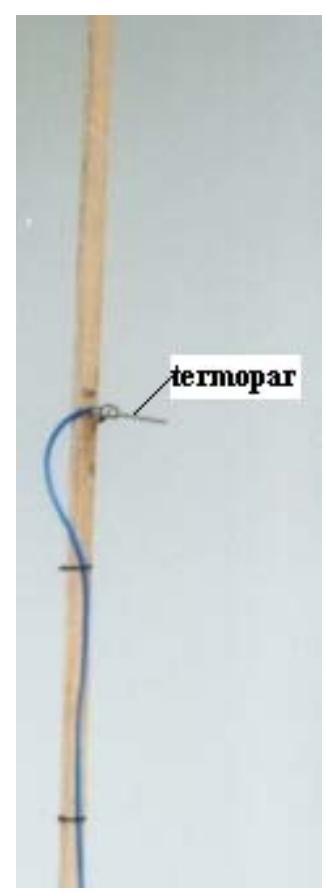

Figura 17- Termopar instalado para registro da temperatura ambiente.

\subsubsection{Velocidade do ar na saída do bocal}

A velocidade do ar foi determinada posicionando-se um anemômetro digital modelo MDA-10, resolução de $0,03 \mathrm{~m} . \mathrm{s}^{-1}$, fundo de escala de 38,8 m.s $\mathrm{s}^{-1}$, erro $\pm 3,0 \%$, produzido pela MINIPA Indústria Eletrônica Ltda, perpendicularmente ao eixo central da turbina. Os valores foram obtidos para cada um dos sete ângulos nas distâncias de 0,2 $\mathrm{m}, 0,4 \mathrm{~m}, 0,6 \mathrm{~m}, 0,80 \mathrm{~m}$ e $1,0 \mathrm{~m}$ à partir da saída do bocal da turbina. Na Figura 18 é mostrado o esquema utilizado para a determinação da velocidade do ar. 


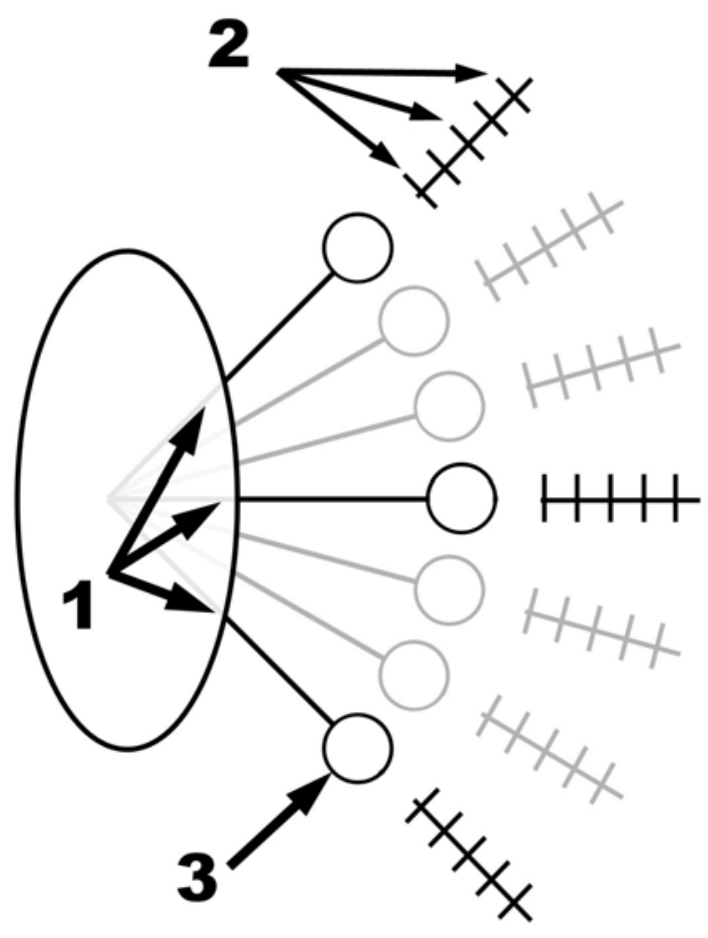

Figura 18- Esquema utilizado para determinação da velocidade do ar (1- ângulos da lança, 2- distâncias do bocal e 3 - bocal do pulverizador).

\subsection{Ensaio preliminar}

O ensaio preliminar envolveu o uso do coletor de gotas, com a finalidade de separar do jato lançado pelo pulverizador as fases líquida e gasosa interceptando a fase líquida com o auxílio das lamelas. O objetivo do ensaio foi avaliar a possibilidade de utilização do coletor baseado no projeto inicial utilizado por Kümmel (1991), com adaptações para esse trabalho, a fim de determinar a vazão.

O pulverizador foi posicionado de modo que o jato de gotas fosse direcionado para a área central do coletor, em seguida foi aberto o registro de calda. A captação da água que sai do coletor foi feita através de mangueiras e os volumes de água coletados nas 
três saídas do coletor foram medidos com provetas de $1 \mathrm{~L}$, com graduações de $0,05 \mathrm{~L}$ e somados. No ensaio, as distâncias do bocal até a área central do coletor e as posições da lança foram escolhidas na seguinte ordem e combinações, iniciando pela maior distância utilizada por Kümmel (1991), e aproximando-se o máximo possível a fím de se evitar perdas: distâncias de 2,0 e 0,5 m para o ângulo da lança em $0^{\circ} ; 0,4 \mathrm{~m}$ para ângulo da lança em $0^{\circ}, 50^{\circ}$ e $60^{\circ}$ e 0,3 m para ângulo da lança em $0^{\circ}$.

A variável considerada para avaliação do coletor foi a taxa de separação, denominada por Kümmel (1991) como a relação entre o volume coletado e o volume consumido no reservatório de calda. Foram observados ainda outros itens funcionais do projeto e formas de utilização do coletor, como declividade das lamelas, tipos da lamela utilizada, distância do bocal até a área de coleta, detalhes de construção da estrutura e posição da lança.

$\mathrm{O}$ coletor não atendeu às expectativas. Esperava-se que o volume coletado fosse aproximadamente o mesmo que o volume consumido e que as taxas de separação fossem bem maiores do que àquelas observadas nos resultados. Dessa forma o equipamento não foi utilizado no ensaio principal, tendo em vista o número elevado de erros na medição do volume coletado.

\subsection{Ensaio principal}

O ensaio principal envolve a medição dos diâmetros dos orifícios dos discos dosadores, a avaliação da altura da coluna de líquido no sistema, a determinação da vazão teórica, a determinação da vazão média experimental e as análises estatísticas.

\subsubsection{Medição dos diâmetros dos orifícios dos discos dosadores}

A medição dos diâmetros dos orifícios foi feita com o auxílio de um projetor óptico, modelo HB 400, fabricado pela Starrett Precision Optical. O disco dosador foi posicionado numa bancada e sua imagem ampliada 25 vezes na tela do equipamento. Com o auxílio de um sensor óptico instalado na ponta de uma haste metálica foi 
processada a leitura digital de no mínimo 50 pontos ao redor da imagem. À partir dos 50 pontos e com a ajuda do programa QC 4000, fabricado pela Metronics, determinou-se o raio e o diâmetro para o círculo formado pelos pontos sendo o resultado visível na tela do computador. O diâmetro utilizado foi a média resultante de três medições. Como exemplo, é apresentado no apêndice 1 uma tela de resultados gerada pelo programa.

\subsubsection{Avaliação da altura da coluna de líquido no circuito hidráulico}

A altura total da coluna de líquido no circuito é dada pela eq. (4), considerando-se $h_{a}=0,3 \mathrm{~m} ; 0 \leq h_{1} \leq 0,08 \mathrm{~m} ; h_{s}=L$. $\operatorname{sen} \theta$ e $L=0,7 \mathrm{~m}$.

$$
\mathrm{h}=\mathrm{h}_{\mathrm{a}}+\mathrm{h}_{1}-\mathrm{h}_{\mathrm{s}}
$$

Em que:

$\mathrm{h}_{\mathrm{a}}=$ altura da base do reservatório em relação à base da lança $(\mathrm{m}) ;$

$\mathrm{h}_{1}=$ altura da coluna de líquido dentro do reservatório (m);

$\mathrm{h}_{\mathrm{s}}=$ altura da extremidade da lança $(\mathrm{m})$;

$\mathrm{L}=$ comprimento da lança $(\mathrm{m}) \mathrm{e}$

$\theta$ = ângulo da lança em relação à horizontal (em graus).

Para analisar a influência da variação de $\mathrm{h}_{1}$ na variação da vazão de líquido, são feitas comparações das vazões com o reservatório de calda cheio e vazio para diferentes ângulos da lança.

A equação de Bernoulli, apresentada na eq. (5), mostra a relação entre a velocidade e a pressão em um escoamento sem atrito. Para os dois pontos extremos do circuito de líquido em questão:

$$
\frac{V_{1}^{2}}{2 g}+\frac{P_{1}}{\gamma}=\frac{V_{2}^{2}}{2 g}+\frac{P_{2}}{\gamma} \rightarrow V_{2}^{2}-V_{1}^{2}=\left(P_{1}-P_{2}\right) \frac{2 g}{\gamma}
$$


Como $\mathrm{P}=\gamma$.h e considerando $\mathrm{V}_{1}=0$ e $\mathrm{V}_{2}=\mathrm{V}$, tem-se:

$$
V=\sqrt{h .2 g}
$$

Em que:

$\mathrm{h}=$ diferença de altura entre os pontos 1 e 2 , e

$\mathrm{g}=$ aceleração da gravidade $\left(\mathrm{m} \cdot \mathrm{s}^{-2}\right)$

Se considerarmos a quantidade de água que sai ou passa por uma dada secção A, com uma certa velocidade $\mathrm{V}$, temos a noção da vazão teórica $\mathrm{Q}$. A equação geral é , pois, $Q=V$. A, substituindo-se na eq. (6) tem-se que:

$$
Q=A \sqrt{h .2 g}
$$

- $\underline{\text { Para } \theta=-60^{\circ}}$ :

$h_{s}=0,7 \operatorname{sen}\left(-60^{\circ}\right)=-0,6$

reservatório cheio: $\mathrm{h}=0,3+0,08-(-0,6)=0,98 \mathrm{~m}$

$Q_{C}=K \sqrt{0,98}=K .0,99$

reservatório vazio: $\quad h=0,3+0,0-(-0,6)=0,90 m$

$Q_{V}=K \sqrt{0,90}=K .0,95$

$\frac{Q_{V}}{Q_{C}}=\frac{0,95}{0,99}=0,96$

$\rightarrow \quad Q_{v}=96 \% Q_{C}$

- $\underline{\operatorname{Para} \theta=0^{\circ}}$.

$\mathrm{h}_{\mathrm{s}}=0,7 \operatorname{sen}\left(0^{\circ}\right)=0$ 
reservatório cheio: $\quad \mathrm{h}=0,3+0,08-0=0,38 \mathrm{~m}$

$Q_{C}=K \sqrt{0,38}=K \cdot 0,62$

reservatório vazio: $\quad h=0,3+0,0-0=0,30 \mathrm{~m}$

$Q_{V}=K \sqrt{0,30}=K .0,55$

$\frac{Q_{V}}{Q_{C}}=\frac{0,55}{0,62}=0,89 \quad \rightarrow \quad Q_{v}=89 \% Q_{C}$

- $\underline{\text { Para } \theta=60^{\circ}}$ :

reservatório cheio: $\quad \mathrm{h}=0,3+0,08-(0,6)=-0,22=0,22 \mathrm{~m}$ (considera-se a altura como positiva para efeito de comparação).

$Q_{C}=K \sqrt{0,22}=K \cdot 0,47$

reservatório vazio: $\quad h=0,3+0,0-(0,6)=-0,30=0,30 \mathrm{~m}$

$Q_{V}=K \sqrt{0,30}=K .0,55$

$\frac{Q_{V}}{Q_{C}}=\frac{0,47}{0,55}=0,86 \quad \rightarrow \quad Q_{v}=86 \% Q_{C}$

Pode-se perceber que na situação onde $\theta=60^{\circ}$, a vazão tem um valor negativo. Esta situação ocorre porque nos cálculos acima não está sendo considerada a força de sucção devido ao ar que passa na lança. Por outro lado, os cálculos mostrados acima permitem mostrar que a variação da vazão em função da variação de $\mathrm{h}_{1}$ atinge no 
máximo 14\% quando o efeito da sucção não é considerado. E esta variação será considerada desprezível neste problema.

\subsubsection{Cálculo da vazão teórica}

De acordo com Fox \& McDonald (2001), diversos fatores limitam o uso da eq. (7). Como exemplo estão os efeitos do atrito quando os contornos do orifício são abruptos e também as tomadas de pressão, que acabam influenciando o escoamento.

A eq. (7) é então ajustada para:

$$
Q=C A \sqrt{2 g h}
$$

Em que:

C é o Coeficiente de descarga (adimensional), e no caso deste problema pode ser ajustado por uma dependência linear de $\mathrm{P}_{3}$ de acordo com a relação, Fox \& McDonald (2001):

$$
C=C_{\infty}+\alpha \cdot P
$$

Em que $\mathrm{C}_{\infty}=0,56$ para o caso de uma razão $\mathrm{D}_{\mathrm{o}} / \mathrm{D}_{\mathrm{m}}$ muito pequena, para:

$\mathrm{D}_{\mathrm{o}}=$ diâmetro do orifício $(\mathrm{m}) \mathrm{e}$

$\mathrm{D}_{\mathrm{m}}=$ diâmetro interno da mangueira $(\mathrm{m})$.

E $\alpha$ pode ser ajustado pelos dados experimentais, resultando em

$\alpha=0,000037$

Tem-se então:

$\mathrm{C}=0,56+0,000037 \mathrm{P}_{3}$, para $\mathrm{P}_{3}$ estando em $\mathrm{Pa}$

Portanto, a eq. (8) fica ajustada para:

$$
Q=6.10^{4}\left(0,56+0,000037 P_{3}\right) A \sqrt{2 \frac{\left(P_{3}-P_{v}\right)}{\rho}}
$$


Em que:

$$
\begin{aligned}
& Q=\text { vazão }\left(\mathrm{L} \cdot m i n^{-1}\right) \\
& \rho=\text { massa específica da água }\left(\mathrm{kg} \cdot \mathrm{m}^{-3}\right) \mathrm{e} \\
& \mathrm{P}_{\mathrm{v}}=-1200 \mathrm{~Pa} \text { (pressão de sucção devido ao ar que passa na lança). }
\end{aligned}
$$

\subsubsection{Cálculo da vazão média experimental}

$\mathrm{Na}$ determinação do volume de água consumido em cada tratamento foram consideradas algumas modificações no circuito hidráulico. Como o nível de água dentro do reservatório de calda não era visível, foi construído um tubo indicador de nível. Para tanto utilizou-se um tubo transparente de vinil flexível, com diâmetro nominal interno de $9,53 \mathrm{~mm}\left(3 / 8^{\prime \prime}\right)$, ligando a parte superior à inferior do reservatório de calda utilizando-se conexões hidráulicas, luva com diâmetro interno de 7,94 mm (5/16"), porca cônica com diâmetro interno de 7,94 mm (5/16"), anéis de borracha e início de linha. Para que a mangueira de nível se mantivesse na posição vertical, a mesma foi fixada a um suporte de madeira com a ajuda de abraçadeiras plásticas. Um esquema do tubo indicador de nível pode ser visto na Figura 19.

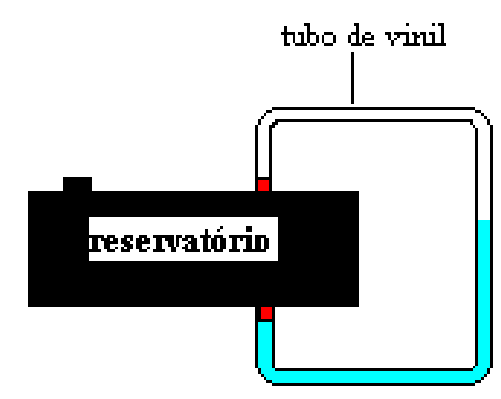

c) Sistema C - visual

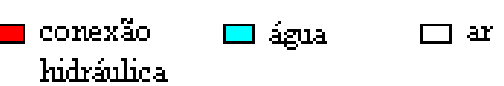

Figura 19- Tubo indicador de nível. 
Através da eq. (12) calculou-se o volume de água consumido no tubo indicador de nível.

$\mathrm{V}_{1}=\pi \mathrm{r}^{2} \mathrm{~h}_{1}$

Em que:

$\mathrm{V}_{1}=$ volume consumido no tubo indicador de nível (L);

$\mathrm{r}=$ raio interno da mangueira de nível $(\mathrm{m}) \mathrm{e}$

$\mathrm{h}_{1}=$ altura inicial no tubo indicador de nível (m) menos a altura final no tubo indicador de nível (m).

As mangueiras do circuito hidráulico, com comprimento total de 1,2 $\mathrm{m}$ foram totalmente preenchidas com a água iniciando-se os tratamentos sempre com volume constante de $59,4 \cdot 10^{-3} \mathrm{~L}$.

Através da eq. (13) calculou-se o volume consumido nas mangueiras.

$\mathrm{V}_{2}=\pi \mathrm{r}^{2} \mathrm{~h}_{2}$

Em que:

$\mathrm{V}_{2}=$ volume consumido nas mangueiras do circuito hidráulico (L);

$\mathrm{r}=$ raio interno das mangueiras do circuito hidráulico $(\mathrm{m}) \mathrm{e}$

$\mathrm{h}_{2}$ é altura inicial da água nas mangueiras (m) menos a altura final da água nas mangueiras (m).

Devido ao formato irregular do reservatório, o volume inicial de água de $2 \mathrm{~L}$ foi indicado pela altura de $0,08 \mathrm{~m}$, utilizando-se uma régua posicionada no interior do mesmo.

O tempo considerado no cálculo da vazão foi obtido após ter cessado totalmente o jato de gotas de água do pulverizador.

O volume total de água consumida no circuito hidráulico não foi coletado durante o ensaio e foi obtido através da eq.(14).

$\mathrm{V}_{\mathrm{t}}=\mathrm{V}_{1}+\mathrm{V}_{2}+\mathrm{V}_{3}$

Em que: 
$V_{T}=$ volume total consumido $(\mathrm{L})$;

$\mathrm{V}_{3}=$ volume de água consumida dentro do reservatório (L)

A vazão média foi calculada pela eq. (15).

$Q=\frac{V_{t}}{t}$

Em que:

$Q=$ vazão média $\left(\mathrm{L} \cdot \mathrm{min}^{-1}\right)$;

$\mathrm{t}=$ tempo após ter cessado a saída do jato de gotas (min)

O valor médio da vazão média $(\bar{Q})$ de cada tratamento é dado pela eq. (16)

$\bar{Q}=\frac{\sum Q}{n}$

Em que:

$\Sigma \mathrm{Q}=$ a somatória da vazão das repetições de um tratamento $\left(\mathrm{L} \cdot \mathrm{min}^{-1}\right) \mathrm{e}$

$\mathrm{n}=$ número de medições.

\subsubsection{Planejamento estatístico}

O planejamento estatístico dos ensaios envolveu um delineamento inteiramente casualizado no esquema fatorial $2 \times 7$, com cinco repetições. No estudo do delineamento utilizou-se o aplicativo Statistical Analisis Systems (SAS) para análise de variância com aplicação do teste $\mathrm{F}$ e comparação entre médias dos tratamentos através do teste de Tukey. Com os dados de vazão média obtidos no item 3.7.4 foram feitas a comparação das médias e determinadas as faixa de menor variação para a vazão.

Nos ensaios foram consideradas as seguintes variáveis:

- dois diâmetros de orifícios correspondentes aos discos dosadores bege A e B, cujos valores são apresentados no item 4.2.1, que são 0,76 mm e 0,42 mm; 
- sete ângulos da lança em relação ao plano horizontal, que foram: $0^{\circ}, 20^{\circ}, 40^{\circ}, 60^{\circ},-20^{\circ}$, $-40^{\circ}$ e $-60^{\circ}$.

Estabelecidas as variáveis o pulverizador foi fixado na estrutura de apoio e abastecido o circuito hidráulico com água. A lança foi posicionada no ângulo desejado e a máquina então foi acionada conforme recomendação do fabricante, mantendo-se o motor na máxima aceleração, acionado o sistema de aquisição dos dados e aberto o registro de calda. Toda vez que o nível do reservatório de combustível atingia cerca de $25 \%$ da sua capacidade, o mesmo era aberto e abastecido, evitando a parada do motor durante os ensaios.

Para verificar a influência das pressões sobre a vazão média de cada disco, foram feitos os testes de correlação de Pearson e gráficos de tendência. Para verificar a influência da posição da lança sobre a velocidade do ar na saída do bocal medida em diferentes distâncias, foi realizada a análise pelo modelo linear generalizado, com aplicação do teste F. 


\section{RESULTADOS E DISCUSSÃO}

No desenvolvimento do presente trabalho, os resultados, análises e discussões envolveram separadamente os testes preliminares, com a utilização do coletor de gotas, a determinação do diâmetro do orifício dos discos dosadores e os ensaios para avaliação do pulverizador.

\subsection{Ensaio preliminar}

A análise e discussão dos aspectos relacionados à utilização do coletor, envolvem considerações sobre a relação entre o volume de água pulverizada e o volume coletado, denominado por Kümmel (1991) como taxa de separação.

Os resultados das taxas de separação (\%) e início do escoamento da água (s) para as provetas, constam na Tabela 1 .

Observando-se a Tabela 1, verifica-se que as maiores taxas de separação referemse aos ângulos de lançamento em $0^{\circ}$, variando de $38,6 \%$ a 91,2\% para a distância de 0,3 $\mathrm{m}$ e de $45,5 \%$ a $67,6 \%$ para a distância $0,4 \mathrm{~m}$. Os valores, à exceção de 91,2\%, são baixos se comparados aos obtidos por Kümmel (1991), na faixa de 80 a 90\%.

Para o ângulo de $50^{\circ}$ na distância de $0,4 \mathrm{~m}$ os valores obtidos variaram de $4,7 \%$ a $31,3 \%$. Para o ângulo de $60^{\circ}$ na distância de $0,4 \mathrm{~m}$ e $0^{\circ}$ para as distâncias de $0,5 \mathrm{~m}$ e $2 \mathrm{~m}$, não foi coletado o líquido, em função respectivamente do pequeno volume de gotas produzido pelo jato e a uma grande dispersão das gotas próximo ao bocal, respectivamente.

A grande variação de resultados em função do grande número de variáveis envolvidas nos testes como por exemplo, distância do coletor, posição da lança, 
declividade das lamelas, volume de calda pulverizada, tipo de lamela, tamanho da estrutura, perdas por evaporação fora e dentro das lamelas, não permitem a utilização do coletor, visando o objetivo do trabalho.

Tabela 1. Taxas de separação (\%) e tempo inicial de escoamento (s) obtidos para a distância do coletor e ângulo da lança.

\begin{tabular}{cccc}
\hline Distância & $\begin{array}{c}\text { Ângulo da lança } \\
\text { com relação ao } \\
\text { plano horizontal } \\
(\mathrm{m})\end{array}$ & $\begin{array}{c}\text { Início do } \\
\text { escoamento }\end{array}$ & Taxa de separação \\
\hline 0,3 & $0^{\circ}$ & $(\mathrm{s})$ & $(\%)$ \\
0,3 & $0^{\circ}$ & 240 & 91,2 \\
0,3 & $0^{\circ}$ & 60 & 38,6 \\
0,3 & $0^{\circ}$ & 60 & 47,1 \\
0,4 & $0^{\circ}$ & 180 & 45,0 \\
0,4 & $0^{\circ}$ & 150 & 67,6 \\
0,4 & $0^{\circ}$ & 60 & 63,9 \\
0,4 & $50^{\circ}$ & 300 & 45,5 \\
0,4 & $50^{\circ}$ & 240 & 4,7 \\
0,4 & $50^{\circ}$ & 240 & 19,6 \\
0,4 & $60^{\circ}$ & - & 31,3 \\
0,5 & $0^{\circ}$ & - & - \\
2,0 & $0^{\circ}$ & - & - \\
\hline
\end{tabular}

\subsection{Ensaio principal}

\subsubsection{Diâmetro do orifício do disco dosador}

Na Tabela 2 são apresentados os valores dos diâmetros dos orifícios das unidades dos discos dosadores, cor bege, fornecidas pelo fabricante e determinadas a partir da 
metodologia descrita no item 3.7.1, com destaque para as unidades escolhidas para o ensaio.

Tabela 2. Diâmetro dos orifícios dos discos dosadores utilizados na escolha dos discos A e B.

\begin{tabular}{|c|c|c|}
\hline Unidades & \multicolumn{2}{|c|}{$\begin{array}{l}\text { diâmetro dos orifícios } \\
\left(10^{-3} \mathrm{~m}\right)\end{array}$} \\
\hline 1 & 0,70 & 0,40 \\
\hline 2 & 0,77 & 0,40 \\
\hline 3 & 0,76 & 0,41 \\
\hline 4 & 0,78 & 0,42 \\
\hline CV (\%) & 3,8 & 2,2 \\
\hline
\end{tabular}

No final dos ensaios o disco dosador de menor diâmetro apresentou um aspecto mais amarronzado, como pode ser visto na Figura 20. Esse aspecto é resultado do maior tempo de contato do material com a água, do disco B, 160247s (44h 30min 47s), 70\% a mais do que o disco dosador A que foi de $54384 \mathrm{~s}$ (15h 6min 24s).

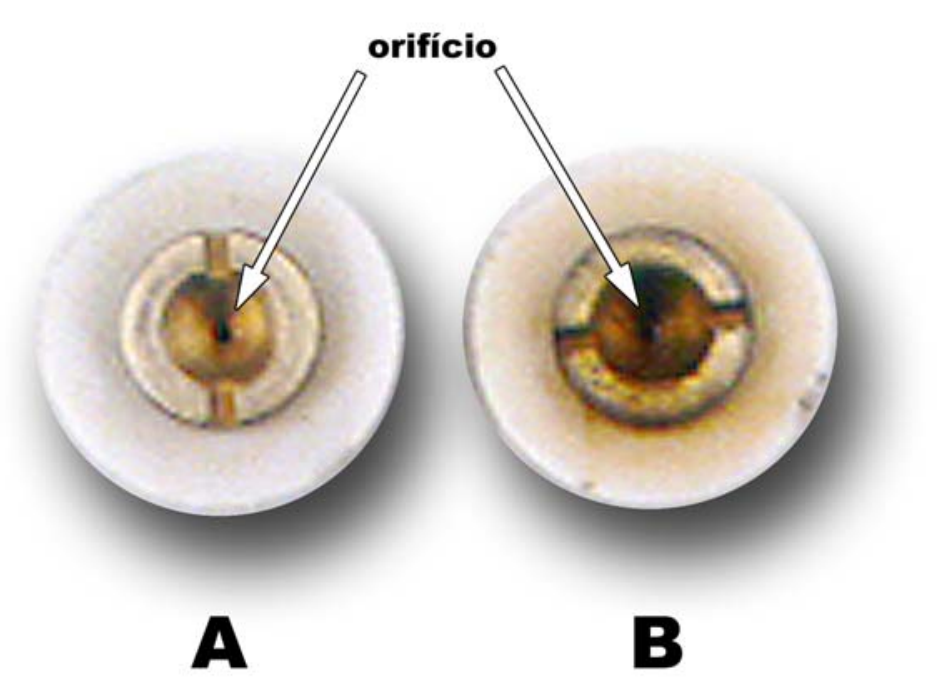

Figura 20- Vista superior dos discos dosadores A $($ diâmetro $=0,76 \mathrm{~mm})$ e B $($ diâmetro $=$ $0,42 \mathrm{~mm})$. 


\subsubsection{Análise da influência da rotação do motor na vazão média}

Na tabela 3 são apresentados os dados da análise descritiva dos valores de rotação. A média geral foi $6863 \mathrm{rpm}$ e o coeficiente de variação foi de 3,67\%. O intervalo de confiança para a média foi de 7367 e 6358 rpm, ao nível de 95\% de probabilidade, mostrando que os valores de rotação máxima e mínima estão muito próximas dos valores máximo e mínimo do intervalo de confiança. É importante notar que a rotação variou de 7411 a $6367 \mathrm{rpm}$, ou seja 14\%. Em princípio, a metodologia previa que a rotação do motor ficasse constante ao longo dos ensaios, no entanto isto não ocorreu.

Tabela 3. Estatística descritiva dos dados de rotação monitorados durante os ensaios.

\begin{tabular}{cccccc}
\hline Variável & Média & Mediana & Desvio & mínimo \\
$(\mathrm{rpm})$ & $(\mathrm{rpm})$ & $\begin{array}{c}\text { padrão } \\
(\mathrm{rpm})\end{array}$ & $\begin{array}{c}\text { máximo } \\
(\mathrm{rpm})\end{array}$ & \\
\hline rotação & 6863 & 6824 & 252,1 & 6367 & 7411 \\
\hline
\end{tabular}

Para verificar se essa variação influenciou os resultados de vazão média utilizou-se o Sistema de Análise Estatística (SAS) para analisar a rotação, representado no modelo da eq. (17) como uma covariável.

$$
\mathrm{y}_{\mathrm{ijk}}=\mu+\mathrm{I}_{\mathrm{i}}+\mathrm{D}_{\mathrm{j}}+\mathrm{R}_{\mathrm{k}}
$$

Considerando o modelo ajustado apresentado na eq. (17), utilizou-se os procedimentos de análise do modelo linear generalizado (GLM) com aplicação do teste F, para testar as hipóteses:

$\mathrm{Ho}_{1}: \mathrm{I}=0$, para todo $\mathrm{i}$ vs. $\mathrm{H}_{\mathrm{a} 1}: \mathrm{I} \neq 0$, para algum $\mathrm{i}$

$\mathrm{Ho}_{2}: \mathrm{D}=0$, para todo $\mathrm{j}$ vs. $\mathrm{H}_{\mathrm{a} 2}: \mathrm{D} \neq 0$, para algum $\mathrm{j}$

$\mathrm{Ho}_{3}: \mathrm{R}=0$, para todo $\mathrm{k}$ vs. Ha3: $\mathrm{R} \neq 0$, para algum $\mathrm{k}$.

Em que: 
$\mathrm{y}_{\mathrm{ijk}}$ é o valor observado para vazão média $(\mathrm{ml} / \mathrm{min})$ correspondente ao efeito dos níveis dos fatores de tratamento;

$\mu$ é média geral;

$\mathrm{I}_{\mathrm{i}}$ é o efeito do nível i do fator ângulo da lança;

$\mathrm{D}_{\mathrm{j}}$ é o efeito do nível $\mathrm{j}$ do fator diâmetro do orifício do disco dosador e

$\mathrm{R}_{\mathrm{k}}$ é o efeito do nível $\mathrm{k}$ do fator rotação.

Os resultados da análise de covariância para a vazão média, são apresentados na Tabela 4.

O teste F, mostrou que o ângulo da lança e o diâmetro do orifício são significativos $(\mathrm{p}<0,0001)$ em explicar as variações de vazão média, ou seja, rejeita-se $\mathrm{H}_{01}$ e $\mathrm{H}_{\mathrm{o} 2}$, ao nível $\alpha<5 \%$ de significância.

A covariável rotação não é significativa, $(\mathrm{p}$-valor $=0,1109)$ para explicar a variação na vazão e para a faixa de rotação considerada. Rejeita-se deste modo a hipótese alternativa $\left(\mathrm{H}_{\mathrm{a} 3}: \mathrm{R} \neq 0\right)$ ao nível $\alpha<5 \%$ de significância.

Tabela 4. Análise de covariância para os valores da vazão média com aplicação do teste

F .

\begin{tabular}{cccccc}
\hline $\begin{array}{c}\text { Fonte de } \\
\text { variação }\end{array}$ & $\begin{array}{c}\text { Graus de } \\
\text { liberdade }\end{array}$ & $\begin{array}{c}\text { Soma de } \\
\text { quadrados }\end{array}$ & $\begin{array}{c}\text { Quadrado } \\
\text { médio }\end{array}$ & $\mathrm{F}$ & Pr $>\mathrm{F}$ \\
\hline Ângulo da & 6 & 28731,26 & 4788,54 & $33,52^{*}$ & $<0,0001$ \\
lança & 1 & 65697,53 & 65697,53 & $459,82^{*}$ & $<0,0001$ \\
Diâmetro & 1 & 374,58 & 374,58 & 2,62 & 0,1109 \\
Rotação & 57 & 8143,97 & 142,87 & & \\
Resíduo & 65 & & & & \\
Total & & & & & \\
\hline
\end{tabular}

Obs: A significância para 5\% de probabilidade para o teste $\mathrm{F}$, é indicada, por um asterisco $\left(^{*}\right)$. 


\subsubsection{Análise da influência dos fatores disco dosador e ângulo da lança na vazão média}

Visto que não se obteve significância para a rotação, considerou-se o modelo do delineamento inteiramente casualizado no esquema fatorial $2 \times 7$, representado pela eq. (18),

$$
\mathrm{yijk}=\mu+\mathrm{I}_{\mathrm{i}}+\mathrm{D}_{\mathrm{j}}+\left(\mathrm{ID}_{\mathrm{ij}}\right)
$$

utilizando-se os procedimentos de análise do modelo linear generalizado (GLM) com aplicação do teste $\mathrm{F}$, para testar as hipóteses:

$\mathrm{Ho}_{1}: \mathrm{I}=0$, para todo $\mathrm{i}$ vs. $\mathrm{H}_{\mathrm{a} 1}: \mathrm{I} \neq 0$, para algum $\mathrm{i}$

$\mathrm{Ho}_{2}: \mathrm{D}=0$, para todo $\mathrm{j}$ vs. $\mathrm{H}_{\mathrm{a} 2}: \mathrm{D} \neq 0$, para algum $\mathrm{j}$

$\mathrm{Ho}_{3}:(I * \mathrm{D})=0$, para todo $\mathrm{k}$ vs. $\mathrm{H}_{\mathrm{a} 3}:(\mathrm{I} * \mathrm{D}) \neq 0$, para algum $\mathrm{k}$,

Em que:

$\mathrm{y}_{\mathrm{ijk}}$ é o valor observado para vazão média $\left(10^{-3} \mathrm{~L} / \mathrm{min}\right)$ correspondente ao efeito dos níveis dos fatores de tratamento;

$\mu$ é média geral;

$\mathrm{I}_{\mathrm{i}}$ é o efeito do nível i do fator ângulo da lança;

$\mathrm{D}_{\mathrm{j}}$ é o efeito do nível $\mathrm{j}$ do fator diâmetro do orifício do disco dosador e

$\left(\mathrm{ID}_{\mathrm{ij}}\right)$ é o efeito da interação ângulo da lança e diâmetro do orifício do disco dosador.

O resultado da análise de variância para a vazão média é apresentado na Tabela 5: 
Tabela 5. Análise de variância para os valores de vazão média com aplicação do teste $\mathrm{F}$.

\begin{tabular}{cccccc}
\hline $\begin{array}{c}\text { Fonte de } \\
\text { variação }\end{array}$ & $\begin{array}{c}\text { Graus de } \\
\text { liberdade }\end{array}$ & $\begin{array}{c}\text { Soma de } \\
\text { quadrados }\end{array}$ & $\begin{array}{c}\text { Quadrado } \\
\text { médio }\end{array}$ & $\mathrm{F}$ & Pr>F \\
\hline Ângulo da & 6 & 26791,05 & 4465,17 & $2057,04^{*}$ & $<0,0001$ \\
lança & 1 & 67468,02 & 67468,02 & $31081,50^{*}$ & $<0,0001$ \\
Diâmetro & 6 & 8405,68 & 1400,95 & $645,40^{*}$ & $<0,0001$ \\
I*D $^{*}$ & 52 & 112,88 & 2,17 & & \\
Resíduo & 65 & & & & \\
Total & & & & & \\
\hline
\end{tabular}

Obs: A significância para 5\% de probabilidade para o teste $\mathrm{F}$ é indicada por um asterisco $\left(^{*}\right)$.

A análise dos resultados confirma a influência do ângulo da lança e do diâmetro do orifício na variação da vazão média. A interação dupla (ângulo*diâmetro) significativa (p-valor da interação <0,0001), sugere a comparação das médias de vazão média, pelo teste de Tukey.

Na comparação entre as médias de vazão $\left(10^{-3} \mathrm{~L} \cdot \mathrm{min}^{-1}\right)$ dos 14 tratamentos, foram observadas diferenças significativas entre todos os tratamentos.

Tabela 6. Vazões médias obtidas para os discos dosadores A e B em função dos ângulos da lança, nos 14 tratamentos.

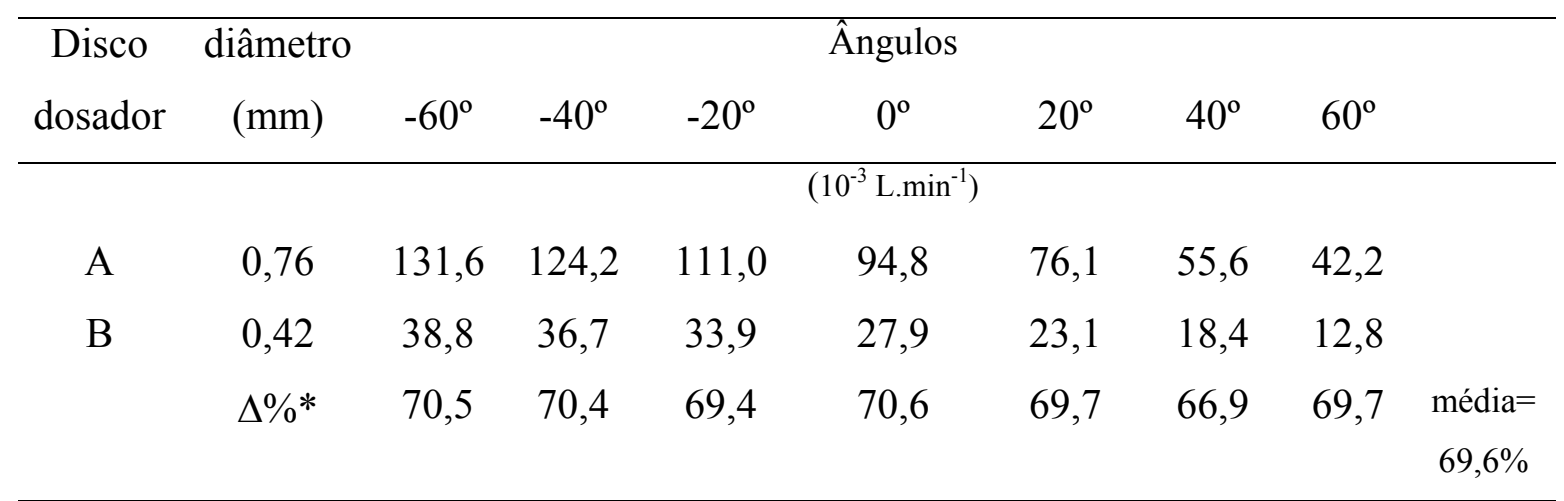

$* \Delta \%=$ variação percentual entre as vazões médias dos discos para um mesmo ângulo.

Obs: $\mathrm{O}$ valor da diferença mínima significativa (dms), ao nível de $\alpha<5 \%$ foi de $0,74.10^{-3} \mathrm{~L}_{\mathrm{min}}{ }^{-1}$. 
O efeito dos diâmetros dos discos dosadores e do ângulo da lança, sobre a vazão média, podem ser visualizados na Figura 21, construída a partir dos dados mostrados na Tabela 6. Observa-se uma grande desuniformidade de vazão para faixa de aplicação compreendida entre os ângulos de $60^{\circ}(1,05 \mathrm{rad})$ e $-60^{\circ}(-1,05 \mathrm{rad})$ no caso do disco dosador A (diâmetro $=0,76 \mathrm{~mm}$ ), que é normalmente utilizado pela SUCEN, no controle do Ae. aegypti.

As diferenças entre os valores de vazão média máxima e mínima para os discos $\mathrm{A}$ e B foram $89,4 \cdot 10^{-3} \mathrm{~L} \cdot \mathrm{min}^{-1}$ e $26,0.10^{-3} \mathrm{~L} \cdot \mathrm{min}^{-1}$, respectivamente. Em termos percentuais isso representa uma variação de $67,9 \%$ e $67,0 \%$ para os discos A e B, respectivamente. Apesar dos valores serem semelhantes, o disco dosador B (diâmetro $=0,42 \mathrm{~mm}$ ), apresentou maior uniformidade para o intervalo entre $60^{\circ} \mathrm{e}-60^{\circ}$.

Comparando-se os diâmetros dos orifícios verifica-se que houve um aumento médio na vazão de 69,6\%, com aumento de $0,34 \mathrm{~mm}$ no diâmetro, comparando-se os mesmos ângulos. Isso mostra a importância na escolha do disco, podendo ocorrer risco de sub ou superdosagem e perdas significativas de produto.

Para o disco dosador A (diâmetro $=0,76 \mathrm{~mm}$ ), a menor variação de vazão ocorreu para o intervalo de aplicação entre $-60^{\circ}$ e $-40^{\circ}\left(7,4 \cdot 10^{-3} \mathrm{~L} \cdot \mathrm{min}^{-1}\right)$.

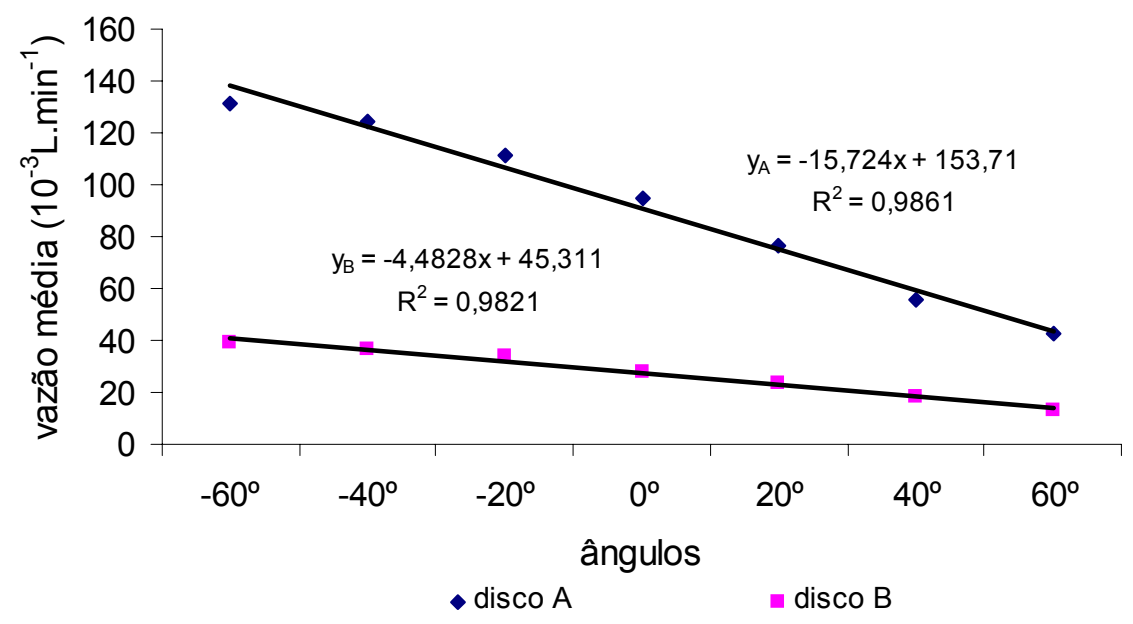

Figura 21- Curvas das vazões médias obtidas nos tratamentos para os discos dosadores A e B em função do ângulo da lança. 
Na prática, em condições normais a maior parte das aplicações ocorrem em portas, janelas elevadas ou em sobrados, onde os ângulos da lança são positivos por isso tem maior importância. Neste sentido, utilizando-se dos dados da Tabela 6, verifica-se que o intervalo de menor variação foi entre os ângulos de $40^{\circ}$ e $60^{\circ}\left(13,4.10^{-3} \mathrm{~L}_{\mathrm{min}}{ }^{-1}\right)$ para o disco A e entre $20^{\circ}$ e $40^{\circ}\left(4,7 \cdot 10^{-3} \mathrm{~L} \cdot \mathrm{min}^{-1}\right)$ para o disco B (diâmetro = 0,42 mm).

De acordo com os resultados de vazão média determinou-se as equações de regressão e os valores dos coeficientes de determinação $\left(\mathrm{R}^{2}\right)$, que foram, 0,9861 para o disco A e 0,9821 para o disco B mostrando haver relação linear entre as leituras e o intervalo de ângulos utilizados.

Embora o operador manuseie a lança do pulverizador na maior parte das vezes em ângulos positivos, a diversidade de relevos e tipos de residências no meio urbano, não descarta a possibilidade de posicionamento da lança em outros ângulos.

\subsubsection{Análise das pressões de serviço nos circuitos hidráulico e pneumático da máquina}

Na Figura 22 é apresentado o comportamento das pressões médias determinadas nos quatro pontos dos circuitos hidráulico e pneumático versus a vazão média, durante os ensaios dos discos dosadores A (Fig. 22 A) e B (Fig. 22 B). O resultados das quatro pressões obtidas nos tratamentos são apresentados no anexo F.

Observa-se nos gráficos que ocorre um aumento da pressão de serviço com o aumento da vazão para a pressão no ponto P3, localizado próximo ao corpo dosador na saída do bocal, tanto para o dosador A como para o dosador B.

O sensor de pressão no ponto P3 registrou valores que variaram de 1,8 $\mathrm{kPa}$ a 10,2 $\mathrm{kPa}$. As pressões nos pontos $\mathrm{P} 2$, próxima a conexão de saída do reservatório de inseticida, e P4, dentro do reservatório de calda, apesar de estarem em pontos distintos apresentam valores médios muito semelhantes, haja vista a pequena coluna de água dentro do reservatório de calda, correspondente a $0,8 \mathrm{kPa}(0,08 \mathrm{~m}$ de coluna de água) e às perdas de carga entre os dois pontos. 

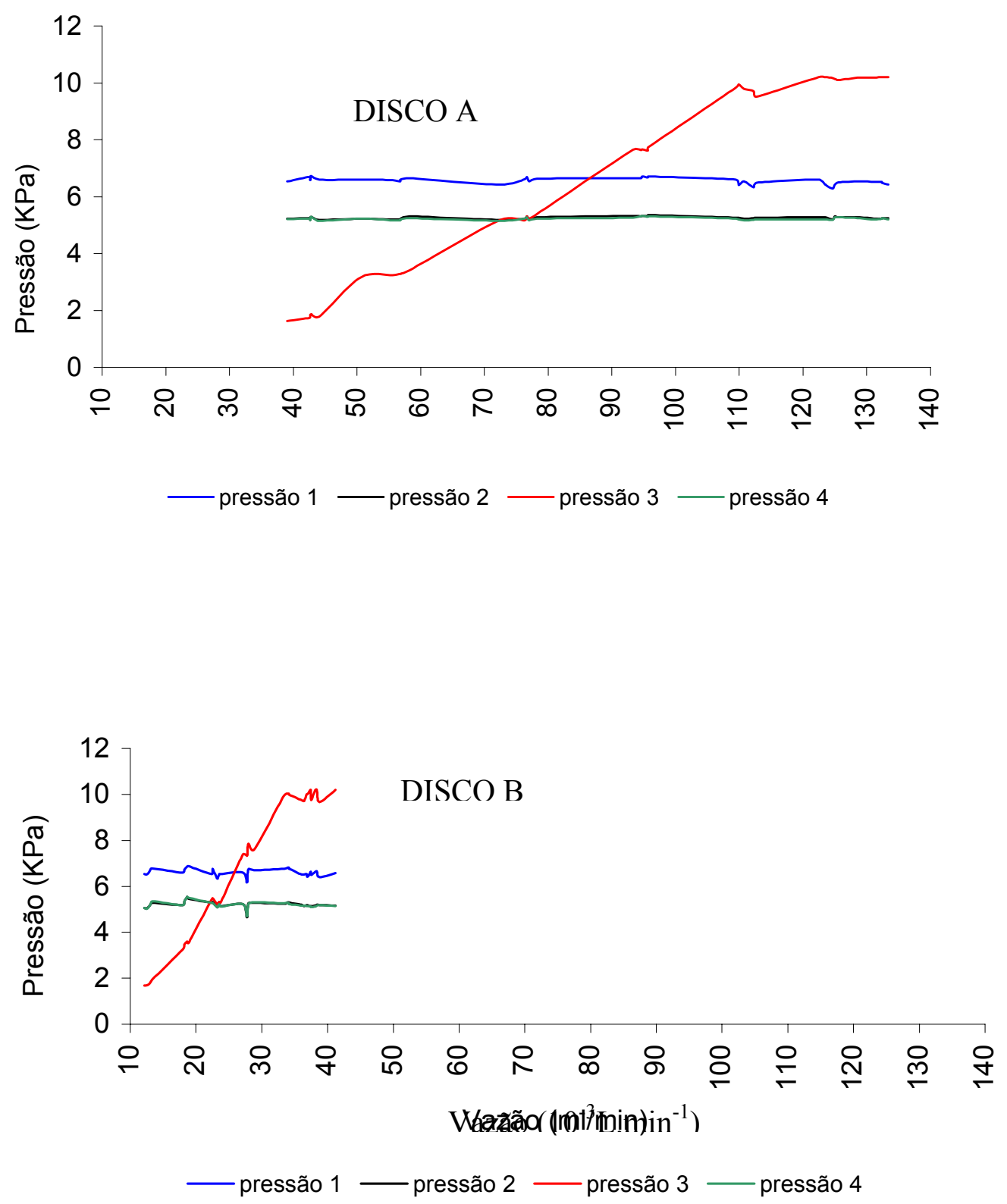

Figura 22- Comportamento das pressões P1(pressão 1), P2 (pressão2), P3 (pressão 3) e P4 (pressão 4) em função das vazões médias, determinadas para os discos dosadores.

A pressão gerada pela bomba centrífuga e determinada no ponto $\mathrm{P} 1$, na mangueira de fornecimento de ar para o reservatório, foi em média de $6,6 \mathrm{kPa}$. Os resultados dos 
testes de correlação de Pearson, entre vazão média e pressões são mostrados separadamente para os discos A e B na Tabela 7, considerando-se:

$\mathrm{H}_{\mathrm{o}}$ (hipótese nula): Os dados não são correlacionados.

$\mathrm{H}_{1}$ (hipótese alternativa): Os dados são correlacionados.

Tabela 7. Teste de correlação de Pearson para as pressões médias.

\begin{tabular}{cccc}
\hline Discos dosadores & Pressões de serviço & $\begin{array}{c}\text { coeficiente de } \\
\text { correlação }\end{array}$ & p- valor \\
\hline \multirow{2}{*}{ Disco dosador A } & P1 & $-0,514$ & $0,002^{*}$ \\
& P2 & 0,275 & 0,110 \\
& P3 & 0,988 & $0,000^{*}$ \\
Disco dosador B & P4 & 0,131 & 0,454 \\
& P1 & $-0,211$ & 0,253 \\
& P2 & $-0,135$ & 0,470 \\
& P3 & 0,985 & $0,000^{*}$ \\
& P4 & $-0,224$ & 0,225 \\
\hline
\end{tabular}

Observa-se na Tabela 7 que ocorre correlação positiva entre as pressões no ponto P3 e as vazões médias para ambas os discos, com valores de coeficiente de correlação de 0,988 e 0,985 respectivamente, além das evidências estatísticas $(p=0)$ de rejeitar a hipótese de correlação nula, ou seja, os dados são correlacionados.

Ocorre também associação positiva para as pressões nos pontos P2 e P4, com coeficientes de correlação de 0,275 e 0,131 , respectivamente. Entretanto, apresentam p-valor $>0,05$, ou seja, não há evidência estatística para rejeitar a hipótese de correlação nula, $\mathrm{H}_{\mathrm{o}}$. Isto se justifica pelo fato de que as pressões nos pontos P2 e P4 foram apenas monitoradas, mantendo-se constantes com o aumento da vazão média.

A alta correlação entre a pressão no ponto P3 e os valores de vazão média podem ser explicadas considerando-se o teorema de Bernoulli: o total de energia do sistema no ponto P3 é o resultado das componentes elevação $(\mathrm{z})$, pressão $\left(\mathrm{p} \cdot \gamma^{-1}\right)$ e cinemática $\left(v^{2} \cdot(2 g)^{-1}\right)$.

As cargas hidráulicas estáticas resultantes da elevação até o ponto de saída da calda podem explicar as diferenças entre vazões obtidas nos ensaios. A cargas hidráulicas estáticas foram determinadas tomando-se como referencial a máxima altura 
de água no reservatório. Os resultados das cargas hidráulicas estáticas são apresentados na Tabela 8.

Tabela 8. Cargas hidráulicas estáticas determinadas no ponto de saída da calda, de acordo com os ângulos da lança.

\begin{tabular}{cc}
\hline Ângulos & $\begin{array}{c}\text { Carga hidráulica } \\
(\mathrm{kPa})\end{array}$ \\
\hline $60^{\circ}$ & $-3,60$ \\
$40^{\circ}$ & $-1,90$ \\
$20^{\circ}$ & 0,50 \\
$0^{\circ}$ & 4,25 \\
$-20^{\circ}$ & 5,95 \\
$-40^{\circ}$ & 8,40 \\
$-60^{\circ}$ & 10,15 \\
\hline
\end{tabular}

$\mathrm{O}$ valor da pressão no ponto $\mathrm{P} 3$, encontrado pelos sensores, é teoricamente o resultado do valor no ponto $\mathrm{P} 4$ menos o valor da carga hidráulica (z) para o respectivo ângulo.

Embora os valores de pressão encontrados nos pontos do circuito hidráulico e pneumático sejam específicos do projeto da máquina avaliada neste trabalho, a comparação com os valores encontrados no trabalho de Jollands (1991) mostrou que os valores de pressão são baixos. $\mathrm{O}$ volume de ar produzido pela bomba centrífuga e conduzido até o reservatório de calda é reduzido e insuficiente para gerar grandes pressões, haja vista que grande parte do volume de ar é direcionado para o interior da lança criando a corrente de ar.

\subsubsection{Dados experimentais versus teóricos}

Utilizando o desenvolvimento do modelo teórico apresentado na modelagem matemática do item 3.7.3, pode-se comparar os dados teóricos com os experimentais 
Tabela 9. Dados experimentais.

\begin{tabular}{cccccc}
\hline Ângulo & $\begin{array}{c}\text { Cota } \\
\left(10^{-2} \mathrm{~m}\right)\end{array}$ & $\begin{array}{c}\mathrm{Q}_{\mathrm{A}} \\
\left(10^{-3} \mathrm{~L} \cdot \mathrm{min}^{-1}\right)\end{array}$ & $\begin{array}{c}\mathrm{P} 3_{\mathrm{A}} \\
(\mathrm{kPa})\end{array}$ & $\begin{array}{c}\mathrm{Q}_{\mathrm{B}} \\
\left(10^{-3} \mathrm{~L} \cdot \mathrm{min}^{-1}\right)\end{array}$ & $\begin{array}{c}\mathrm{P} 3_{\mathrm{B}} \\
(\mathrm{kPa})\end{array}$ \\
\hline$+60^{\circ}$ & $-30,6$ & 42,2 & 1,8 & 12,8 & 1,8 \\
$+40^{\circ}$ & $-15,0$ & 55,6 & 3,3 & 18,4 & 3,5 \\
$+20^{\circ}$ & 6,0 & 76,1 & 5,3 & 23,1 & 5,3 \\
$0^{\circ}$ & 30,0 & 94,8 & 7,7 & 27,9 & 7,5 \\
$-20^{\circ}$ & 53,9 & 111,0 & 10,0 & 33,9 & 10,0 \\
$-40^{\circ}$ & 75,0 & 124,2 & 10,2 & 36,7 & 9,8 \\
$-60^{\circ}$ & 90,6 & 131,6 & 10,2 & 38,8 & 10,1 \\
\hline
\end{tabular}

Analisando a Tabela 9 verifica-se que para um mesmo ângulo de lança a pressão P3 não sofre alteração (Figura 23), o que demostra que o diâmetro do orifício não tem influência sobre o valor da pressão P3. A Figura 23 demostra uma variação linear entre a Pressão $\mathrm{P}_{3}$ com ângulo da lança, até um ponto limite que acontece no ângulo de $-20^{\circ}$. 


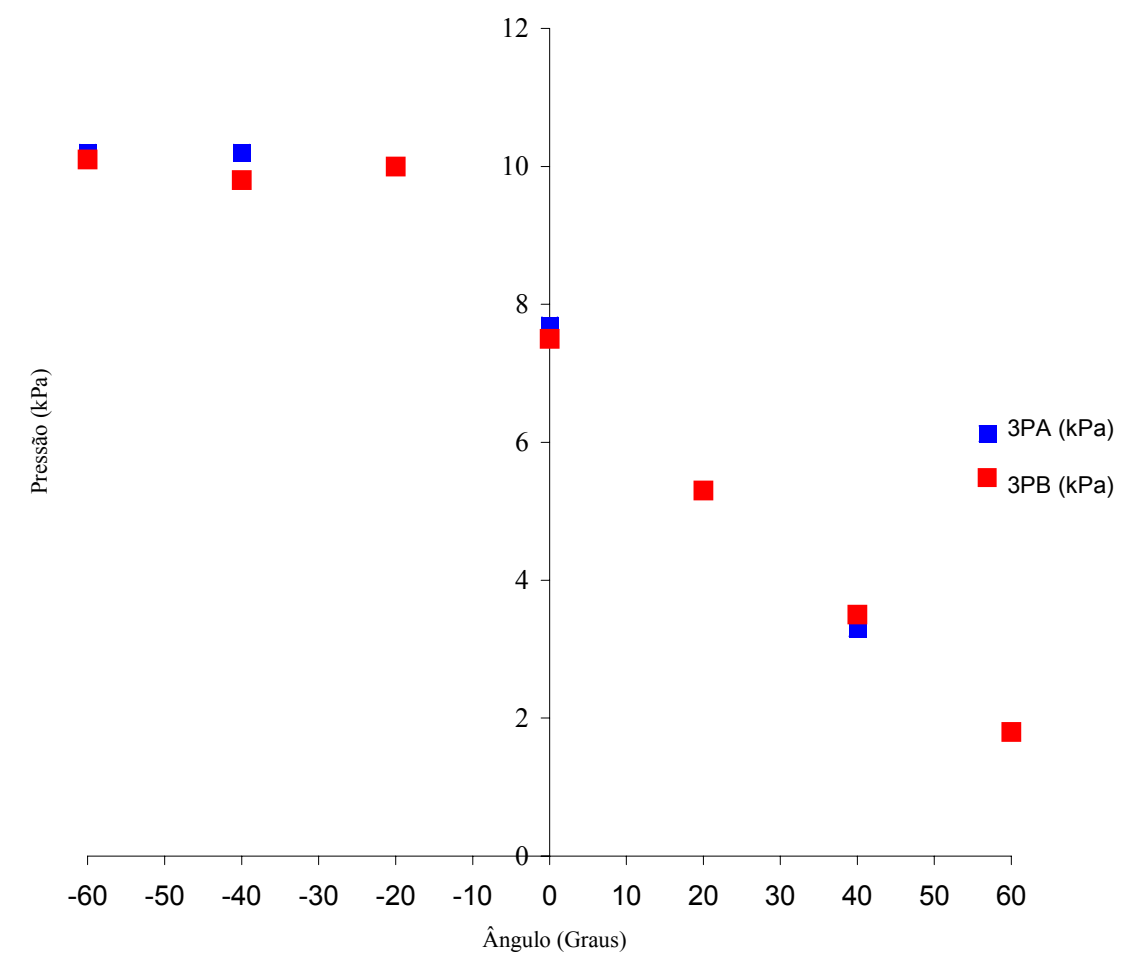

Figura 23 - Comportamento da Pressão $\mathrm{P}_{3}$ com a variação do ângulo da lança.

Os dados teóricos para a vazão apresentados na Tabela 10 são geradas pela eq. (11). Sua representação gráfica é dada pela Figura 24.

Tabela 10. Dados experimentais e teóricos das vazões para os discos dosadores A e B.

\begin{tabular}{cccccc}
\hline Angulo & $\begin{array}{c}\text { Cota } \\
\left(10^{-2} \mathrm{~cm}\right)\end{array}$ & $\begin{array}{c}\mathrm{Q}_{\mathrm{A}} \text { Exp. } \\
\left(10^{-3} \mathrm{~L} \cdot \mathrm{min}^{-1}\right)\end{array}$ & $\begin{array}{c}\mathrm{Q}_{\mathrm{B}} \text { Exp. } \\
\left(10^{-3} \mathrm{~L} \cdot \mathrm{min}^{-1}\right)\end{array}$ & $\begin{array}{c}\mathrm{Q}_{\mathrm{a}} \text { Teórico } \\
\left(10^{-3} \mathrm{~L} \cdot \mathrm{min}^{-1}\right)\end{array}$ & $\begin{array}{c}\mathrm{Q}_{\mathrm{b}} \text { Teórico } \\
\left(10^{-3} \mathrm{~L} \cdot \mathrm{min}^{-1}\right)\end{array}$ \\
\hline$+60^{\circ}$ & $-30,6$ & 42,2 & 12,8 & 41,8 & 12,8 \\
$+40^{\circ}$ & $-15,0$ & 55,6 & 18,4 & 55,7 & 17,6 \\
$+20^{\circ}$ & 6,0 & 76,1 & 23,1 & 74,2 & 22,7 \\
$0^{\circ}$ & 30,0 & 94,8 & 27,9 & 96,9 & 29,0 \\
$-20^{\circ}$ & 53,9 & 111,0 & 33,9 & 119,7 & 34,4 \\
$-40^{\circ}$ & 75,0 & 124,2 & 36,7 & 121,8 & 36,0 \\
$-60^{\circ}$ & 90,6 & 131,6 & 38,8 & 121,8 & 36,9 \\
\hline
\end{tabular}


Pode-se verificar que os dados teóricos se aproximam dos resultados experimentais com um boa concordância .

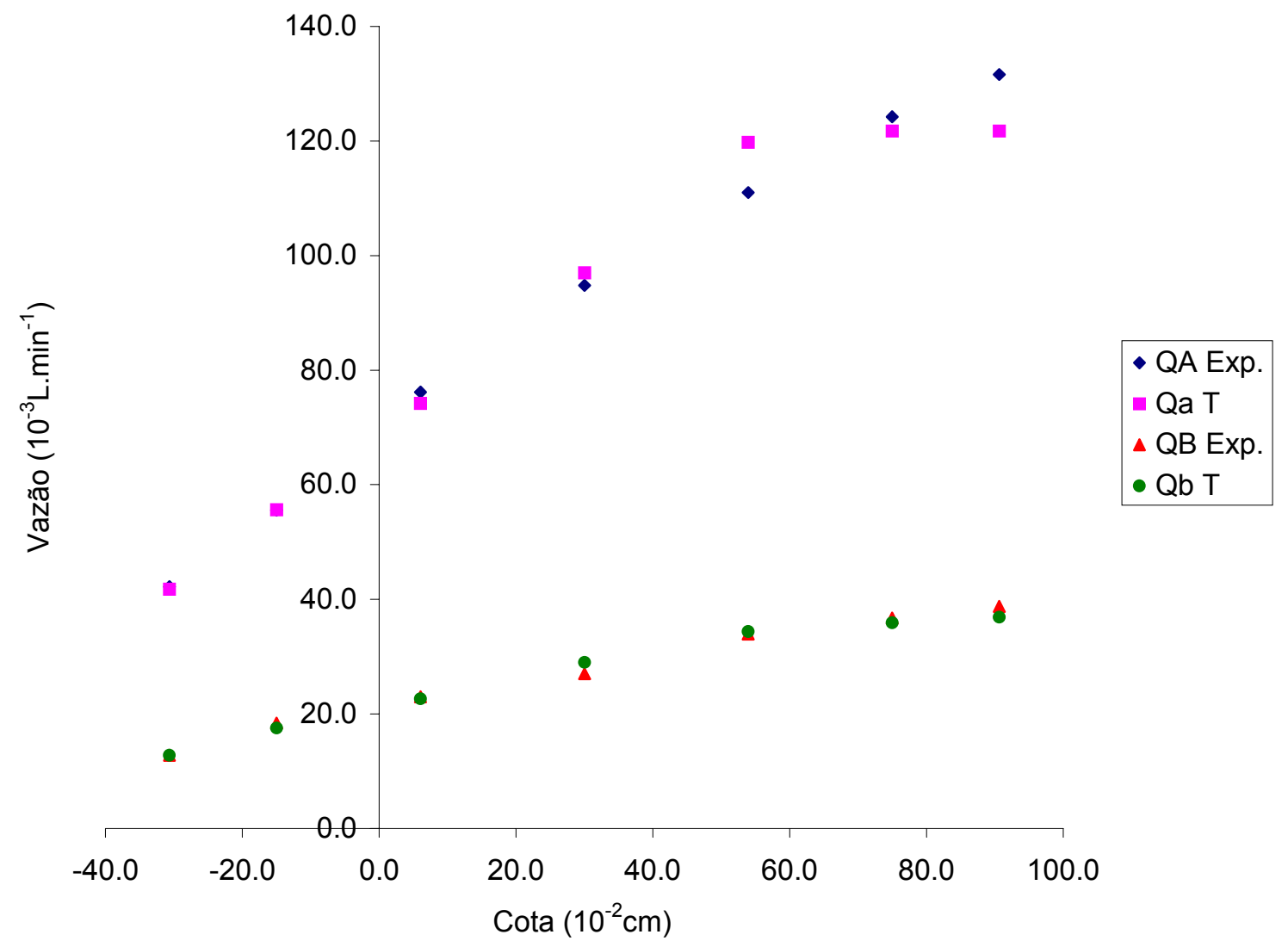

Figura 24 - Comparação das vazões dos discos dosadores A e B, dados teóricos versus experimentais.

\subsubsection{Temperatura do reservatório de calda e temperatura do ambiente durante os ensaios}

$\mathrm{Na}$ Tabela 11 são apresentados os valores das temperaturas médias registradas durante os ensaios. A temperatura média do ambiente durante os ensaios variou entre a máxima de $25,7^{\circ} \mathrm{C}$ (tratamento $\mathrm{A}-60^{\circ}$ ) e a mínima de $18,2^{\circ} \mathrm{C}$ (tratamento $\mathrm{B} 40^{\circ}$ ), com média de $22,4^{\circ} \mathrm{C}$. As temperaturas médias do ambiente apresentadas em todos os tratamentos foram muito próximas às temperaturas iniciais da água, isso mostra que o aquecimento da água no interior do reservatório não é conseqüência do calor gerado pela 
temperatura ambiente, mas deve-se à dissipação do calor gerado pelo aquecimento do motor.

Todos os tratamentos que utilizaram o disco dosador de menor diâmetro apresentaram maiores temperaturas finais, à exceção do tratamento $\mathrm{B} 40^{\circ}$, mesmo assim o acréscimo de temperatura foi significativo haja vista o tempo de funcionamento do motor nesse tratamento $(6699 \mathrm{~s})$. A maior temperatura final foi obtida no tratamento $\mathrm{B} 60^{\circ} \operatorname{com} 37,2^{\circ} \mathrm{C}$ e a menor com o tratamento $\mathrm{A}-40^{\circ}$ com $28,7^{\circ} \mathrm{C}$ o que mostra mais uma vez a grande influência do tempo de funcionamento do motor no aquecimento da água.

Tabela 11. Temperaturas médias inicial e final dentro do reservatório de calda e do ambiente, durante os ensaios.

\begin{tabular}{|c|c|c|c|c|c|}
\hline Tratamento & $\begin{array}{l}\text { Temperatura } \\
\text { do ar }\end{array}$ & \multicolumn{2}{|c|}{$\begin{array}{l}\text { temperatura da água no } \\
\text { reservatório de calda }\left({ }^{\circ} \mathrm{C}\right)\end{array}$} & $\Delta_{\mathrm{f}-\mathrm{i}}$ & $\begin{array}{r}\text { Tempo de } \\
\text { duração (s) }\end{array}$ \\
\hline A $0^{\circ}$ & 20,9 & 18,6 & 28,8 & 10,1 & 1303 \\
\hline A $20^{\circ}$ & 23,0 & 21,1 & 31,9 & 10,8 & 1623 \\
\hline A $40^{\circ}$ & 20,2 & 20,5 & 30,0 & 9,5 & 2170 \\
\hline A $60^{\circ}$ & 22,5 & 20,3 & 33,6 & 13,3 & 2864 \\
\hline A $-20^{\circ}$ & 24,4 & 21,8 & 31,5 & 9,7 & 1115 \\
\hline $\mathrm{A}-40^{\circ}$ & 21,3 & 21,7 & 28,7 & 6,9 & 997 \\
\hline $\mathrm{A}-60^{\circ}$ & 25,7 & 23,8 & 31,9 & 8,0 & 941 \\
\hline $\mathrm{B} 0^{\circ}$ & 22,8 & 21,3 & 33,0 & 11,8 & 4428 \\
\hline $\mathrm{B} 20^{\circ}$ & 22,0 & 21,2 & 32,7 & 11,5 & 5287 \\
\hline $\mathrm{B} 40^{\circ}$ & 18,2 & 17,0 & 28,9 & 11,9 & 6699 \\
\hline $\mathrm{B} 60^{\circ}$ & 24,5 & 22,6 & 37,2 & 14,7 & 9464 \\
\hline B-20 $0^{\circ}$ & 21,5 & 20,7 & 32,7 & 12,0 & 3647 \\
\hline B- $40^{\circ}$ & 22,9 & 22,9 & 34,3 & 11,3 & 3372 \\
\hline B- $60^{\circ}$ & 23,7 & 24,4 & 33,9 & 9,5 & 3258 \\
\hline $\begin{array}{l}\text { Média } \\
\text { Geral }\end{array}$ & 22,4 & 21,3 & 32,1 & 10,8 & - \\
\hline
\end{tabular}

A maior e a menor diferença encontradas entre a temperatura inicial e final da água no reservatório de calda foram de $14,7^{\circ} \mathrm{C}$ e $6,9^{\circ} \mathrm{C}$, respectivamente, sendo que a média foi de $10,8^{\circ}$ C. Observando-se os valores do apêndice 3 para viscosidade da água, 
verifica-se que as variações de temperatura da água dentro do reservatório de calda não devem representar influência significativa nos resultados das vazões.

\subsubsection{Efeito do ângulo da lança e da distância na velocidade do ar na saída do bocal}

Para verificar a influência do ângulo da lança na velocidade do ar $\left(\mathrm{m} . \mathrm{s}^{-1}\right)$ avaliouse o modelo apresentado na eq. (20),

$$
\mathrm{y}_{\mathrm{i}}=\mu+\mathrm{I}_{\mathrm{i}}
$$

Utilizando-se os procedimentos de análise do modelo linear generalizado (GLM) com aplicação do teste F, para testar as hipóteses:

Ho: $\mathrm{I}=0$ para todo $\mathrm{i}$ vs. $\mathrm{H}_{\mathrm{a}}: \mathrm{I} \neq 0$, para algum $\mathrm{i}$,

Em que:

$\mathrm{y}_{\mathrm{i}}$ é a velocidade do vento $\left(\mathrm{m} . \mathrm{s}^{-1}\right)$;

$\mu$ é a média geral e

$\mathrm{I}_{\mathrm{i}}$ é o efeito do nível i do fator ângulo de lançamento na velocidade do ar.

Os resultados da análise do modelo são apresentados na tabela 12 e sugerem que não existe influência dos ângulos na variação da velocidade do ar (p-valor $>>0,05)$, ou seja, não se rejeita a hipótese Ho para nível $\alpha<5 \%$ de significância. Portanto, o modelo apresenta-se inadequado.

Tabela 12. Resultados do teste F e P-valor, para velocidade do ar $\left(\mathrm{m} \cdot \mathrm{s}^{-1}\right)$.

\begin{tabular}{ccc}
\hline Fonte de variação & teste $\mathrm{F}$ & P-valor \\
\hline Modelo & $0,07^{\mathrm{ns}}$ & 0,9987 \\
Inclinação & $0,07^{\mathrm{ns}}$ & 0,9987 \\
\hline
\end{tabular}

Os resultados estatísticos podem ser melhor visualizados na Figura 25, onde verifica-se que os pontos representados pela velocidade do ar $\left(\mathrm{m} . \mathrm{s}^{-1}\right)$ numa mesma posição praticamente se sobrepõe para qualquer que seja o ângulo. Esse resultado mostra que a distribuição do produto aplicado não deve ser comprometido do ponto de vista do 
volume de ar gerado, visto que, este é diretamente proporcional à velocidade do ar na saída do bocal.

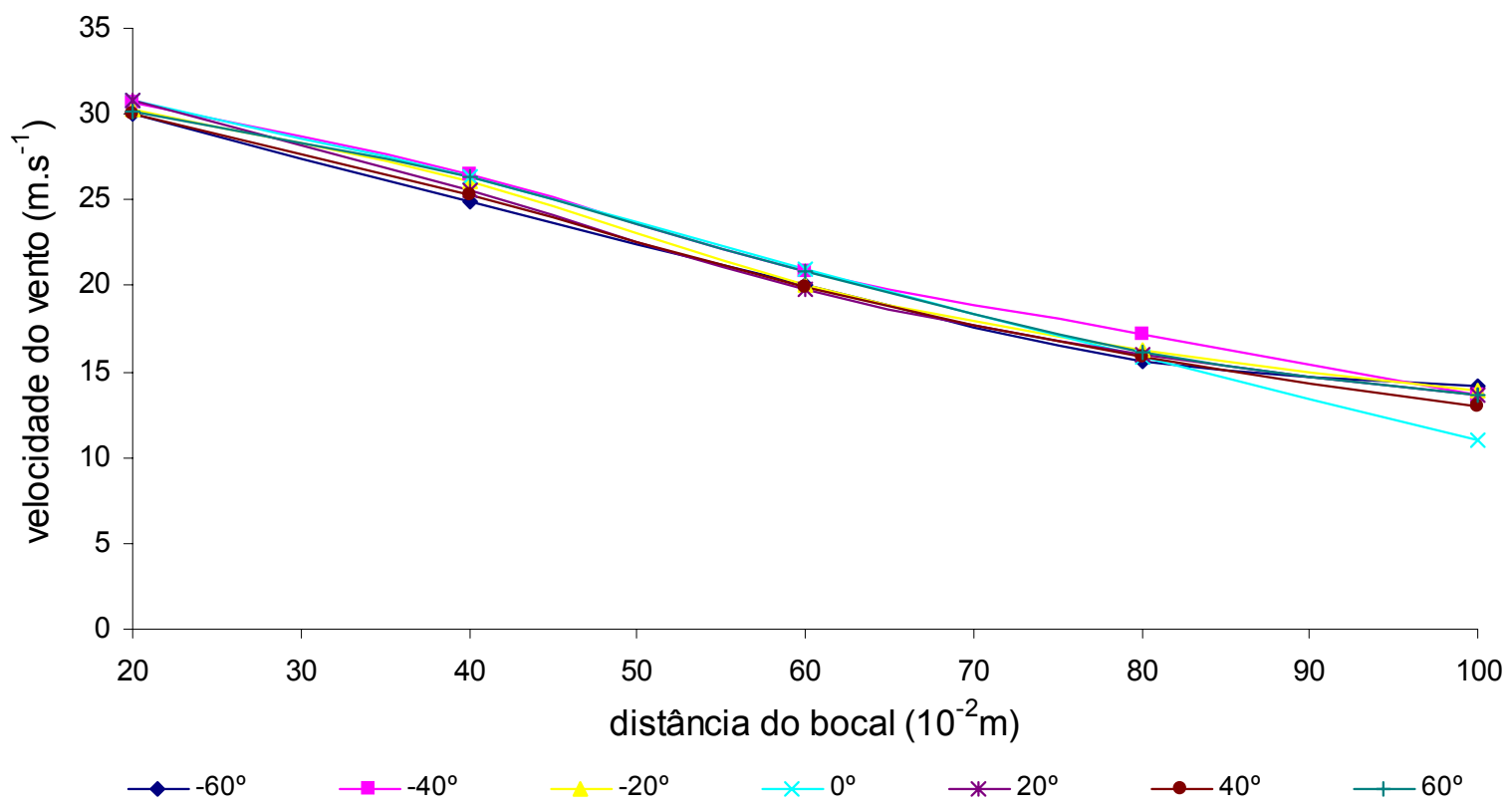

Figura 25- Velocidade do ar $\left(\mathrm{m} . \mathrm{s}^{-1}\right)$ em função das distâncias do bocal e ângulo da lança.

$\mathrm{Na}$ Tabela 13 são apresentados os resultados obtidos através dos dados apresentados no apêndice 2. Observa-se na Tabela 13 que ocorreu uma redução acentuada da velocidade do ar de $27,3 \mathrm{~m} \cdot \mathrm{s}^{-1}$ para $11,9 \mathrm{~m} \cdot \mathrm{s}^{-1}$, num intervalo de apenas 0,8 m. Em porcentagem isso significa em torno de $56,3 \%$.

Tabela 13. Estatística descritiva do dados de velocidade do ar.

\begin{tabular}{ccccccc}
\hline Distância & Média & $\begin{array}{c}\text { desvio } \\
\text { padrão } \\
\left(\mathrm{m} \cdot \mathrm{s}^{-1}\right)\end{array}$ & $\begin{array}{c}\text { mínimo } \\
(\mathrm{m})\end{array}$ & $\begin{array}{c}\text { máximo } \\
(\mathrm{m})\end{array}$ & $\begin{array}{c}\Delta_{\text {máx-mín }}{ }^{*} \\
(\mathrm{~m})\end{array}$ & $\begin{array}{c}\mathrm{CV} \\
(\%)\end{array}$ \\
\hline 0,2 & 30,4 & 1,89 & 27,8 & 31,4 & 11,3 & 1,86 \\
0,4 & 25,9 & 3,01 & 21,9 & 27,4 & 20,0 & 3,49 \\
0,6 & 20,4 & 2,85 & 17,3 & 21,9 & 21,0 & 4,18 \\
0,8 & 16,1 & 3,81 & 13,2 & 25,3 & 47,0 & 7,07 \\
1,0 & 13,3 & 3,61 & 9,7 & 15,2 & 36,0 & 8,12 \\
\hline
\end{tabular}

$* \Delta_{\text {máx-mín }}=$ variação percentual entre o valor máximo e mínimo da velocidade do ar em função da distância. 
Os valores de velocidade máxima e mínima apresentam redução à medida que se afastam do bocal. Essa tendência de queda na velocidade do ar mostrada pela curva, na prática pode se constituir em uma dificuldade de penetração do produto aplicado na área alvo, e conseqüentemente na baixa eficiência da aplicação. A perda de energia após a saída do bocal é resultado da resistência do ar.

Uma observação importante a considerar é o fato de que o ar gerado pela bomba centrífuga, na velocidade de $85 \mathrm{~m} . \mathrm{s}^{-1}$ (Jacto, s.d.), sofre ao longo de sua trajetória uma redução de $66,9 \%$ na velocidade, até a distância de $0,2 \mathrm{~m}$ do bocal, cuja média é de 27,3 $\mathrm{m} . \mathrm{s}^{-1}$. Esse fato merece uma análise mais detalhada das perdas de energia que ocorrem na condução do ar, quando passa pela curva móvel, lança e turbina onde parte dessa energia é destinada ao fracionamento do líquido que é succionado pela corrente de ar.

\subsection{Considerações finais}

Observou-se no decorrer do trabalho que diferentes ângulos da lança resultam em diferentes vazões para um disco restritor; entretanto não existe referência no manual do fabricante quanto ao ângulo da lança a ser utilizado nos procedimentos de calibração. Portanto sugere-se como procedimento inicial de calibração a determinação das curvas de vazão características para cada situação, incluindo na aplicação o ângulo da lança. Em função das características da área, ou imóvel a ser trabalhado não obtendo o volume desejado de aplicação ajusta-se o ângulo da lança, o tempo de aplicação e/ou a troca do disco restritor se for necessário, como preconizado pelo fabricante.

Outro parâmetro que deve ser considerado na melhoria da aplicação é a determinação do espectro de gotas, porém é necessário equipamentos específicos (como é o caso do analisador de partículas por difração de laser) que garantam a eficiência na coleta das gotas do aerossol $(<50 \mu \mathrm{m})$. Sugere-se como proposta de trabalho futuro a determinação do espectro de gotas para as várias situações apresentadas no presente trabalho, de outro modo a inclusão dessa etapa tornaria o custo do trabalho inviável . 
Ao final dos ensaios observou-se também a presença de resíduos no sistema de mangueira. $\mathrm{O}$ volume inicial de água no sistema de mangueiras era de $59,4.10^{-3} \mathrm{~L}$ e o volume médio de água que permaneceu no sistema pode ser visto na Tabela 14.

Os valores de 52,4 e $50,0.10^{-3} \mathrm{~L}$ encontrados para o ângulo de inclinação $60^{\circ}$ podem significar perdas de material, ao levar a máquina diretamente para a manutenção considerando-se uma aplicação em ultra baixo volume. Deve-se recomendar ao operador no final de uma jornada de trabalho que ele deva esgotar o produto das mangueiras, posicionando a lança nos ângulos de $-40^{\circ}$ ou $-60^{\circ}$, visto que para esses ângulos ocorreu o esvaziamento total do sistema de mangueiras.

Tabela 14. Volume médio de água remanescente no sistema hidráulico de acordo com os tratamentos.

Volume de água remanescente no circuito

Tratamentos hidráulico

\begin{tabular}{cc} 
& $\left(10^{-3} \mathrm{~L}\right)$ \\
\hline A $60^{\circ}$ & 52,4 \\
A $40^{\circ}$ & 8,7 \\
A $20^{\circ}$ & 8,0 \\
A $0^{\circ}$ & 6,3 \\
A $-20^{\circ}$ & 2,6 \\
A $-40^{\circ}$ & 0,0 \\
A $-60^{\circ}$ & 0,0 \\
B $60^{\circ}$ & 50,0 \\
B $40^{\circ}$ & 9,3 \\
B $20^{\circ}$ & 11,0 \\
B $0^{\circ}$ & 6,2 \\
B $-20^{\circ}$ & 2,7 \\
B $-40^{\circ}$ & 0,0 \\
B $-60^{\circ}$ & 0,0 \\
\hline
\end{tabular}


A presença de pequenos volumes de água dentro das mangueiras, pode constituirse, quando utilizando-se de defensivos, em possíveis causas de intoxicação, principalmente nas operações de manutenção. Observa-se que a lança, na medida em que é erguida, resulta no aumento na quantidade de água no sistema. 


\section{CONCLUSÕES}

- A associação adequada entre o ângulo da lança e o uso de um determinado disco dosador influencia significativamente os valores de vazão média da máquina, e conseqüentemente no resultado do controle do vetor. Por isso é fundamental que operador deva ser orientado para compensar a menor vazão de calda nos maiores ângulos, aumentando o tempo de aplicação para uma mesma dosagem de defensivo.

- Recomenda-se utilizar numa aplicação o disco dosador B (diâmetro = 0,42 mm), visto que o mesmo apresentou melhor uniformidade de vazão em relação ao disco dosador $\mathrm{A}\left(\right.$ diâmetro $=0,76 \mathrm{~mm}$ ) na faixa ampla de $-60^{\circ}$ a $60^{\circ}$.

- O aumento na vazão média de $69,6 \%$ com a troca dos discos dosadores, mostra que a escolha adequada do tipo de disco pode contribuir para a redução significativa das perdas do produto e evitar aplicações com sub ou superdosagens.

- Sugere-se ao fabricante dos discos dosadores ensaiados a inclusão de um disco de cor diferente da bege para que não seja comprometida a uniformidade de aplicação.

- A pressão no ponto 3, localizado próximo à saída do bico apresentou forte relação para as variações da vazão média.

- A pressão exercida pela bomba centrífuga para dentro do reservatório de calda não é suficientemente elevada para compensar as perdas de carga hidráulica, resultantes do posicionamento do bocal nos maiores ângulos.

- A falta de pressão para os ângulos acima de $20^{\circ}$ resultou nos maiores volumes de resíduos na mangueira. 
ANEXOS 
ANEXO A- ESTRUTURA DE APOIO DO PULVERIZADOR 
ANEXO B- DESENHO DO COLETOR DE GOTAS E PERFIL DAS LAMELAS 


\section{ANEXO C- DIAGRAMA DO CIRCUITO ELETRÔNICO PARA OS SENSORES DE} PRESSÃO.
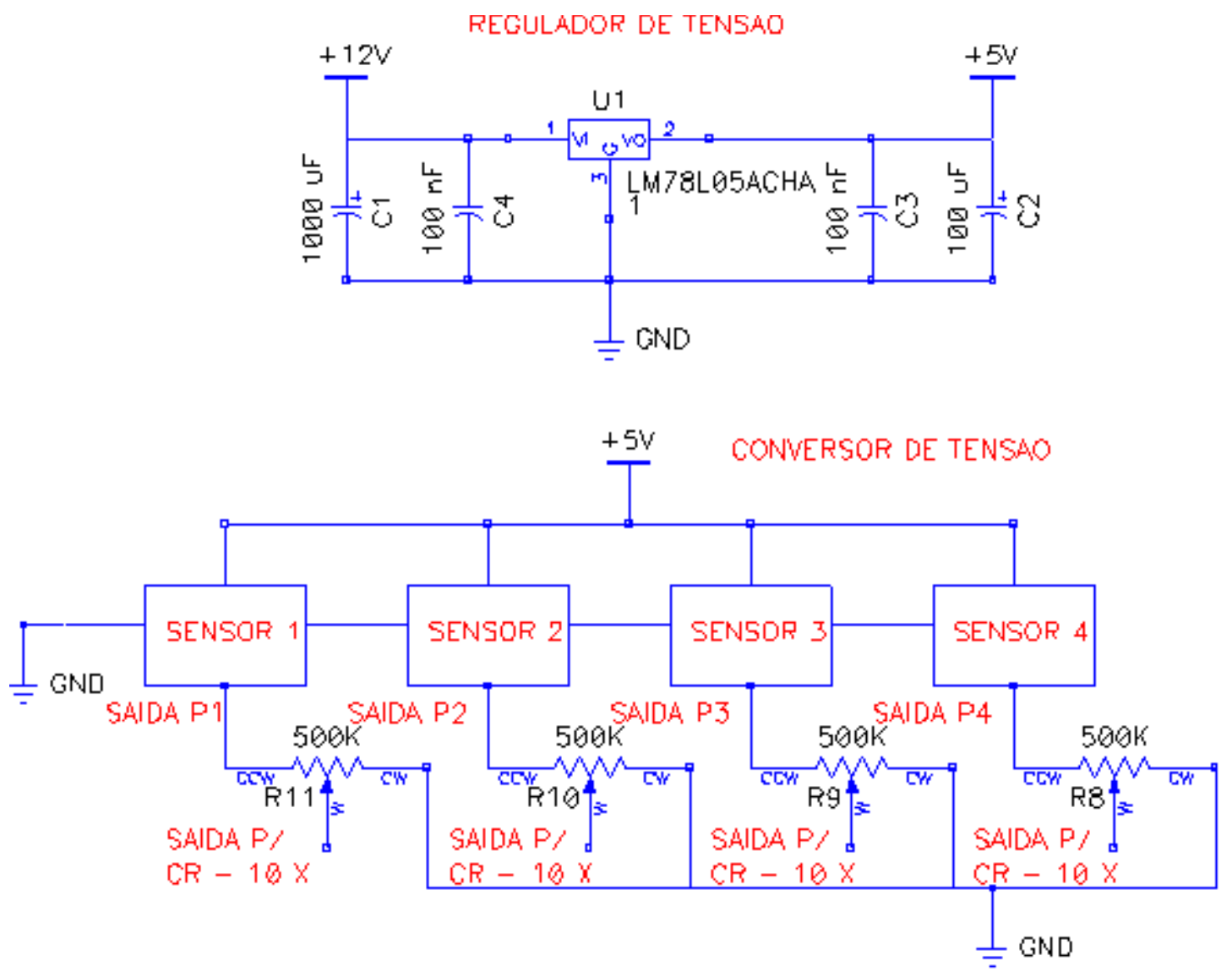
ANEXO D- Diagrama do circuito eletrônico utilizado para o sistema de monitoramento da rotação $(\mathrm{rpm})$

DA (SCHEMATIC)

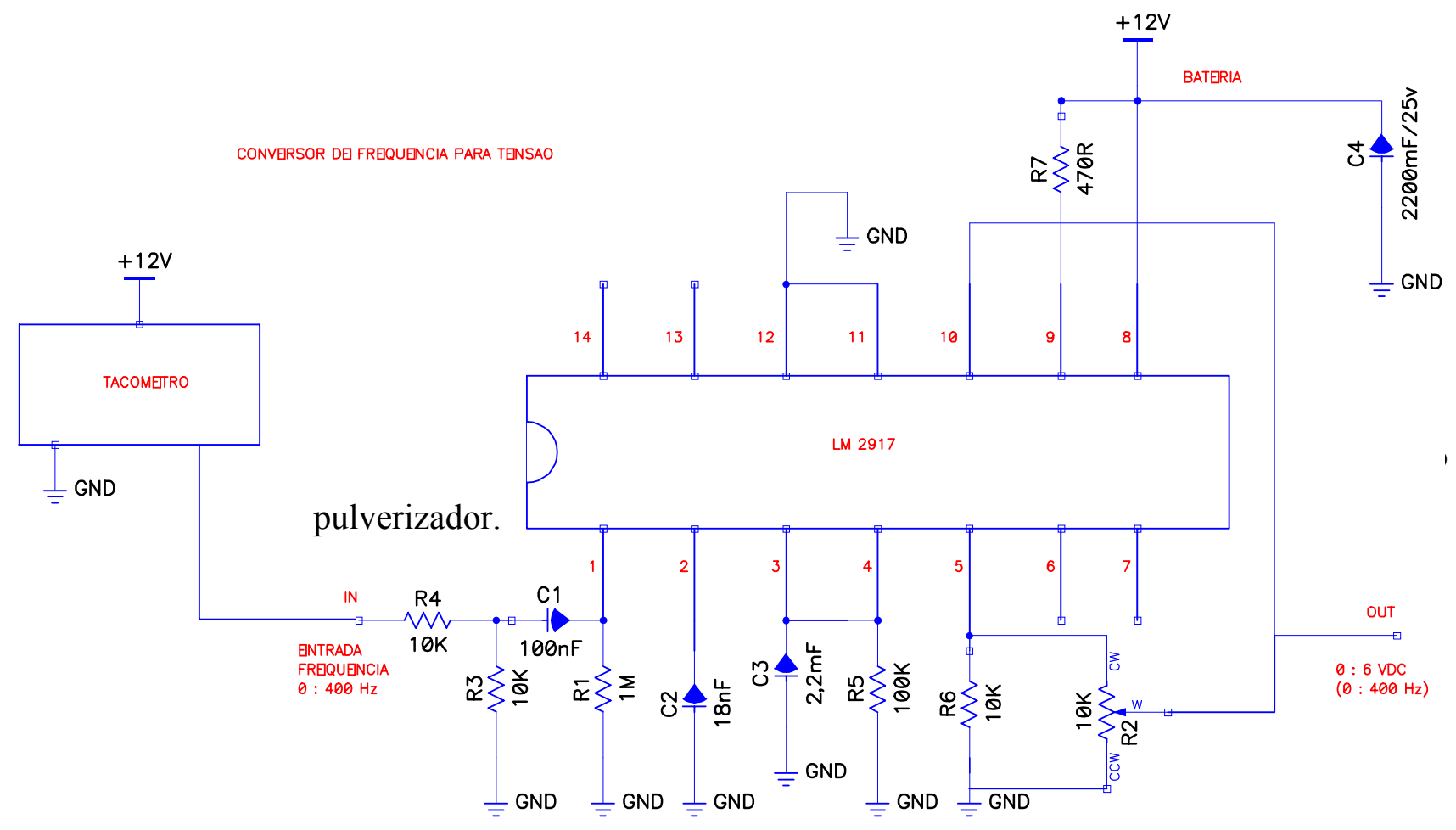

Os diagramas foram feitos com o aplicativo ACCEL 
ANEXO E- PROTOCOLO DE PROGRAMAÇÃO PARA AQUISIÇÃO E ARMAZENAMENTO DOS DADOS PARA O SISTEMA DE AQUISIÇÃO DE DADOS CR10X.

JACTO.CSI, Table 1

$;\{\mathrm{CR} 10 \mathrm{X}\}$

; $\{\mathrm{CR} 10 \mathrm{X}\}$

;

*Table 1 Program

01:1 Execution Interval (seconds)

1: Temp (107) (P11)

01:1 Reps

2:9 SE Channel

3:3 Excite all reps w/E3

4:8 Loc [Ref_Temp]

5: 1.0 Mult

6:0 Offset

2:Volts (SE) (P1)

1:1 Reps

2:25 $2500 \mathrm{mV} 60 \mathrm{~Hz}$ Rejection Range

3:1 SE Channel

4:1 Loc [pressao1]

5: $\quad 0.0435$ Mult

6: $\quad-8.6933$ Offset

3:Volts (SE)(P1) 
1:1 Reps

2:25 $2500 \mathrm{mV} 60 \mathrm{~Hz}$ Rejection Range

3:2 SE Channel

4:2 Loc [pressao2]

5: $\quad 0.0435$ Mult

6: $\quad-8.6933$

4: Volts (SE)(P1)

1:1 Reps

2:25 $2500 \mathrm{mV} 60 \mathrm{~Hz}$ Rejection Range

3:3 SE Channel

4:3 Loc [pressao3]

5: $\quad 0.0435$ Mult

6: $\quad-8.6933$ Offset

5: Volts (SE) (P1)

1:1 Reps

2:25 $2500 \mathrm{mV} 60 \mathrm{~Hz}$ Rejection Range

3:10 SE channel

4:4 Loc [pressao 4]

5: $\quad 0.0435$

6: $\quad-8.6933$ Offset

6: Volts (SE) (P1)

1:1 Reps

2:25 $2500 \mathrm{mV} 60 \mathrm{~Hz}$ Rejection Range

3:4 SE Channel

4:5 Loc [RPM]

5: $\quad 4.8$ Mult

6: 0 Offset 
7: Thermocouple Temp (DIFF) (P14)

1: $1 \quad$ Reps

2: $21 \quad 2.5 \mathrm{mV} 60 \mathrm{~Hz}$ Rejection Range

3: 3 DIFF Channel

4: 01 Type T (Copper-Constantan)

5: 8 Ref Temp Loc [ Ref_Temp]

6: 6 Loc [temp ]

7: 1.0 Mult

8: 0 Offset

8: Thermoucouple Temp (DIFF) (P14)

1:1 Reps

2: $21 \quad 2.5 \mathrm{mV} 60 \mathrm{~Hz}$ Rejection Range

3: 04 DIFF Channel

4: 01 Type T (Copper-Constantan)

5: 8 Ref Temp Loc [ Ref_Temp]

6: 7 Loc [ tempar]

7: 1.0 Mult

8: 0 Offset

9: If Flag/Port (P91)

1: 51 Do if Port 1 is Low

2: 30 Then Do

10: Do (P86)

1:10 Set Output Flag High (Flag 0)

11: Real Time (P77)

1: 0111 Day,Hour/Minute, Seconds (midnight=0000) 


\section{2:Resolution (P78)}

\section{1:1 High Resolution}

13: Sample (P70)

1:7 Reps

2:1 Loc [pressao1]

14: End (P95)

*Table 2 Program

02: $0.0000 \quad$ Execution Interval (seconds)

*Table 3 Subroutines

End Program 
ANEXO F- PRESSÕES REGISTRADAS

Tabela 1. Pressões de médias nos pontos P1, P2, P3 e P4 obtidos nos ensaios, de acordo com os tratamentos utilizados

\begin{tabular}{|c|c|c|c|c|}
\hline Tratamento & pressão & 1 Pressão & $\begin{array}{l}2 \text { Pressão } \\
(\mathrm{kPa})\end{array}$ & 3 Pressão 4 \\
\hline A $60^{\circ}$ & 6,6 & 5,2 & 1,8 & 5,2 \\
\hline $\mathrm{A} 40^{\circ}$ & 6,6 & 5,2 & 3,3 & 5,2 \\
\hline A $20^{\circ}$ & 6,6 & 5,2 & 5,3 & 5,2 \\
\hline A $0^{\circ}$ & 6,7 & 5,3 & 7,7 & 5,3 \\
\hline A $-20^{\circ}$ & 6.7 & 5,2 & 10 & 5,2 \\
\hline A $-40^{\circ}$ & 6,4 & 5,3 & 10,2 & 5,2 \\
\hline A $-60^{\circ}$ & 6,5 & 5,2 & 10,2 & 5,2 \\
\hline B $60^{\circ}$ & 6,7 & 5,2 & 1,8 & 5,2 \\
\hline B $40^{\circ}$ & 6,8 & 5,4 & 3,5 & 5,4 \\
\hline B $20^{\circ}$ & 6,5 & 5,2 & 5,3 & 5,2 \\
\hline B $0^{\circ}$ & 6,5 & 5,1 & 7,5 & 5,1 \\
\hline $\mathrm{B}-20^{\circ}$ & 6,7 & 5,2 & 10,0 & 5,2 \\
\hline $\mathrm{B}-40^{\circ}$ & 6,5 & 5,2 & 9,8 & 5,1 \\
\hline $\mathrm{B}-60^{\circ}$ & 6,6 & 5,2 & 10,1 & 5,1 \\
\hline
\end{tabular}




\section{REFERÊNCIAS BIBLIOGRÁFICAS}

\section{AMERICAN SOCIETY OF AGRICULTURAL ENGINEERS. ASAE standards}

1996. St. Joseph, 1996. p.159-161: ASAE S 327.2; Terminology and definitions for agricultural chemical applications.

ARAGÃO, M.B.; AMARAL, R.S. do; LIMA, M.M. Aplicação espacial de inseticida em saúde pública. Cadernos de Saúde Pública, v.2, n.4, p.147-166, abr./jun. 1988.

ARNOLD, A.C.; THORNHILL, E.W. The evaluation of a knapsack u.l.v. aerosol generator. PANS, v. 25, n.4, p.444-447, Dec. 1979.

ASSOCIAÇÃO BRASILEIRA DE NORMAS TÉCNICAS. Aplicação de defensivos agrícolas: TB-344. Rio de Janeiro, 1988. 4p.

ASSOCIAÇÃO BRASILEIRA DE NORMAS TÉCNICAS. Métodos de aplicação de defensivos agrícolas: TB-394. Rio de Janeiro, 1991a. 2p.

ASSOCIAÇÃO BRASILEIRA DE NORMAS TÉCNICAS. Máquinas e implementos aplicadores de defensivos agrícolas: CB-208. Rio de Janeiro, 1991b. 2p.

ASSOCIAÇÃO BRASILEIRA DE NORMAS TÉCNICAS. Pulverizador agrícola:NBR-12936. Rio de Janeiro, 1993. 5p.

BALASTREIRE, L.A. Máquinas agrícolas. São Paulo: Manole, 1987. 307p. 
BANSAL, A.S. Dynamic response and vibration control at the source in a poweredknapsack sprayer. Agricultural Mechanization in Asia, Africa and Latin America,v.29, n.3, p. 23-26, 1998.

BERNACKI, H.; HAMAN, J.; KANAFOJSKI, Cz. Agricultural machines: theory and construction. Warsaw: Central Institute of Scientific, Technical and Economic Information, 1972. cap.15, p. 780-865: Insect, plant disease and weed controlling machines.

CAMBRIGDE ANIMAL AND PUBLIC HEALTH LIMITED. Ficam ${ }^{\circledR}$ ULV technical dossier. Cambridge, 1987. 50p.

CENTRO DE VIGILÂNCIA EPIDEMIOLÓGICA. Divisão de Zoonoses. www.cve.saude.sp.gov.br/htm/Den_dir.htm (18 set. 2001).

CLAYPHON, J.E. Comparison trials of various motorised knapsack mistblowers at the Cocoa Research Institute of Ghana. PANS, v. 17, n. 2, p.440-443, June 1971.

CLAYPHON, J.E. The evaluation of a motorised knapsack mistblower. PANS, v.25, n.4, p.440-443, Dec. 1979.

DEPARTAMENTO DE ENGENHARIA E MECÂNICA DA AGRICULTURA. Boletim da Divisão de Mecanização Agrícola. São Paulo: Divisão de Mecanização Agrícola, 1957-58. 198p.

DOEBELIN, E.D. Measurement systems: application and design. New York: McGraw-Hill, 1966. 743p. 
DUKES, J.C.; HALLMON,C.F., SHAFFER, K.R.; HESTER, P.G. Effects of pressure and flow rate on cythion® droplet size produced by three different ground ULV aerossol generators. Journal of the American Mosquito Control Association, v.6,n.2,p. 279-292, June 1990.

EL AWADY, M.N. An atomization theory for swirl nozzles. Transactions of the ASAE, v.21 ,n.1, p.70-74, Jan./Feb. 1978.

FAO Agricultural pesticides sprayers: FAO technical standards: sprayer specifications and test procedures. Rome, 1998. v.2,63p.

FEITOSA FILHO, J.C.; BOTREL, T.A.; PINTO, J.M. Desempenho de injetores tipo venturi em condições de descarga livre e pressurizada. Engenharia Agrícola, v.17, n.3, p.20-35, mar. 1998.

FOX, R. W.; McDONALD, A. T. Introdução à mecânica dos fluidos. 5.ed. Rio de Janeiro: Livros Científicos Técnicos, 2001. 662p.

FUNDAÇÃO INSTITUTO BRASILEIRO DE GEOGRAFIA E ESTATÍSTICA. Censo demográfico2000.http://www.ibge.gov.br/ibge/estatistica/populacao/censo2000 (17 set. 2001)

FUNDAÇÃO INSTITUTO BRASILEIRO DE GEOGRAFIA E ESTATÍSTICA. Pesquisa Nacional de Saneamento Básico - 2000. http://www.ibge.net/home/estatistica/populacao/condicaodevida/pnsb/lixo_coletado/ lixo_coletado104shtm (05 abr. 2001)

FUNDAÇÃO NACIONAL DE SAÚDE. Plano de intensificação das ações de controle do dengue. Brasília, 2001. 123p. 
GADANHA JÚNIOR, C. D.; MOLIN, J. P.; COELHO, J. L. D.; YHAN, C. H.; TOMIMORI, S. M. A. W. Máquinas e implementos agrícolas do Brasil. São Paulo:IPT, 1991. 468 p.

GÖPEL, W.; HESSE, J.; ZEMEL, J.N.; RICOLFI, T.; SCHOLZ, V.J. Thermal sensors. New York: VCH Publ., 1990. 460p.

GRANDKE, T.; HESSE, J. Introduction. In: GÖPEL, W.; HESSEL,J.; ZEMEL,J.N.; GRANDKET,T.; V.KO, W.H. Sensors: a comprehensive survey. New York: VCH Publ., 1989. cap.1, p.2-16.

HIGGINS, A.E.H. The selection of spraying equipment. Pest Articles an Summaries, v.12, n. 2/3, p.109-115, July 1966.

HOLWAY, R.T.; MORRIL, A.W.; SANTANA, F.J. Mosquito control activities of the U.S. armed forces in the Republic of Vietnam. Mosquito News, v.27, n.3, p. 297307, Sept. 1967.

INSTRUMENT SOCIETY OF AMERICA. ANSI standards 1975. Research Triangle Park, 1975. p.111-121: ISA S37.1; Electrical transducer nomenclature and terminology.

ISMAIL, K.A.R.; GONÇALVES, M.M.; BENEVENUTO, F.J. Instrumentação básica para engenharia. Campinas: Ed.do autor, 1998. 470p.

JOLLANDS, P. Evaluation of knapsack mistblowers for the control of coffee leaf rust in Papua New Guinea. BCPC Monograph, v.46, p.177-184, 1991. 
KLASSEN, W. World food security up to 2010 and the global pesticide situation. In: INTERNATION CONGRESS OF PESTICIDE CHEMISTRY, 8., Washington, 1995. Washington: International Atomic Energy Agency, 1995. p. 1-32.

KÜMMEL, K.; GOHLICH, H.; WESTPAL,O. Development of practice oriented control test methods for orchard spray machines by means of a vertical test stand. BCPC Monograph, v.46, p.27-33, 1991.

LAUREANO, G. J. Projeto de um gerador de gotas tipo micronair para os atomizadores costais motorizados. Campinas, 1983. 147p. Dissertação (Mestrado) - Faculdade de Engenharia de Alimentos e Agrícola, Universidade Estadual de Campinas.

LENCASTRE, A. Manual de hidráulica geral.. São Paulo: EDUSP, 1972. 411p.

LOFGREN, C.S. Ultralow volume applications of concentrated insecticides in medical and veterinary entomology. Annual Review of Entomology, v. 15, p.321-342, 1970.

MAQUINARIA para manejo de cultivos. México:Trilhas, 1987. p.41-78: Aspersoras, nebulizadoras y espolvoreadoras. (Manuales para Educación Agropecuária, 44)

MÁQUINAS AGRÍCOLAS JACTO S.A. Manual de instruções multispray 2000. Pompéia, s.d. 26p.

MARER, P.J. The safe and effective use of pesticides. Davis: Division of Agriculture and Natural Resouces, 1988. $356 \mathrm{p}$.

MATTHEWS, G.A. Pesticide application methods. 2.ed. New York: Longman, 1992. 405p. 
MATTHEWS. G.A.; THORNHILL, E.W. Pesticide application equipment for use in agriculture: manually carried equipment. Rome: FAO, 1994. cap. 5 p.53-58: Motorized knapsack mistblowers.

MIALHE, L.G. Máquinas agrícolas: ensaios \& certificação. Piracicaba:FEALQ, 1996. 722p.

MOSER, E.; HUSSAIN, Md. D. Electrostatic spraying with a knapsack sprayer. Agricultural Mechanization in Asia, Africa and Latin, v.16, n.3, p. 41-46, 1985.

MOTOROLA INC. Sensor device data: handbook. s.l., 1998. sec.3, p 3-5: Pressure sensor products.

MOUNT, G.A.; PIERCE, N.W.; LOFGREN, C.S; JACK, S. Droplet size and kill of adult mosquitoes with ultralow volume aerial sprays dispersed from a rotarycylinder atomizer. Mosquito News, v.31, n.3, p.326-330, 1971.

NATAL, D. Manejo integrado de mosquitos. São Paulo: USP, Faculdade de Saúde Pública, 2000. 53p.

ORGANIZACIÓN MUNDIAL DE LA SALUD. Problemas técnicos de las operaciones de lucha antivectorial: primer informe del Comité de Expertos de la OMS em Biologia de los vectores y Lucha antivectorial. Ginebra,1977. 44p. (Série de Informes Técnicos, 603)

OZKAN, E.H. Recommendations for pesticide applicator training in USA based on licensing and training procedures in Western Europe. Applied Engineering in Agriculture, v.15, n.1, p. 25-30, 1999. 
PATEL, S.L. Aspee micronizer nozzle for motorised mist blower. Agricultural Mechanization in Asia, v. 10, n.1, p.69- 75, 1979.

PATEL, S.L. Pesticide spray volume determination. Agricultural Mechanization in Asia, v.12, n.4, p. 35-40, Oct. 1981.

PERTEL, J. Manual de tecnologia de aplicação de defensivos agrícolas-módulo II. Viçosa: CPT, 1996. 52p.

PRATT, H.D.; LITTIG, K.S. Insecticide application equipment for the control of insects of public health importance. 3.ed. Atlanta: Center for Disease Control, 1976. $48 p$.

PREEST, D. S. A mistblower modification enabling treatment of individual trees with different chemicals. PANS, v. 25, n. 3, p.299-301, Sept. 1979.

RAMOS, H.H.; RAMOS, R.C.; COELHO, M.C.M; COELHO, P.J. Avaliação do parque de pulverizadores em utilização no estado de São Paulo, In: CONGRESSO BRASILEIRO DE ENGENHARIA AGRÍCOLA, 27., Poços de Caldas, 1998. Anais. Poços de Caldas: Sociedade Brasileira de Engenharia Agrícola, 1998. p.301-303.

SALYANI, M.; SERDYNSKI, J.W. A device and method for sprayer calibration. Applied Engineering in Agriculture, v.9, n.1, p.29-32, Jan. 1993.

SCHOOLEY, J.F. Termometry. Boca Raton: CRC Press, 1986. cap 6, p.163-209: Modern thermometers.

SINDICATO NACIONAL DA INDÚSTRIA DE PRODUTOS PARA DEFESA AGRÍCOLA . www.andef.com.br/dentro/bbanco.htm (15 nov.2000) 
SOLO. Chronik 1948-1950. http://www.solo-germany.com/english/inhalt/chronik_4850.html (29 Jan. 1998)

TAKENAGA, T. A trend of pesticides applicator in study. Agricultural Mechanization in Asia, v. 4, n. 1, p.120-127, 1973.

TAYLOR, W.A.; RICHARDSON, W.G. A simple technique for the rapid calibratio of a laboratory pesticide sprayer. PANS, v. 18, n.4, p. 457-458, Dec. 1972.

THOMPSON, G.A. Some errors inherent in U.L.V. operations. Mosquito News, v. 33, n.3, p.364-367, 1973.

TOSIN, R.C.; SANTOS, J.E.G.; SANTOS FILHO, A.G.dos; FERNANDES, J.C. Nível de ruído em pulverizadores costais motorizados (compact disc). In: CONGRESSO BRASILEIRO DE ENGENHARIA AGRÍCOLA, 24., Fortaleza, 2000. Anais. Fortaleza: Sociedade Brasileira de Engenharia Agrícola, 2000.

VAN DER MEIJDEN, G. Pesticide application techniques in West Africa. FAO, Regional Office for Africa Accra, Ghana and Agricultural Engineering Branch, Agricultural Support Systems Division. http://www.fao.org/docrep/X5858e00.htm (15 Nov. 2000).

WARD, S.M. Spray characteristics of a rotary atomizer. Agricultural Mechanization in Asia, Africa and Latin America, v.16, n.4, p.30-32, 1985.

WERNECK, M.M. Transdutores e interfaces. Rio de Janeiro: Livros Técnicos e Científicos, 1996. 405p. 
WOMAC, A.R.; HART, W.E.; MAYNARD II, R.A. Drop spectra for pneumatic atomizers at low discharge rates. Transactions of the ASAE, v.41, n.4, p.941-949, 1998.

WORLD HEALTH ORGANIZATION. Chemical methods for the control of vectors and pests of public health importance. s.l.: D.C. Chavasse; H.H.Yap., 1997. $129 \mathrm{p}$. 
APÊNDICES 
APÊNDICE 1 - JANELA APRESENTADA PELO PROGRAMA QC-4000, MOSTRANDO O RAIO E O DIÂMETRO OBTIDO NA LEITURA DOS ORIFÍCIOS.

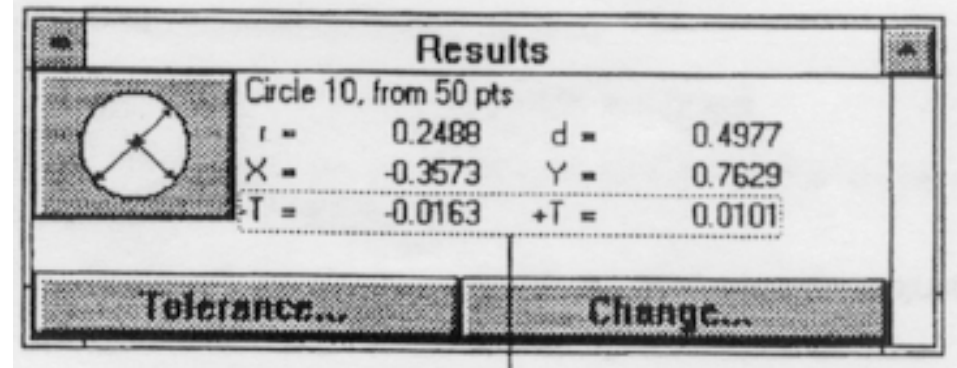


APÊNDICE 2- Quadro dos resultados de velocidade do ar $\left(\mathrm{km} \cdot \mathrm{h}^{-1}\right)$ medida em diferentes ângulos e distâncias do bocal do pulverizador.

\begin{tabular}{|c|c|c|c|c|c|c|c|c|c|c|c|c|c|c|}
\hline \multicolumn{5}{|c|}{ inclinação de $-20^{\circ}$} & \multicolumn{5}{|c|}{ inclinação de $-40^{\circ}$} & \multicolumn{5}{|c|}{ inclinação de $-60^{\circ}$} \\
\hline \multicolumn{5}{|c|}{ distâncias $\left(10^{-2} \mathrm{~m}\right)$} & \multicolumn{5}{|c|}{ distâncias $\left(10^{-2} \mathrm{~m}\right)$} & \multicolumn{5}{|c|}{ distâncias $\left(10^{-2} \mathrm{~m}\right)$} \\
\hline 20 & 40 & 60 & 80 & 100 & 20 & 40 & 60 & 80 & 100 & 20 & 40 & 60 & 80 & 100 \\
\hline 101.6 & 85 & 58.2 & 58.6 & 47.8 & 103.9 & 90.6 & 68.6 & 56.9 & 48.2 & 98.6 & 81 & 70.7 & 53.6 & 47.4 \\
\hline 101.7 & 89 & 66.3 & 49.9 & 50.2 & 101.6 & 90.5 & 68.2 & 56.6 & 48.5 & 96.8 & 81.7 & 68.3 & 50.5 & 45.2 \\
\hline 102.6 & 88.7 & 70.2 & 52.7 & 47.6 & 100.1 & 87.6 & 70.4 & 55.9 & 46.9 & 98.1 & 80.2 & 69.9 & 53.4 & 47.5 \\
\hline 99.3 & 87.2 & 70.8 & 54.5 & 46.5 & 100.4 & 88.1 & 67.1 & 54.5 & 45.4 & 99.2 & 83.3 & 69.2 & 52.4 & 47.9 \\
\hline 99.9 & 85.3 & 71.4 & 55.4 & 47.8 & 102.5 & 88.5 & 67 & 54 & 45.1 & 95.9 & 86.1 & 66.5 & 54.1 & 50.5 \\
\hline 101.3 & 87.6 & 72.4 & 50.4 & 48.8 & 102 & 88.1 & 68.8 & 54.6 & 46.3 & 99.2 & 76 & 67.6 & 52.3 & 48.2 \\
\hline 101.1 & 87.4 & 71.7 & 47.9 & 48.4 & 102.6 & 84.5 & 69.6 & 57.8 & 47.4 & 101.9 & 76.1 & 67.8 & 53.3 & 47 \\
\hline 100.5 & 85.5 & 72.3 & 51.1 & 48.9 & 102.9 & 84.8 & 68.8 & 59.8 & 47.2 & 100 & 73.1 & 68.6 & 52.3 & 48.9 \\
\hline 100.5 & 86 & 71.6 & 48.8 & 46.4 & 102.1 & 84.6 & 70.2 & 56.5 & 47.3 & 100.3 & 86 & 66.4 & 53 & 49.9 \\
\hline 100.2 & 85.3 & 72.1 & 44.6 & 47.3 & 102.7 & 88.8 & 71.2 & 56.6 & 45.2 & 100.2 & 84.3 & 67.3 & 52.3 & 50.6 \\
\hline 100.4 & 84.9 & 69.4 & 47.6 & 47.2 & 103.1 & 88.3 & 63.8 & 56.4 & 45.7 & 100.3 & 86.6 & 62.5 & 52 & 49.2 \\
\hline 100.9 & 85.9 & 60.5 & 46.1 & 45.2 & 102 & 89 & 71.5 & 57.7 & 45.8 & 99.6 & 87.5 & 65.9 & 55 & 49.2 \\
\hline 100.1 & 86.4 & 69.2 & 45.3 & 45.9 & 103.4 & 88.8 & 71.4 & 57.6 & 45.4 & 99.7 & 86.1 & 63.3 & 53.5 & 47.6 \\
\hline 100.9 & 84.8 & 65.4 & 48.5 & 44.2 & 103.1 & 89.1 & 71.7 & 57.6 & 42.6 & 100.8 & 86.8 & 65.9 & 54.4 & 47.6 \\
\hline 100.4 & 89 & 64.1 & 52.8 & 42.4 & 102.4 & 89.1 & 69 & 57.6 & 43.5 & 101.2 & 83.4 & 67.3 & 56 & 47.6 \\
\hline 100.9 & 88 & 64.3 & 84.4 & 44.4 & 102.1 & 89.1 & 66.9 & 57.6 & 43.4 & 101.4 & 76.5 & 64.3 & 52.6 & 47.6 \\
\hline 100.2 & 87.3 & 64.2 & 55 & 45.3 & 102.5 & 89.1 & 73 & 56.4 & 43.2 & 99.1 & 79.1 & 64 & 54.1 & 47.6 \\
\hline 100.2 & 86.3 & 69 & 56.7 & 45.6 & 102.2 & 89.1 & 68 & 55.8 & 40.8 & 100.1 & 85.6 & 65.8 & 51.8 & 48.6 \\
\hline 101.6 & 87.2 & 63.2 & 54.7 & 46 & 102.6 & 90 & 71.8 & 55.4 & 44.5 & 100.8 & 80 & 65.4 & 49.5 & 45.6 \\
\hline 99.3 & 88 & 59.4 & 55.8 & 49.1 & 103.1 & 88.9 & 72.3 & 58.1 & 45.5 & 101.1 & 81.1 & 67.6 & 47.3 & 43.7 \\
\hline 100.8 & 87.2 & 62.9 & 56 & 46.7 & 102.5 & 89.7 & 71.3 & 59.2 & 48.2 & 99.7 & 86 & 66.2 & 52 & 43.7 \\
\hline 100.5 & 87.3 & 62.6 & 52.5 & 46.5 & 102.9 & 88.6 & 71.3 & 58.8 & 47.2 & 100.8 & 81.3 & 65.8 & 51.4 & 42.8 \\
\hline 100.5 & 88 & 64.1 & 55.1 & 45.6 & 102.3 & 88.5 & 63.3 & 58.9 & 46.1 & 100.3 & 82.4 & 68.4 & 52.9 & 45.1 \\
\hline 100.3 & 88.3 & 66.3 & 57.9 & 45.6 & 101.8 & 88.1 & 72.2 & 58.6 & 42.8 & 100.6 & 88.6 & 67.8 & 50.1 & 46 \\
\hline 101.5 & 88.7 & 65.6 & 58.7 & 44.9 & 102.4 & 87.3 & 72 & 59.1 & 43.5 & 100.9 & 87.1 & 68.6 & 49.2 & 47.2 \\
\hline 102.2 & 87.8 & 70.7 & 59 & 46.1 & 101.4 & 88 & 70.9 & 59.3 & 46 & 101.9 & 87.4 & 64.9 & 49 & 45.9 \\
\hline 102.8 & 89 & 68.5 & 57.7 & 46.2 & 102.5 & 89 & 70.7 & 57.3 & 47.2 & 101.2 & 86.3 & 66.9 & 48.2 & 45.6 \\
\hline
\end{tabular}


APÊNDICE 2- Quadro dos resultados de velocidade do ar $\left(\mathrm{km} \cdot \mathrm{h}^{-1}\right)$ medida em diferentes ângulos e distâncias do bocal do pulverizador.

\begin{tabular}{|c|c|c|c|c|c|c|c|c|c|c|c|c|c|c|c|c|c|c|c|}
\hline \multicolumn{5}{|c|}{ inclinação de $0^{\circ}$} & \multicolumn{5}{|c|}{ inclinação de $20^{\circ}$} & \multicolumn{5}{|c|}{ inclinação de $40^{\circ}$} & \multicolumn{5}{|c|}{ inclinação de $60^{\circ}$} \\
\hline \multicolumn{5}{|c|}{ distâncias $\left(10^{-2} \mathrm{~m}\right)$} & \multicolumn{5}{|c|}{ distâncias $\left(10^{-2} \mathrm{~m}\right)$} & \multicolumn{5}{|c|}{ distâncias $\left(10^{-2} \mathrm{~m}\right)$} & \multicolumn{5}{|c|}{ distâncias $\left(10^{-2} \mathrm{~m}\right)$} \\
\hline 20 & 40 & 60 & 80 & 100 & 20 & 40 & 60 & 80 & 100 & 20 & 40 & 60 & 80 & 100 & 20 & 40 & 60 & 80 & 100 \\
\hline 102.7 & 89.3 & 69.8 & 53.3 & 37 & 101.8 & 86.6 & 62.3 & 55.7 & 42.9 & 103.2 & 75.6 & 68.4 & 53.5 & 43 & 100.4 & 89 & 69.9 & 56.1 & 46.3 \\
\hline 101.9 & 87.8 & 69.3 & 53.1 & 38.6 & 103.6 & 88 & 66.1 & 57.2 & 43.9 & 103.3 & 86.2 & 67.6 & 55.2 & 43 & 102 & 88.8 & 68.4 & 55 & 45.8 \\
\hline 102.6 & 89.7 & 70 & 53.6 & 39.5 & 102 & 86.4 & 63.7 & 57.3 & 44.5 & 102 & 86 & 67.2 & 54.6 & 42.5 & 99.8 & 88.9 & 68.4 & 55.6 & 46 \\
\hline 103.1 & 89.2 & 71.1 & 53.2 & 39.7 & 102.6 & 85.5 & 64.5 & 55.8 & 45.9 & 102.4 & 86.1 & 66.2 & 54.7 & 44 & 103.3 & 88.3 & 69.4 & 56.3 & 45.6 \\
\hline 103.1 & 88.1 & 68.6 & 52.1 & 39.2 & 102.9 & 84.7 & 63.6 & 55.4 & 43.7 & 102.5 & 83.4 & 65.7 & 55 & 44.5 & 94.7 & 89.3 & 70.6 & 55.3 & 46.4 \\
\hline 103.6 & 89.1 & 70 & 52.2 & 39.5 & 102.9 & 84.8 & 57.8 & 56.8 & 44.9 & 102.1 & 84.1 & 65.1 & 55 & 41.8 & 100 & 86.7 & 70.6 & 54.5 & 46.4 \\
\hline 103.7 & 88.3 & 69.6 & 53.6 & 38.6 & 102.7 & 86.9 & 65.4 & 56 & 45.2 & 101.9 & 85.2 & 65.1 & 54.3 & 41.6 & 101.9 & 87.9 & 70.6 & 54.4 & 46.6 \\
\hline 100.8 & 87.9 & 70.9 & 53.4 & 36.1 & 104.7 & 85.2 & 65.8 & 55.5 & 46 & 102.1 & 85.2 & 67.7 & 54.2 & 42.9 & 100.9 & 83 & 68.2 & 51.9 & 46.6 \\
\hline 102.9 & 88.5 & 72 & 50.7 & 35.8 & 103.4 & 85.9 & 66.7 & 55.7 & 45.7 & 101.2 & 77.9 & 64.3 & 54 & 42.9 & 100.9 & 85.6 & 70 & 53 & 45.9 \\
\hline 102.97 & 88.7 & 70.9 & 46.7 & 37.1 & 103 & 83.6 & 64.2 & 55.7 & 46.5 & 100.8 & 80.2 & 66.5 & 53.9 & 43.1 & 101.1 & 91.3 & 67.9 & 53.3 & 44.5 \\
\hline 103.5 & 87.3 & 71.4 & 51.5 & 39.3 & 102 & 83.6 & 63.9 & 54.4 & 46.2 & 101.6 & 85.3 & 67.4 & 53.5 & 43.6 & 100.3 & 87.7 & 69.1 & 54.2 & 46.1 \\
\hline 103.3 & 87.6 & 71.1 & 51.1 & 36.9 & 102.3 & 83.8 & 64.7 & 54.1 & 43.6 & 101.7 & 83.8 & 67.3 & 53.9 & 43.4 & 100.7 & 88.7 & 70.8 & 53.4 & 46.1 \\
\hline 103.9 & 89.1 & 70.9 & 51.1 & 37.3 & 103.5 & 81.6 & 65.3 & 54.2 & 45.3 & 99.2 & 86.1 & 65.6 & 48.4 & 43.6 & 100.5 & 87 & 70.6 & 52.7 & 45.2 \\
\hline 101.9 & 90.5 & 70.1 & 46.5 & 35 & 102.7 & 81.5 & 66 & 53.5 & 46.9 & 95.9 & 83.9 & 67 & 49.8 & 44.7 & 100.9 & 86.9 & 69.2 & 52.5 & 46.7 \\
\hline 102.4 & 88.9 & 71.1 & 54.4 & 32.4 & 102.6 & 82.7 & 67.6 & 52.3 & 46.2 & 92.9 & 82.9 & 66.9 & 51.9 & 43.8 & 100.3 & 88.1 & 69.1 & 53.4 & 44.8 \\
\hline 103 & 89.2 & 71.3 & 54.4 & 36.2 & 102.9 & 84 & 68.8 & 50.7 & 44.7 & 94.6 & 85.1 & 65.1 & 50.2 & 43.5 & 100.7 & 86.6 & 68.5 & 53.8 & 44.5 \\
\hline 101.9 & 88.2 & 69.6 & 55.1 & 34.9 & 103.8 & 83.9 & 69.3 & 43.9 & 46.5 & 98.8 & 84.4 & 61.5 & 51.5 & 43.4 & 100.2 & 88.1 & 69.8 & 50 & 45.6 \\
\hline 103 & 88.5 & 69.5 & 55.8 & 37.5 & 103.5 & 84.4 & 67.2 & 48.5 & 44.5 & 100.3 & 88.1 & 65.8 & 52.1 & 42.3 & 100.5 & 87.9 & 71.1 & 46.3 & 43.6 \\
\hline 103.9 & 86.6 & 71.3 & 52.1 & 36.7 & 103.6 & 84.8 & 66.4 & 51.5 & 46.5 & 99 & 87.2 & 67.9 & 50.8 & 43.5 & 100.1 & 87.7 & 68.8 & 52.2 & 43.7 \\
\hline 103.7 & 87.7 & 71 & 54.3 & 38.2 & 104 & 85.7 & 67.8 & 49.6 & 47.7 & 96.8 & 88.6 & 66.2 & 52.5 & 42.7 & 99.9 & 88.9 & 70.4 & 52.2 & 45 \\
\hline 102.5 & 86.8 & 71.1 & 53.9 & 34.2 & 102.7 & 87.6 & 67.7 & 49.2 & 45.5 & 97.3 & 85.9 & 69.4 & 51.3 & 43.2 & 100.6 & 89.1 & 68.8 & 52.7 & 46.1 \\
\hline 103.8 & 82.9 & 69.8 & 53.9 & 37 & 102.1 & 88 & 69.1 & 50.6 & 46.1 & 96.4 & 85.4 & 69.2 & 50.1 & 43.2 & 101.4 & 81.6 & 69.7 & 54.5 & 45.3 \\
\hline 99.7 & 87.2 & 69.9 & 54.3 & 35.1 & 102.3 & 84.3 & 66.4 & 51 & 46.2 & 101.6 & 85.5 & 69.2 & 51.1 & 43.2 & 100.2 & 88.3 & 68.1 & 54.4 & 42.9 \\
\hline 103.8 & 87.4 & 69.9 & 55.5 & 35.1 & 102.3 & 86.9 & 66.9 & 50.6 & 43.6 & 102.2 & 85.8 & 66.3 & 50.3 & 43.9 & 100.2 & 88.8 & 67.9 & 55.8 & 45.7 \\
\hline 103.8 & 87.8 & 69.1 & 53.7 & 35.1 & 102.5 & 86.2 & 65.7 & 52 & 47.2 & 102.9 & 82.2 & 65.9 & 55.7 & 43.6 & 99.2 & 86.7 & 67.4 & 54.4 & 44.1 \\
\hline 103.5 & 85.4 & 65.4 & 56.8 & 36.7 & 103.3 & 83.2 & 66.2 & 53.1 & 46.8 & 101.1 & 85 & 66.3 & 58.9 & 43.3 & 100 & 88.7 & 69.4 & 54.4 & 45.6 \\
\hline 102.4 & 84.2 & 66 & 52.6 & 36.9 & 103.3 & 84.7 & 66.2 & 52.3 & 46.8 & 99.8 & 85.1 & 66.7 & 55.4 & 44 & 97.9 & 87.9 & 69.4 & 54.5 & 46.2 \\
\hline
\end{tabular}


APÊNDICE 3 - Propriedades físicas da água (Unidades no Sistema Internacional).

\begin{tabular}{|c|c|c|c|c|c|}
\hline $\begin{array}{c}\text { Temperatura } \\
\left({ }^{\circ} \mathrm{C}\right)\end{array}$ & $\begin{array}{c}\text { Densidade } \\
\left(\mathrm{kg} / \mathrm{m}^{3}\right)\end{array}$ & $\begin{array}{l}\text { eso específico }{ }^{a} \\
\left(\mathrm{kNm}^{3}\right)\end{array}$ & $\begin{array}{c}\text { Viscosidade dinâmica } \\
\left(\mathrm{N} . \mathrm{s} / \mathrm{m}^{2}\right)\end{array}$ & $\begin{array}{c}\text { Viscosidade cinemática } \\
\left(\mathrm{m}^{2} / \mathrm{s}\right)\end{array}$ & $\begin{array}{c}\text { Tensão superficial } \\
(\mathrm{Nm})\end{array}$ \\
\hline 0 & 999,9 & 9,81 & $1,79.10^{-3}$ & $1,79.10^{-6}$ & $7,56.10^{-2}$ \\
\hline 5 & 1000 & 9,81 & $1,52 \cdot 10^{-3}$ & $1,52 \cdot 10^{-6}$ & $7,49.10^{-2}$ \\
\hline 10 & 999,7 & 9,80 & $1,31 \cdot 10^{-3}$ & $1,31 \cdot 10^{-6}$ & $7,42 \cdot 10^{-2}$ \\
\hline 20 & 998,2 & 9,79 & $1,00 \cdot 10^{-3}$ & $1,00 \cdot 10^{-6}$ & $7,28.10^{-2}$ \\
\hline 30 & 995,7 & 9,76 & $7.98 .10^{-4}$ & $8,01 \cdot 10^{-7}$ & $7,12 \cdot 10^{-2}$ \\
\hline 40 & 992,2 & 9,73 & $6,53.10^{-4}$ & $6,58 \cdot 10^{-7}$ & $6,69 \cdot 10^{-2}$ \\
\hline 50 & 988,1 & 9,69 & $5,47.10^{-4}$ & $5,53 \cdot 10^{-7}$ & $6,79 \cdot 10^{-2}$ \\
\hline 60 & 983,2 & 9,64 & $4,67.10^{-4}$ & $4.75 .10^{-7}$ & $6,62 \cdot 10^{-2}$ \\
\hline 70 & 977,8 & 9,59 & $4,40.10^{-4}$ & $4,13 \cdot 10^{-7}$ & $6,44 \cdot 10^{-2}$ \\
\hline 80 & 971,8 & 9,53 & $3,55.10^{-4}$ & $3,65.10^{-7}$ & $6,26 \cdot 10^{-2}$ \\
\hline 90 & 965,3 & 9,47 & $3,15 \cdot 10^{-4}$ & $3,26 \cdot 10^{-7}$ & $6,08 \cdot 10^{-2}$ \\
\hline 100 & 958,4 & 9,40 & $2,82 \cdot 10^{-4}$ & $2.94 .10^{-7}$ & $5,89 \cdot 10^{-2}$ \\
\hline
\end{tabular}

a considerando aceleração da gravidade, $\mathrm{g}=9,807 \mathrm{~m} \cdot \mathrm{s}^{-2}$ 